\title{
Crafting on the fringe: \\ A contextualised analysis of government development policy and self- employed commodity production in Newfoundland
}

\author{
PhD Dissertation \\ Department of Sociology and Anthropology \\ Carleton University
}

\section{Lynda Harling Stalker \\ May 2006}

다. L. Lynda Harling Stalker 2006 


$\begin{array}{ll}\begin{array}{l}\text { Library and } \\ \text { Archives Canada }\end{array} & \begin{array}{l}\text { Bibliothèque et } \\ \text { Archives Canada }\end{array} \\ \begin{array}{l}\text { Published Heritage } \\ \text { Branch }\end{array} & \begin{array}{l}\text { Direction du } \\ \text { Patrimoine de l'édition }\end{array} \\ \begin{array}{l}\text { 395 Wellington Street } \\ \text { Ottawa ON K1A ON4 }\end{array} & \begin{array}{l}\text { 395, rue Wellington } \\ \text { Ottawa ON K1A ON4 } \\ \text { Canada }\end{array}\end{array}$

Your file Votre référence ISBN: 978-0-494-16667-3 Our file Notre référence ISBN: 978-0-494-16667-3

NOTICE:

The author has granted a nonexclusive license allowing Library and Archives Canada to reproduce, publish, archive, preserve, conserve, communicate to the public by telecommunication or on the Internet, loan, distribute and sell theses worldwide, for commercial or noncommercial purposes, in microform, paper, electronic and/or any other formats.

The author retains copyright ownership and moral rights in this thesis. Neither the thesis nor substantial extracts from it may be printed or otherwise reproduced without the author's permission.
AVIS:

L'auteur a accordé une licence non exclusive permettant à la Bibliothèque et Archives Canada de reproduire, publier, archiver, sauvegarder, conserver, transmettre au public par télécommunication ou par l'Internet, prêter, distribuer et vendre des thèses partout dans le monde, à des fins commerciales ou autres, sur support microforme, papier, électronique et/ou autres formats.

L'auteur conserve la propriété du droit d'auteur et des droits moraux qui protège cette thèse. $\mathrm{Ni}$ la thèse ni des extraits substantiels de celle-ci ne doivent être imprimés ou autrement reproduits sans son autorisation.
In compliance with the Canadian

Privacy Act some supporting forms may have been removed from this thesis.

While these forms may be included in the document page count, their removal does not represent any loss of content from the thesis.
Conformément à la loi canadienne sur la protection de la vie privée, quelques formulaires secondaires ont été enlevés de cette thèse.

Bien que ces formulaires aient inclus dans la pagination, il n'y aura aucun contenu manquant.

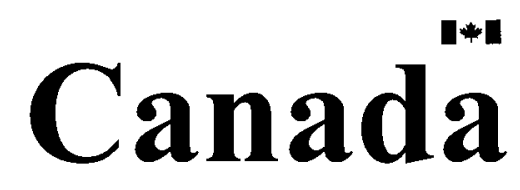




\section{Abstract}

This study is an empirically-based critique of Newfoundland government's craft industry policy report and the narratives of craftspeople from across the province. I begin by taking the report and analysing it using a criticalanalytical approach. By doing this, I draw attention to how this is a marketfocussed report where the craftworkers' voices are absent and where the craftworkers are treated as disembodied economic entities.

I present an analysis of craftspeople's narratives. I find that selfemployed work for Newfoundland craftspeople encompasses far more than the economic priorities and benefits associated with being a commodity producer. My analysis shows that other important considerations for the selfemployed commodity producer include control over the immediate work environment, control over time, and control over the work process. Though these may seem to all be individualistic in nature, self-employed work requires both the economic and non-economic support of the household. Self-employed craftspeople must know that there is a guaranteed income for the household and that their families support their decision to do this work.

This dissertation further addresses the concern of place within the context of self-employment. It looks at how Newfoundland plays a critical role in the decision to undertake craftwork. Self-employed craftwork makes it possible for the participants to live in Newfoundland. As this dissertation discusses, this type of work fits with the Newfoundland social norms and values. However, upon analysing of the narratives, it is apparent that there is 
tension between the craftspeople and locals. While craftwork epitomises the Newfoundland values of self-sufficiency and hands-on work, the local population offers craftspeople neither economic nor non-economic support.

I argue that the top-down economic development strategy used in the craft strategy report gives little voice to the commodity producers it attempts to support. There needs to be recognition that self-employed commodity producers are not disembodied economic entities. Development policies, particularly those geared at self-employed work, should consider the various social and personal concerns that go along with commodity production. Through the comparison between the craftspeople's narratives and the Newfoundland craft strategy report, I renew the call for socially grounded economic development. 


\section{Acknowledgements}

This dissertation would not have happened without the help and support of many important people. First I would like to thank the craftspeople in Newfoundland who took the time to help a student who "comes from away" especially when time is so precious to a self-employed person. Their narratives are rich with details that I would not have been able to obtain any other way. Next, I would like to thank the J. R. Smallwood Foundation for their financial support. This organisation supports many valuable projects in Newfoundland. I am glad they saw mine as worthy of support.

I have been fortunate to have a committee of exceptionally talented and committed advisors. Dr. Janet Siltanen and Dr. Andrea Doucet, my cosupervisors, have guided and mentored me from the initial steps. Their commitment and encouragement enabled me to finish this project. Dr. Wallace Clement graciously came on board half-way through the dissertation and made valuable contributions that helped to shape my work.

I could not have completed this project without the support of my family. My parents, David and Sharron, have always been a mere telephone call away with words of encouragement. My mother-in-law, Susan, provided a place where household strategies were truly put to the test. Her assistance with childcare was invaluable. Asta Merie and Adam, my two darling children, arrived at various points throughout this project. I thank them for

understanding the times I spent on the computer away from them. Finally, my 
husband Andrew. He has believed in this project through many ups and downs. Without him this project would not have been completed - thank you. There were two men, Michael Stalker and Charles Gordon, who started out with me on this dissertation but due to their untimely deaths were not able to see me through to the end. I remember them fondly and thank them for their support. 
Abstract

.. i

\section{Acknowledgments}

iii

\section{Table of contents}

v

\section{Preface}

vii

\section{Chapter One - Crafting a puzzle}

- Introduction

- Setting

- Theoretical and conceptual placement

- Embedded work

- Development and underdevelopment

- Household and household strategies

- Place

- Motivation and meaning

- Commodity producer

- Puzzle

- Participants

- Conclusion

\section{Chapter Two - Crafting knowledge}

- Introduction

- The path to the puzzle

- An actionist approach

- The three levels of knowledge

- Narratives and document research - Use and analysis

- Conclusion

\section{Chapter Three -- Crafting development}

- Introduction

- Historical context of Newfoundland development

- Joey Smallwood's development attempts

- Cultural industries

- Development since Joey Smallwood

- Ray's models of cultural industries

- Cultural industries in Newfoundland 
- Culture of mediocrity to a culture of excellence?

- Newfoundland and Labrador Craft Industry Development Strategy: Summary and recommendations (2002)

- Defining craft

- Local and extra-local

- Traditional skill

- $(R e) c r e a t i o n$ of identity

- Conclusion

\section{Chapter Four - Crafting cases}

- Introduction

- Alf: control over immediate work environment

- Joan: embedded in social norms and values

- Mark: control over time

- Brenda: negotiating between craft and manufacturing

- Matthew: importance of place

- Conclusion

Chapter Five - Crafting self-employment

97

- Introduction

- Getting into self-employment

- Economic priorities

- Non-economic priorities

- Economic and non-economic priorities intersect

- Staying in self-employment

- Males

- Females

- Spousal and family support

- Non-economic

- Economic

- Conclusion

Chapter Six - Crafting place

125

- Introduction

- Newfoundland geographically contextualised

- Newfoundland culturally contextualised

- The desire to stay, return or move to Newfoundland

- Commodification of place

- Lack of local support

- Conclusion

Chapter Seven - Conclusion

149 


\section{Bibliography}

\section{4}

Internet sites

177

Appendices

178 


\section{Preface}

In the summer of 2002, I was in the process of refining my PhD research puzzle. I knew approximately the substantive area that I was interested in and my basic epistemological and ontological stances, but I still had not found something that would "getting me on my soapbox" (as my mother would say). Craftwork was going to be the type of work I wanted to look at but I just did not know how I was going to do it. One day I was "googling" various keywords, and I eventually stumbled upon a strategy report recently released by the Newfoundland government on the provincial craft industry. I had done my MA in Newfoundland on rural women knitters and worked in a yarn store in St. John's, so I was curious as to what the report put forward. The report missed many of the pertinent conclusions I had come to in my MA research. The concepts of social identity, lifestyle, and non-economic priorities for craftwork were absent. In fact, I felt the craftworkers were absent from the report. At that moment, I knew I found my "soapbox."

My family and I moved to Newfoundland for the year, while I worked at Memorial University and gathered the work narratives of craftspeople across the province. In this dissertation, you will meet seventeen people who all work at producing crafts. There is Alf, who left the draggers to be home with his family. Jake and Eileen returned to Newfoundland, Jake's childhood home, to start up an apparel business. Mark's wife got a job in St. John's and decided this was his opportunity to strike out on his own. You will also meet 
Matthew, who's desire to stay in Newfoundland was so strong that he thought he would have nothing to lose by taking a course on jewellery-making something he had never contemplated before in his life but found a passion. There are others too that will give you an idea of what it is to be a selfemployed craftworker in a peripheral area: Nick, Brenda, Frances, Joan, Laurie, Bill, Anthony, Jill, Louise, Jim, Catherine and Brad. Their narratives, while telling individual stories and experiences, come together to show how important concepts like control, households, and place are to understanding self-employed commodity production.

Underpinning all the narratives is one character that cannot be ignored - Newfoundland. The culture, society, political structure, historical context, and physical environment shape the meaning and motivations behind my participants' actions. At some level, Newfoundland is evident in all the narratives. This can be seen in Matthew's desire to remain in the province after living on the mainland, Mark's romantic notion of artisan lifestyle, and Jim's choice of local natural resources to make his products. Not only do we see Newfoundland in the narratives, but also in the government's strategies to develop the craft industry. The desire to create and support work that is endogenous to the province in the face of a cod moratorium, and is placed on the global marketplace, drives this report. 


\section{Reading this dissertation}

I have entitled this project Crafting on the fringe: A contextualised analysis of government policy and self-employed commodity production in Newfoundland with great deliberation and thought. To begin, the idea of crafting is central to this project on different levels. The type of work under investigation is craftwork. It is about the creation of items on a small-scale; it is representative of an established tradition. It is therefore crucial to have craft in the title. Craft also delineates what it is I am doing; I am crafting a piece of academic research. I am doing my own work in an established tradition. For this reason, I carry on the word "crafting" throughout my chapter titles to indicate what it is I am trying to communicate. The other part of the title I want to bring to attention is the notion of fringe. While some may think this is a bit derogatory, and perhaps suggesting the work my participants is unimportant, this is not how I use the term. I understand fringe as indicating how self-employed craft work is being done on the periphery of Canada, geographically and socially. Newfoundland's location in the middle of the North Atlantic, on the periphery of Canada, means that there is a unique culture. Being in Newfoundland means that you are on the "fringe" of political and economic power that is located in Central Canada. Furthermore, this craftwork is not the usual type of work in today's increasingly technologically focussed society. It is not central to discussions about work in Canada, and really in other western societies as well. As well, self-employed work is not the usual type of work in Canada. It is on the fringe of standard relationships. 
Lastly, fringe has a double entrendre meaning relating to craftwork. The edges of textiles are frequently adorned with fringes. I therefore have used this title in a deliberate manner to communicate issues central to this project.

The dissertation is presented in seven chapters. In the first two chapters, I outline my conceptual, theoretical and methodological approaches. I discuss the puzzle I set out to investigate, how I understand the puzzle, and how I went about obtaining information necessary to engage the puzzle. I show that the puzzle is about how to locate my critique of a government development policy (i.e., the strategy report for Newfoundland's craft industry) in the narratives of those who are the policy's anticipated beneficiaries. Through narrative analysis I show that the non-economic priorities expressed to me by craftworkers, such as control and place, are missing from the assumed priorities attributed to the economic disembodied entity presented in the report as the self-employed craftworker.

With the theoretical and methodological arguments in place, I move on to the analysis. Chapter three is about the policy report in question. I set out a contextualised analysis that situates the report within the specific historical, social, political and economic conditions of Newfoundland, and the broader literature on socio-economic development. My purpose in this chapter is to lay out what I see as the crux of current development policy problems - that is, treating workers, whether self-employed or not, as disembodied and disconnected economic entities. 
For chapters four, five and six I turn to my participants' narratives. In these chapters, you will read two different types of narratives. In chapter four, you will find the stories of five participants that are presented as first-order narratives (Elliot, 2005). In these case, we see how people constitute meaning and identity through their telling about their work. I have added subheadings to each narrative to indicate what I see as important themes in each person's narrative, such as place, time, and control.

Chapters five and six present second-order narratives. In these chapters I take the knowledge I gathered from my participants and order them in a way that I believe makes sense of the social world and their particular experiences (Elliot, 2005). In essence, this is the method I employ to present my epistemological stance when it comes to questions about work and socioeconomic development. In chapter five I show that, beyond economic priorities, self-employed craftworkers have non-economic priorities, such as control of time and work environment, which provide meaning to their work. I also want to illustrate how being self-employed is not about just the individual; there are household strategies that are central to decisions made by craftspeople. In Chapter six, the character of Newfoundland assumes a more central role. In this chapter, my objective is to show how place permeates perceptions of work at many levels of understanding. In this project, place presents tensions in the craftsperson's experience and understanding of work. We see that it is part of the reason why people venture into selfemployed craftwork. Newfoundland provides the cultural and natural 
inspiration to do this type of work. Newfoundlanders have been successful in cultural industries. We need only to look at the achievements of Newfoundland musicians, such as Great Big Sea, and comedians, like Rick Mercer and Mary Walsh. The rugged landscape influences the design and form of traditional and contemporary crafts. We see that there is a practicality in the traditional crafts and the contemporary crafts often depict images such as whales and puffins. However, there is, at the same time, a lack of local support (financial and encouragement) for craftwork.

In the final chapter, I draw together the two types of narratives and use them to engage with the policy analysis. I make suggestions about how there can be a move away from the market-driven development policy exemplified by the craft strategy report, to a form of development that is socially grounded in the experiences and requirements of the self-employed (and workers generally) in "underdeveloped" regions. 


\section{Chapter One}

\section{Crafting a puzzle}

In 2002, the Newfoundland and Labrador government released a report on the current and future state of the province's craft industry. It is an attempt to set the groundwork for socio-economic development policy. In this report, they are upholding the accomplishments of areas (such as Maine, Quebec and Ireland) that have used local craft practices as means to rejuvenate local economies. In essence, they propose the creation of a cultural economy. This involves taking the "traditions" of a place and producing them for sale. This translates into Newfoundland taking their "traditional" crafts - primarily textiles and food production - and making them as uniquely "Newfoundland" as possible. They then place the wares on the market for sale. One can see this as a definite, and perhaps in the government's eyes, innovative way of tackling the unemployment problems that have plagued rural Newfoundland and Labrador, especially since the cod moratorium of 1992.

Crafts are activities separate from art. Where art are pieces with the intention to communicate an idea through abstract media, "the crafts are essentially handwork or work in which if machines are used they are used as tools, as things the worker uses with skill" (Coleman, 1988: 147). They are items that have an intended utility to them and are created within an established tradition. The Newfoundland government, however, extends this definition to include all involved in the craft industry: retailers, galleries, social development programmes, suppliers, and producers. The government reports that there are 
two thousand people and two hundred companies working in crafts. ${ }^{1}$ This study, however, focusses on the craft producers, the self-employed people whose work is to make crafts.

\section{Setting}

Newfoundland and Labrador is the newest province in the Canadian Confederation, having joined in 1949. It consists of the island of Newfoundland, located in the North Atlantic, and Labrador, a northern area of Canada's mainland. Newfoundland's mainstay industry has been the cod fishery. The Grand Banks of the North Atlantic have been world renowned for the quantity of fish they have sustained. Up until the 1950's, cod was preserved by salting and drying. The fish was traded with Britain, the Caribbean, and Portugal, in exchange for various items such as cloth, pottery, molasses, and rum. Today, there is still evidence of the salt cod industry in the form of abandoned fish stages (platforms that fish were dried on in every outport community), but most fish is now frozen and sold into markets in the United States.

Since joining Confederation, the province has seen their "traditional" lifestyle change substantially. With Confederation came the promises of a better life. Newfoundlanders could take advantage of social programmes, like unemployment insurance and old age pensions, and the government would receive transfer payments from the federal government to commence "development." Joey Smallwood, the crusader of confederation and first premier,

\footnotetext{
${ }^{1}$ In a personal communication the assistant to the Deputy Minister of Innovation, Rural Development and Trade stated that the government has not broken down the industry to look at the number of craft producers in the province.
} 
impatiently announced in 1950, "We must develop or perish" (quoted in Leto, 1998: 1). Smallwood thought that if Newfoundland developed, and in his mind, this meant industrial development, they could stop the flow of out-migration that was growing in Newfoundland. ${ }^{2}$ Smallwood sponsored the creation of plants to manufacture everything from hydroelectricity to chocolate bars and rubber boots, and implemented the infamous resettlement of Newfoundlanders to "growth centres". Leto (1998) points out that the combination of Newfoundland's history as a fishing colony, and Smallwood's haste and lack of planning, caused the industrial development to fail. Newfoundlanders for generations had known how to work with natural resource harvesting - timber, hunting, and especially fishing. The Newfoundland government ignored natural resources for industrial creation; they wasted their limited and valuable monetary resources as nearly all the manufacturing initiatives failed (Leto, 1998).

With Confederation, Newfoundland became a "peripheral province," with respect to both geography and power. This has led to Newfoundlanders becoming dependent on mainland Canada for many basics (such as Employment Insurance payments, and fishing quotas). Newfoundlanders are not the only ones to experience this. Atlantic Canada as a whole has been seen as being dependent on Central Canada for many "benefits" that have had negligible impact on the region's development (Veltmeyer, 1990). In the past decade, Newfoundlanders have experienced further changes to their lives. In 1992, the federal government imposed a cod moratorium due to low fish stocks. Many

\footnotetext{
${ }^{2}$ Outmigration was not a phenomenon unique to Newfoundland. It was also all prevalent across Canada's Maritime region.
} 
people dependent upon the fishery, such as harvesters and fish plant workers, were left without employment. Since the decline of the cod fishery, the province has been investigating other industries to develop. These have included offshore oil, information technology, and other species to fish (e.g. crab and shrimp). At the end of the 1990's, the Canadian media reported that Newfoundland had the fastest growing economy in the country; however, many people who live in the outports would disagree. When one listens to the popular call-in shows, one hears how those in the rural areas feel that St. John's (the capital and largest city) is the only place benefiting from this growth.

\section{Theoretical and conceptual placement}

Michele Barrett (1999) and Mary Evans (2003) both point out that sociology as a discipline has turned strongly to an exploration of the social world that uses culture and consumption as the key concepts. This cultural turn has been characterised by a shift "away from socio-economic or social structure explanation and towards recognition of the importance of cultural meaning. Part and parcel of this shift is the decline of the concept of class as a primary explanatory factor and the rise of interest in subjectivity and identity, where sexuality, gender, race and ethnicity are seen as equally important" (Barrett, 1999: 14). This would seem to imply that culture and its influences must be understood separate and apart from discussions of social structures. This distinction perpetuates the dichotomies that have plagued sociology since its inception (see Ray, 1999). 
Miriam Glucksmann (2000), as well as Evans (2003), argue that we need to maintain an understanding of social relationships and acts of agency as being mediated by the material, economic and non-economic activities that structure social life. This allows one to combine the cultural identity with social structures. One can see how people negotiate between these two influences to develop meaning and motivation for their work. With a move away from the strict materialist / culturalist dichotomy one is able to see how people negotiate between the demands of macro social institutions with the concerns of their locality. This theoretical understanding falls in line with what Clement (1997) has called the new Canadian political economy. In this fundamentally materialist perspective "social relations are located within the context of the economic, political and cultural / ideological on the one hand, and dimensions of time and space on the other" (5-6). It allows one to explore the many dimensions that people incorporate into the meanings and motivations they have for their actions. It is through these influences that Clement points out that one becomes a "social being" (3).

Craftwork in Newfoundland provides a unique case study into how these cultural and material influences come to bear on people. All these elements are a part of the social world that guides the choices that one makes. In order to understand how they influence an individual it is important to understand how one is motivated to undertake an action and what meaning that action has attached to it. An exploration of craftwork will allow one to see the culmination of the material and cultural. By its very nature, craftwork, especially when done for 
economic gain, is a cultural industry. This means that it is the production of culture.

\section{Embedded work}

Work is a term brandied about in everyday language without much discussion about what it actually means. It goes beyond just paid employment; however, work entails many more dimensions than monetary gain. Work is embedded in the social, economic, political and cultural spheres that surround the worker. It carries with it "the social meaning of activities, their values and the context in which they are undertaken ... [and] such activities are embedded in the system of social relationships involving the transfer of labour, material, and products within it" (Freidson, 1990: 152). The idea of work has moved away from being solely about the production of goods and services to an understanding of work as it relates to social relationships.

Social relationships are the ties that one has to his or her culture, society and community. They include (but not exclusively) tradition, family, gender and status. These relationships guide one to see what is appropriate work depending upon your station and status in the community. Despite the belief that craftwork is a "noble" endeavour done alone by a dedicated individual in his or her workshop (Hickey, 1996), craftspeople are not isolated from others. They are members of households, communities, and cultures that shape the work they perform. Craftwork is not only embedded in the contemporary social relationships, but it is also reflecting, and evaluated by traditions. The traditions 
are the patterns of practice that proceed from one generation to the next. Traditions are the common inheritance of cultural elements. The work, when it conforms to the established traditions, can allow one to feel as if he or she is a member of a community (see Hinrichs, 1998). It can reaffirm that the worker belongs in a community. The work then comes to dynamically reflect the community's attitudes and relationships toward its members.

My dissertation shows that the important social relationships to the Newfoundland craftworkers are those that they experience with their households and with the provincial government. The relationships in the household focus on how the craftsperson and his or her family divide the labour to ensure the economic viability of the household. This includes who works at craft production and who needs to have employment outside the household. Furthermore, the relationship with the Newfoundland government shapes and influences the craftsperson's work. The government does this formally through regulations and financial support programmes, and informally by guiding, advising, and steering craftspeople into certain markets.

\section{Development and underdevelopment}

Development is a concept that comes out of the post-WWII era of American governments doing rehabilitation work in Europe and trying to stem off the advances of communism in Third World countries (Veltmeyer, 2005). It generally involves improving the socio-economic living conditions in poor regions by 
implementing institutional structural changes that will allow these changes to take place (ibid).

Newfoundland, like the other Atlantic Canadian provinces, is often described as being underdeveloped. Brodie (1990) puts forth two general ways to look at underdevelopment. The first is to understand underdevelopment as internal problems. He explains:

These theories assume that regions are discrete entities that are separated and isolated from other regions by some formal criteria. No linkages between regions are postulated in their definition and, as a result, factors explaining the characters of regions are sought within the region itself. Some regions are less prosperous than others, not because of their interrelationships with other regions or the nation-state, but because of some malfunction within them (1990: 16).

This stance, at least in its entirety, is not one that is often used to describe underdevelopment in Atlantic Canada. The more popular understanding comes from external or relational critiques. Disparity for these theorists is caused by exploitation and interdependence. "It demands a theory of regional imbalance because it identifies the sources of uneven development of a region in its relationship with other relations, not the region itself" (Brodie, 1990: 18).

Veltmeyer (2005), one of the "founding" academics of Maritime Marxism (along with Saucoman and Brym, 1979) puts forward a different understanding of underdevelopment. According to him one can look at underdevelopment traditionally or through a Marxist framework. A traditional understanding of underdevelopment places blame on market failure along with "natural resource 
endowment, shortage of capital, low level of urbanisation and industrialisation, as well as the lack of skilled labour, entrepreneurship and management skills, and, of course, a lack of aggregate demand" (12). To fix this weakness in the market, traditionalists, in other words neo-liberalists, propose strengthening the functioning of the market. A Marxist framework, according to Veltmeyer, agrees that there is a market failure where underdevelopment occurs. The solution, however, is to have government implement development plans that address the centre / periphery power discrepancy. The way this has usually been tackled in Canada is through the use of transfer payments, whereby the "have" provinces transfer money to the "have-not" provinces as a way to equalise economic prosperity. This Marxist framework, as established in Canada's Maritime provinces has all but disappeared due to factors such as globalisation, neoliberalism, and academic and organised labour quiescence (Veltmeyer and Saucoman, 2005). ${ }^{3}$

Donald Savoie (2004), taking an economic view of development, calls for fellow Atlantic Canadians to "untie our economic boat from Ottawa and tie it to the emerging global economy ... [as] Ottawa is slowly pulling the life jacket away from Atlantic Canada" (124-125). The federal government has not had a successful track record when it comes to regional development, frequently resorting to "short-term" solutions in the form of social transfers (Savoie, 2004). With numerous cut-backs in federal spending, the argument is that Atlantic Canada, including Newfoundland, needs to find local long-term resolutions to their underdevelopment.

\footnotetext{
${ }^{3}$ See Saucoman and Brym (1979) for more on the early theoretical stance of Maritime Marxists.
} 
Households and household strategies

Following the understanding of work as socially embedded, I want to discuss households and household strategies. Households are one of the constituents within which work is socially embedded. The household tends to be a catchall phrase. It can be synonymous with family, or the "cooking-pot" analogy (all those who share meals daily (Marshall, 2003)), or anyone who contributes to the wellbeing of all those living in the house. For this research, I took my lead from the respondents. To them the immediate family is top-most in their discussions. ${ }^{4}$

Claire Wallace (2002) provides a comprehensive analysis of the use of household strategies. She traces its use from Ray Pahl's seminal 1984 Division of labour to its use in post-communist and post-fordist studies. Wallace delineates the use of household strategies into three ways of understanding: concept, method of analysis and unit of analysis. Each presents a different take on how to employ the use of this term.

First, conceptually household strategies provide an understanding of the interaction between agency and structure. The household strategies become the location whereby people have to develop ways of incorporating the macro influences of society and culture with what they feel is best for themselves. Warde (1990) points out that there are two ways to conceptualise household strategies: households consciously plan their strategies or strategies can be inferred by the outcomes. The way you use the concept is dependent upon the

\footnotetext{
${ }^{4}$ This is not to say there are not others that contribute to the well-being of the household. Occasionally, parents were mentioned but it was not prevalent throughout the narratives.
} 
research methods employed. Quantitative methods, such as survey research, use the "weaker" definition of household strategies. Warde says that his survey research does not elicit the reasoning around any strategy a household uses. Qualitative methods tend to employ a "stronger" conceptual understanding of the household strategies. These methods will allow people to elaborate and explain the basis for how their strategies allow them to cope with the demands place upon them.

Secondly, as a method of analysis household strategies provide an insight into the combination of activities among the formal and informal spheres and the division of labour that occurs among household members. It can also show how activities and work are found in different economic spheres (such as the home, community and "black market") and how these activities are fluid from one sphere to another.

Lastly, Wallace shows how household strategies are used as units of analysis. Wallace critiques those that use household strategies as their units of analysis; she finds they frequently equate household with the immediate family and see the household solely as an economic entity. She points out that "the household is a social as well as an economic unit and therefore should be studied also in terms of these norms, cultures and values" (281).

I want to use household strategies conceptually. I do this to help explain craftspeople's decisions to be self-employed in Newfoundland. I believe that these decisions are made within the craftspeople's social relationships and involve not only economic but also non-economic priorities. "[M]any household 
strategies are based upon alternative values such as the search for more satisfactory lifestyles ... In such circumstances the study of strategies as a concept is fully justified because people need to reflect upon their use of time and resources" (Wallace, 2002: 284).

Place

A particular time and place will have its own social relationships that shape the motivation for work and meaning of work. Geographical location shapes the way that workers interact with their environment, and informs the development of a culture. The place dictates the work that is necessary for the society. This would be particularly noticeable in rural settings. If one is on the ocean, then the predominant work is the harvesting of ocean resources. If one lives on the prairies, the harvesting of grain is the top priority. When looking at these two examples one can see that the environment has as much influence in shaping the work, through the motivation and meanings attached. The motivation to do work may be that it needs to be done before the weather changes. The meaning may come down to survival.

Place of work is more important than the space work occupies (Peck, 1996). Each place will have its own unique way of instituting social relations of work (Glucksmann, 2000). The experiences of work for two people doing the same job in different places are different, despite the fact that the physical space may be the same. You could have two people with very similar studio set-up and doing the same craft, and not only will the product be different but so will the 
meaning that one attaches to the work. The nature of a place shapes the culture and social relationships of a locality, and thereby makes the motives and meanings for work different. It is how the worker perceives and interacts with a place, not just the spatial environment, which is important.

Some scholars advocating the "global village" deem the locality almost irrelevant. Beck (2000) describes how currently "labour is local, capital is global" (28). This brings about a power struggle between the socio-political institutions and corporations. He suggests that there needs to be a movement away from fixed boundaries and an understanding that the nation state is irrelevant. People today, due to technology, can occupy the same social space as someone on the other side of the world. While this is very likely the case, I would argue that the experience of this social space is shaped by the individuality of one's place. This "global" approach ignores how work is dynamically reflective of social relationships and culture. By focusing solely on the economic and political, there is no analysis of how place shapes the culture within which one works. It is impossible, and undesirable, to ignore the everyday experiences of place. If one does this, one misses a large element of the motives and meanings of work.

Place, and the experience of place, is quite differentiated. One needs to go beyond an essentialist idea of place. For example, the idea of rural versus urban should no longer be seen as the great dichotomy that has historically been proposed, but one should think of vulnerable areas (Ray, 1999). Because of its isolation, Newfoundland as a whole is a vulnerable area; however, within the province, there are places that are more vulnerable than others are. In particular, 
the outport communities experience greater economic disparity than the provincial capital of St. John's. What we need to talk about is how close (spatially, socially, politically) a place is to the centres of power. This notion becomes key to the understanding of how a person experiences a place.

\section{Motivation and meaning}

When looking at work, as with any socially constructed action, it is important to investigate the motives and meanings that the worker attached to his or her work. Motivation is the force that drives one to undertake an action (Campbell, 1999); it is what compels a person to act in a certain manner. Motives, however, are not justifications for an action, but are the drive to undertake an activity. The motivations to undertake certain forms of work can come from internal or external sources. Internal forces could include one's sense of duty to family and community, or the pure enjoyment of an activity. External motives, such as monetary rewards, are often central to a discussion surrounding the selection of a type of work.

It is also important to look at how the work takes on meaning for the individual. Meaning is more than the ends or the goals of an action. It is the emotional attachment that one has for an action. The meaning is the long-term investment one makes toward his or her work. It is not the short-term choices and specific actions, but how all the actions come together meaningfully. People therefore create meanings in order to be able to accomplish their goals (see Campbell, 1998). One needs to see the dynamic relationship that exists between 
the motive behind an action and the meaning attached to it in order to understand the choice workers make.

The decision to undertake craftwork has been described as motivated only by an intrinsic force "that is based on desire to do something for its own sake regardless of external reward; that that the motivation to learn and practise craft is probably related to individualised needs of self-esteem and self-actualisation" (Metcalfe, 1996: 78). The meaning that comes from this take on the motivations comes from the values of "handwork, technical mastery, and passion in one's labour" (Metcalfe, 1996: 78). This description of craftspeople's motives is exceptionally one-sided. It has an underlying assumption that craftspeople live an isolated existence where there is no interaction with others. Becker, in one of his seminal works Art Worlds (1982), shows us that those involved in creative work are part of many social relationships and interactions. When one only looks at intrinsic motivations and meanings, one precludes any discussion about social relationships, gender, ethnicity and class.

Coleman (1988), once a craftsperson himself, ties our motivation to choose one form of craft over another to a tension between a reductive process where monetary "profit" is key, and a constructive process where art and cultural goods are the driving force. He argues that people often assume that the "artist," or in this case the craftsperson is a noble deviant and revered for the appearance of choice.

The motivations and meanings for Newfoundland craftspeople falls in-line with Coleman's tension. There are the intrinsic factors such as the desire to do 
work that they have a talent for. However, despite what Bruce Metcalfe (1997) asserts, craftspeople are very aware of the need to make money to support themselves and their families. Those in Newfoundland would not be doing the craft as work if it did not provide some monetary reward. That said, we see a continuous negotiation between the economic and the non-economic spheres.

\section{Commodity producers}

Craftworkers are categorised as self-employed commodity producers. They sell the results of their work; they own their own means of production to realise their own labour power. This is different from the traditional wageworker who sells their time, a consultant who sells their expertise, and the inventor who sells stock in their ideas (Karlsson, 1995). It is argued that the self-employed worker gains independence where the means of life and the goals of life operate at the same time to develop into a way of life (Karlsson, 1995).

Salmi (2005) points out that it is not quite so simple as this. He states,

The concept of work has a completely different cultural significance for the simple commodity producers than it has for the wage-worker. For wageworkers, being free is the opposite of being at work, but for the selfemployed free time has a different meaning - you are never free from work because you are never put to work (24).

The idea here being that as a self-employed commodity producer you are never independent from your work. It is because your work is constantly around you, unlike the wage worker who gets to "leave" work behind. 
The craftsperson represents the benchmark of unalienated work. A Marxist approach puts forward that this is the case because the craftworker, unlike a wageworker, has control over the work process, a skill that is only acquired with long training, and "the work of the hand and the work of the brain" are not separated (Erikson, 1990; Attwell, 1990). It is as though the craftsperson must experience the perfect work situation, a "labour of love" whereby the work is "voluntary and ... it can be part of the worker's nature and allow self-fulfilment" (Friedson, 1990: 151). The case in Newfoundland is not so idyllic. Yes, there are incidents when the craftsperson experiences independence, but they also become dependent.

Clement (1986) points out that a seemingly independent commodity producer can experience proletarianisation to the point that he or she becomes a dependent producer. This process involves the producer retaining the direct means and ownership of his or her production, while the economic and property ownership is co-opted by capital:

Proletarianisation is thus a process by which capital progressively appropriates the property rights of independent producers, thereby reducing them to performing the obligations of labour while maintaining the outward appearance of their earlier form [of work] (63, italics in original).

In the case of the Newfoundland craftsperson, it is not so much capital that gains economic ownership and control over the producer's work but it is the provincial government. Through regulations and government-sponsored financial 
assistance programmes, the Newfoundland government, as opposed to the market, is the vehicle whereby craftspeople may become dependent commodity producers.

\section{Puzzle}

This dissertation broadly explores the dynamics of regional development. It questions what form of regional development is best suited to "underdeveloped" peripheral areas. The usual manner for regional development is that the state sets out policies and procedures to promote economic development in regions experiencing underdevelopment. What is questionable is whether government actually understands the conditions under which their citizens (for lack of a better descriptor) live and work on a daily basis.

I interrogate the applicability of government economic development policy to the work narratives of those at whom the policy is directed. To investigate the connection, or disconnect, between policy and work narratives, I employ qualitative methods. Using Miriam Gluscksmann's (2000) "Total Social Organisation of Labour" as a theoretical and methodological starting point, I set out to explore the important considerations for the self-employed commodity producer. I not only question the economic sphere within which the craftspeople operate, but I also am interested in the non-economic influences. These include control over the immediate work environment, control over time, and control over the work process. Though these may seem to all be individualistic in nature, selfemployed work requires both the economic and non-economic support of the 
household. A craftsperson cannot do crafts "for a living" unless there is economic stability in his or her household. This usually comes in the way of a steady income from a partner (Knefsey et al, 2001.). For the craftspeople to undertake and continue with self-employed work, they must know that there is a guaranteed income for the household and that their families support their decision to do this work.

Informing this puzzle is the idea of place. Place operates on many levels. First, we see that labour is locally determined. The cultural, social and market conditions vary from one location to another. Peck (1996) in his work on labour and place, concludes: 1) labour markets are socially regulated through complex and interrelated socio-institutional processes; 2) outcomes of these processes are geographically varied; 3 ) labour regulation is spatially differentiated not only in terms of institutional forms, but also socio-economic efforts; and 4) local labour markets cannot be determined a priori, but through theoretically informed concrete research (106). This call to recognise the distinctiveness of a region's labour market is important to this research. When looking at regional development as it relates to work each place handles underdevelopment differently, dependent upon factors such as cultural norms and values, historical placement, and economic conditions.

On another level, place is commodified by governments in regional development schemes. In particular, this is observed when looking at tourist initiatives and the cultural industries. The government wishes to use the uniqueness of place in order to sell it on the market. This means that 
governments direct their policies to direct people into work that exploits the "place." Overton (1996) shows how the regional development policies exploit place in Newfoundland, whereby the government established such things as cooking classes to teach women how to cook a genuine "Newfoundland" meal so that they can work in the tourist industry. The government wishes to ensure that on the market there is an almost uniform presentation of what Newfoundland is. The commodification of place for sale in the marketplace is central to how governments precede in their regional development policies.

This dissertation further addresses the concern of place within the context of self-employed labour. Specifically it looks at how the relatively unique culture of Newfoundland plays a critical role in the decision to undertake craftwork. Whether it is the desire to return, stay or move to the province, self-employed craftwork makes it possible for the participants to be in Newfoundland. As this dissertation discusses, this type of work fits with the Newfoundland social norms and values. However, upon analysing of the narratives, it is apparent that there is a paradoxical relationship between the craftspeople and locals. While craftwork epitomises the Newfoundland values of self-sufficiency and hands-on work, the local population offers craftspeople neither economic nor non-economic support.

Woven throughout this dissertation there is a comparison between the craftspeople's narratives and the provincial strategy report for the craft industry. This report's focus on creating and developing markets for craft products allows for little discussion on the craft producers. I argue that such a top-down 
economic development strategy, which emanates from the government, gives little voice to the commodity producers it attempts to support. There needs to be recognition that self-employed commodity producers are not disembodied economic entities. Development policies, particularly those geared at selfemployed work should incorporate the various social, cultural and personal concerns that go along with commodity production.

\section{Participants}

The participants for this survey are all self-employed commodity producers. They come from various parts of the Newfoundland and do a variety of crafts. The participants are, with the exception of Frances, at approximately the same stage in their lifecycle, and have had previous employment other than what they are currently doing. Amongst the participants are two married couples and two people have paid employment other than what they do for their craft businesses. 


\begin{tabular}{|c|c|c|c|c|c|c|c|}
\hline Name & Craft & $\begin{array}{l}\text { Year of } \\
\text { birth }\end{array}$ & $\begin{array}{l}\text { Marital } \\
\text { Status }\end{array}$ & $\begin{array}{l}\text { Spouse's } \\
\text { occupation }\end{array}$ & $\begin{array}{l}\text { Children } \\
\text { at home }\end{array}$ & Location & $\begin{array}{l}\text { Year started } \\
\text { business }\end{array}$ \\
\hline Nick & $\begin{array}{l}\text { Instrument } \\
\text { maker }\end{array}$ & 1970 & Married & Hostess & 1 & St. John's & 2000 \\
\hline Mark & $\begin{array}{l}\text { Instrument } \\
\text { maker }\end{array}$ & 1964 & Married & Professor & 2 & St. John's & 2002 \\
\hline Brenda & Apparel & 1955 & $\begin{array}{l}\text { Common- } \\
\text { law }\end{array}$ & Professor & 0 & St. John's & 1996 \\
\hline Frances & Apparel & 1929 & Married & $\begin{array}{l}\text { Retired electrical } \\
\text { engineer }\end{array}$ & 0 & Central & Mid-1980s \\
\hline Joan & Food & 1950 & Married & Works with Joan & 2 & Avalon & 1992 \\
\hline Alf * & Woodwork & 1958 & Married & Works with Alf & 2 & Avalon & 1996 \\
\hline Laurie * & Woodwork & 1962 & Married & Works with Laurie & 2 & Avalon & 1996 \\
\hline Bill & Apparel & 1957 & Married & Nurse & 2 & St. John's & 1998 \\
\hline Anthony & Pottery & 1959 & $\begin{array}{l}\text { Common- } \\
\text { law }\end{array}$ & $\begin{array}{l}\text { Works with } \\
\text { Anthony }\end{array}$ & 0 & Western & 1992 \\
\hline Jill & Stonework & 1969 & Married & Sea Captain & 2 & Central & 1996 (approx) \\
\hline Louise & Apparel & 1949 & Widowed & N/A & 0 & Avalon & Early 1990s \\
\hline Matthew & Jewellery maker & 1963 & Married & Hotel Clerk & 2 & Western & 1997 \\
\hline Jim & Food & 1950 & Married & Lab technician & 1 & Western & 1994 \\
\hline Catherine & $\begin{array}{l}\text { Photograph / Art } \\
\text { reproduction }\end{array}$ & 1950 & Married & Professor & 0 & Western & 1999 \\
\hline Brad & $\begin{array}{l}\text { Woodworking / } \\
\text { Multi-media }\end{array}$ & 1966 & Single & N/A & 0 & St. John's & 1996 \\
\hline Jake * & Apparel & 1958 & Married & Works with Jake & 3 & Avalon & 2001 \\
\hline Eileen * & Apparel & 1960 & Married & Works with Eileen & 3 & Avalon & 2001 \\
\hline
\end{tabular}

${ }^{*}$ Couples interviewed together

Table 1: Participants ${ }^{5}$

\footnotetext{
${ }^{5}$ The names have been changed to protect anonymity
} 


\section{Conclusion}

This research project contests the Newfoundland government's approach to regional development, particularly as it relates to self-employed craftspeople. The government, due to its lack of understanding of the conditions under which craftspeople work, produces economic development policies that do not encompass the various economic and non-economic rationales for undertaking self-employment.

To proceed with this puzzle, I have set up the dissertation into the following chapters. First, I will show how I crafted knowledge for this project. I discuss the use of reflexive qualitative methods to gather and analyse the narratives and content of the report under consideration. I situate this project as using a form of material culture that focuses not so much on the products of work, but on the worker. I assert in Chapter Two the importance of understanding the necessity of placing the participants, and myself, into a cultural and social context.

In the third chapter, I set out to craft an understanding for socio-economic development. The first part of this chapter contextualises development in Newfoundland since joining Confederation in 1949, as well as a more general discussion about development. The latter section provides a document analysis of the 2002 craft strategy report. In this section, I highlight how the report is essentially market-focussed without much discussion about the craftspeople in the industry. In particular, I critique its definition of crafts, the relationship of the craft industry with local communities and extra-local tourists, the notion of traditional skills, and the (re)creation of identity. 
Chapter four is where I introduce five craftspeople in case study format. Each of the five represents a first-order narrative relating to a particular experience in selfemployed work. There is Alf, once working on the draggers ${ }^{6}$, took up craftwork to have control over his immediate work environment. Joan demonstrates how selfemployed work is embedded in Newfoundland's social norms and values. Next, there is Mark, for whom self-employment allows for control over time. Brenda shows us the blurring line between craft production and small-batch manufacturing. Finally, I introduce Matthew. He relates to us the importance of place. These five help to contextualise the other craftspeople and allow for greater detail about the context within which self-employed commodity producers in Newfoundland work.

In chapter five, I set out to provide a second-order narrative. It is here that I lay out how I incorporate Glucksmann's "Total Social Organisation of Labour" into this dissertation. We see that the motivations and meaning for self-employed work incorporate not only economic priorities, as would be implicitly insinuated by the craft report, but also the non-economic drivers that are not always captured. I also demonstrate the importance of the household to the self-employed worker. Without the other members of the household, self-employed commodity production is a near impossibility.

The sixth chapter is an analysis of the narratives as it relates to place, in this case Newfoundland. I show how self-employment allows the participants to live in Newfoundland, where there are few opportunities for paid work. I follow this up by revealing how in craft production place becomes commodified. Some of the craftspeople have to make products that are representative of Newfoundland in

\footnotetext{
${ }^{6}$ Draggers are large deepsea fishing boats.
} 
order to sell their wares. Finally, I problematise the tension between the assumed "natural" fit of self-employed craftwork to Newfoundland's social norms and values and the lack of local support for this work.

I conclude this dissertation by calling for socially grounded economic development that provides voice to the self-employed craftwork. I argue that governments need to look beyond the economic benefit self-employment can provide and incorporate a social understanding that enriches the work experience of those already self-employed, and perhaps encourage others to take it up. Furthermore, I contend that, in Newfoundland's case, craftwork should be understood as a cultural industry, not manufacturing, and include it under the auspices of the Department of Culture and Tourism not the Department of Innovation, Trade and Rural Development. By realigning the craft industry this way, I believe one will see only greater economic potential and increased social value. 


\section{Chapter Two \\ Crafting knowledge}

Every researcher must decide how he or she wants to investigate his or her problem at hand. This means becoming comfortable with not only a method of investigation but also with the epistemological and ontological stance that one takes in their research. In this chapter, I demonstrate how I use an actionist approach to explore my questions about how Newfoundland craftspeople experience their selfemployment in relation to the government's socio-economic policies. As such, I will trace how I came to research this puzzle, discuss Schlereth's (1982) actionist approach related to this particular research ${ }^{7}$, and the use and analysis of interviews and document research as data sources.

\section{The path to the puzzle}

As Tim May (1998) advocates, social research needs to be reflexive. He argues that this reflexivity has two components: endogenous and referential. Endogenous reflexivity is "the knowledge we have of our immediate social and cultural milieux" (157), where referential reflexivity is the "knowledge we gain via an encounter with ways of life and ways of viewing the social world that are different from our own" (158). It is through this two-prong understanding that we can do truly reflexive questioning of the connection between knowledge, action, and social circumstances. As Jennifer Mason (2003) puts it, "Reflexivity ... means thinking critically about what you are doing and why, confronting and often challenging your own assumptions

\footnotetext{
${ }^{7}$ Schlereth actually calls this a "behavioural" approach. I have found that this nomenclature is more appropriate to psychology and have thus used a more sociological phrase - "actionist."
} 
and recognising the extent to which your thoughts, actions and decisions shape how you research and what you see" (5). With this awareness of reflexivity, I want to begin by charting the path I took to arrive at this particular research puzzle on Newfoundland self-employed craftspeople.

When I started out on my $\mathrm{PhD}$ dissertation, I initially set out to interrogate the type of work that people did for churches. I was not interested in the church professional (e.g., priests or ministers) but those that volunteer their time and energy. I wanted to see what motivated the people and the meaning this work had for them from a neo-Weberian actionist approach (see Campbell 1998). The idea of the church was not so much to examine it as a religious institution but as a community of like-minded people. I therefore wanted to situate this research in the realm of the sociology of work and community, as opposed to sociology of religion. While I am resolved to look at this in the future, I found that at this point the topic was not going to work in the way I had envisioned.

I had thought of doing work in churches as a desire to steer away from crafts. With just my MA (Wool and needles in my casket: Knitting as habit among rural Newfoundland women, 2000) under my belt, I was quickly labelled "the knitting girl." I wanted to move away from studying crafts so that I would not be pigeonholed. Once I realised that my initial research was not going to work out for me I returned to what I knew. I realised that I needed to go back to the topic about which I am knowledgeable. I then started to toy around with various angles to tackle the idea of work and craft production. I knew roughly that I wanted to look at people who chose to do craftwork, probably as a second career. I wanted to see what drew people to 
work that is labelled as "traditional" in an increasingly information-based society. Where does small-scale physical creation fit into a labour market that is increasingly focussing on IT work?

The genus of this research was the 2002 report on the state of the craft industry in Newfoundland. Upon reading this report, I found that it was lacking the "people" that the report writers say they consulted. From my MA thesis on Newfoundland knitters working for piece rate, I had a grasp on the craft industry in the province. This report was to be the foundation the province was to grow the industry on, but I found that it predominantly concentrated on the marketing of crafts without much attention to the situation of the craft producers. I came to see that this was to be where I could contribute to the dialogues on crafts, work and socioeconomic development.

While I had not considered doing research in Newfoundland again, I knew however that this offered me a unique opportunity to return to a place that I enjoyed. I have long felt that place is important to our understanding of how people make decisions (see Pocius, 2000). I believe that the cultural and social norms and values shape people's actions. It was therefore important to return to the province to gain a further appreciation for the cultural, social, and political atmosphere. I also felt it was important to gain the information I needed from the craftspeople through face-to-face interviews. This allowed me to see where the work was being done, it made sure that the craftsperson experiences little inconvenience, and I was able to travel across Newfoundland to experience (granted to a limited degree) the situations in the outports. As such, I spent a year living and working in Newfoundland while 
conducting my interviews. The year I spent in Newfoundland contributed to my understanding of both the craft industry in the province and the general conditions that exist.

\section{An actionist approach}

I had discovered through my MA qualitative research that Schlereth's (1982) actionist approach to material culture serves well when investigating craftspeople's work. This approach is premised on the idea that a craftsperson's "beliefs, values and aspirations" (58) shape the crafts he or she produces. In turn, the individual's society and culture inform the decisions and actions that he or she undertakes. This approach states that one's production work is isolated from neither the worker nor society. The product reflects both the individual, and the worker's culture / society. This means that there is a direct line from society, to the individual, to the craft.

Fig. 1 - Link between craft, individual, and society

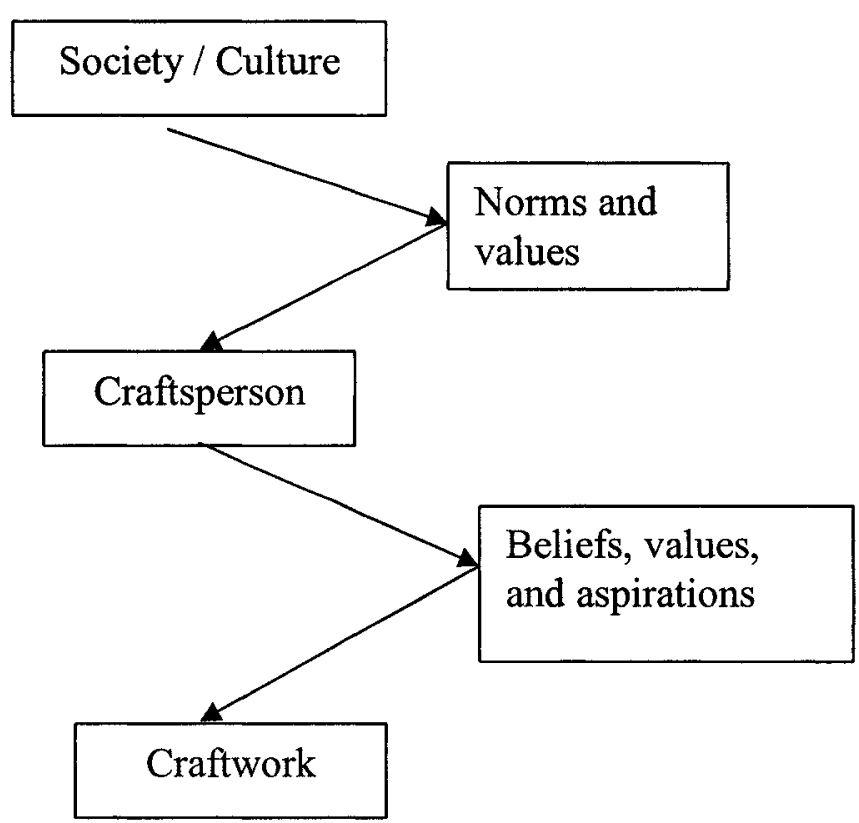


This linkage between the three levels may seem obvious; however, it is important to state. It allows me to be able to interrogate a micro level occurrence, such as craft production, to see how macro decisions (government socio-economic policies) shape work experiences. ${ }^{8}$

\section{Three levels of knowledge}

The next component of Schlereth's approach is to look at production through three levels of knowledge: referential, mediated and experiential. Each level becomes progressively more in depth and requires the researcher to employ different modes of interrogation.

Referential knowledge involves one "seeing" the products created. One needs to view the craft in order to discuss the process involved. One must be familiar with not only the immediate product, but also those within its genre and culture-at-large. To fulfill this level of knowledge I did research both academically and anecdotally. For my MA work on knitters in Newfoundland, I did extensive historical research on Newfoundland crafts, especially textile crafts. I became knowledgeable about the "traditional" Newfoundland crafts and could recognise the elements that made them unique to the area. At the beginning of this particular research, I went to a variety of websites that exhibited Newfoundland crafts, as well as obtaining a copy of the "Studio Guide" provided by the Craft Council of Newfoundland and Labrador. I also attended craft shows and visited retail outlets selling crafts. This prepared me to know the current crafts produced for sale in the

\footnotetext{
${ }^{8}$ Similar approaches include Buroway's (2000) global ethnography. We also see a similar use of the micro occurrences to examine macro phenomena in Winson and Leach's (2002) investigation of contingent work in rural Ontario to explore the effects of globalization.
} 
province. From here, I saw the participants' crafts and, in many instances, the workshops where they did their work, thus being able to visualise the products and processes in order understand the work experiences. One particularly strong case was Alf and Laurie's workshop. Alf proudly said that he had taken dragger line and reels to construct his painting and drying room. ${ }^{9}$ By actually seeing this room, it became more evident what ingenuity this was. The visual therefore provides the researcher with a "reference" point to connect the producer with his or her product.

Mediated knowledge is the "hearing" about the process and product from the producer. In the pursuit of this kind of understanding, the researcher goes out and talks to the producers. In order to obtain mediated knowledge about craft production in Newfoundland, I conducted interviews in the craftspeople's homes, workshops, workplaces and coffee shops. ${ }^{10}$ In essence, the interviews took place wherever it was convenient for the participant. The interviews were done from August 2003 to May 2004, with the bulk being done in August. For the most part, each interview took one to two hours. I used an interview guideline in a semi-structured manner (see below for a discussion on interviews).

Interviews, and the narratives that are given, are really the only way to gain mediated knowledge. The interview setting lets the researcher pursue any line of interrogation about which the participant seems to have more to say. If there is any information that particularly intrigues the researcher, you are able to question the participant further to improve your understanding about what he or she is saying. Hearing is a form of learning that allows one to interact with ideas and information

\footnotetext{
${ }^{9}$ Dragger line and reels are equipment used on large fishing vessels to haul in the nets.

${ }^{10}$ See the appendix for the interview guideline, participant letter, consent form, and an ethical discussion.
} 
that static forms do not allow. Reading the results of a survey or merely listening to a narrative makes cuts you off from what the participant is trying to convey, in that you are not an active participant yourself. Being the front-line interviewer allowed me to question areas where I needed to gain more understanding. One instance where this was an issue was when Mark, an instrument-maker in St. John's, was explaining how he obtained the raw materials to make his instruments. He started off by stating that he got his wood on-line. I probed him further to explain more about the actual woods he used and the difficulty, not to mention the shipping expense, to get the woods to Newfoundland. By doing so, I was able to hear about one of the areas of difficulty that craftspeople can encounter when working in a peripheral and geographically isolated region.

The next level, experiential knowledge, is more complex. Ultimately, the researcher should do the craft themselves. It is not that you need to be a professional or highly proficient, but it is suggested that if you attempt the specific craft you are talking to the participant about you would gain a kinetic understanding. This allows you to connect the jargon with the process and aspects of the product that might otherwise be difficult to visualise. For this research, it is near impossible to try all the various crafts that people in Newfoundland do for any amount of time that would allow you to gain the experiential knowledge. However, I do bring some experiential knowledge in crafts.

For most of my life, I have been a knitter. While I have never operated my own business, I have been involved with this craft at a variety of levels. First, I am a proficient knitter. I began the craft as a child and have continued on to present day. 
Next, I have worked in the retail end of the business. I have worked for two different yarn stores. In particular, I worked in a yarn store in Newfoundland where I learned much about the craft industry in Newfoundland. I encountered professional designers and lifelong amateur knitters alike that gave me an appreciation for what Newfoundlanders look for in crafts. I also learned the isolation of some outport communities, as we had to send out orders to people across the province. Before my graduate studies, I had the opportunity to work in a sector of the craft industry that few have had the opportunity. I worked in sales and marketing for an international textile company that made yarn and threads for primarily handknitters and home sewers. While I did receive a salary, so I have not experienced some of the sales and marketing concerns self-employed people have, I do know what it is like to have to sell and market to a specific market. I also have some experience in helping the design department and product development. This experiential knowledge allows me to understand the trials that some of the craftspeople experience. For example, Joan, a food producer in Eastern Newfoundland, says, "I know how to make fudge, it's the marketing I can't do." I can understand how different the skills are that one needs to promote crafts, especially when you are a small producer. Jim, another food producer, talks about how much time and effort he has to expend to educate people about his product (seaweed preserves). It is time that he would rather spend making his product or product development. Because I bring experience from both the craft and the sales and marketing, I can appreciate both the trials and the pride that the craftspeople experience. 
I believe it is important to know about the place where the work occurs. Peck (1996) points out that the labour market is different from one place to the next. In order to gain this experiential knowledge about Newfoundland, I lived there for a total of three years. The first two years I was in Newfoundland pursuing my Masters degree at Memorial University of Newfoundland (MUN). These two years introduced me to aspects of the Newfoundland culture. It dispelled some of the preconceived, admittedly romantic and pastoral, ideas I had about the province. I also had the opportunity to acquaint myself with family that I did not previously know well, due primarily to geographical distance. This in itself also helped me gain an inside handle on the social organisation of Newfoundland culture. Over the next two years, while living in Ontario, I continued to follow the news in the province. The following year, I spent my time conducting the interviews for this dissertation and working a teaching contract at MUN. Being an instructor, I encountered students from all over the province. I learned about outmigration from those most likely to leave the province - a reoccurring concern in Newfoundland. This year (2003-2004) was one of change in Newfoundland politics; after a long-reign by the Liberal party, Newfoundlanders elected the Progressive Conservatives to government in the fall, and the province had the largest public service strike in their history. This brought about a new rhetoric, in particular the desire to develop small local businesses into medium-sized businesses. The rhetoric makes one believe that these types of business will provide jobs and incentives to retain people. As I continue to monitor current events in Newfoundland, I will watch to see how the development policies will affect the self-employed. 


\section{Narratives and document research: Use and analysis}

Miriam Glucksmann (2000) advocates the combination of qualitative interview research and document research. ${ }^{11}$ She puts forth this combination when it comes to historical sociology as a way not so much to confirm or disprove what people say, but to contextualise their oral testimony. My work is not historical in nature, but when taking the micro experience of work and connecting it to the macro you need sources that address both of these. What I did was to take the semi-structured interview method and provide context to their discussions through various government documents, particularly the 2002 report on the state and future of the Newfoundland craft industry.

The semi-structured interview permits a researcher the latitude to probe for clarification and elaboration on answers, while at the same time providing a framework for comparability across interviews (May, 2001). This is important to the achievement of this dissertation. I was able to take a flexible interview guideline to each of the craftspeople's locations and investigate some of the topics I wanted to learn about, while at the same time allowing the participants the freedom to elaborate on a given topic. It also provides a central path that allows me to compare and contrast each participant's narratives. Semi-structured interviews are also effective because I am only with the participant for a short time. As such, it is best to have a way to guide the conversation. It does not prohibit a participant to take the interview in a direction they wish (as tangents can provide information that you were not expecting); however, it helps me to be sure that I get their narratives to be as explicit as possible about their relationship to their work.

\footnotetext{
${ }^{11}$ In chapter 5 , there is a more detailed discussion on her "Total Social Organisation of Labour."
} 
Narrative analysis is a case-centred approach that sheds light on C. Wright Mills "sociological imagination," where biography, history and society intersect (Reissman, 2004). The narrators' telling of their experiences "are located in particular times and places, and individuals' narratives about their troubles are works of history as much as they are about individuals, the social spaces they inhabit, and the societies they live in" (Reissman, 2004: 333). Through the narrative we see different forms of action, with the motives and meanings attached to these actions (Laslett, 1999). As well we see the ways in which people reveal elements of their identity and make sense of their social relationships, social situations and history (Bamberg and McCabe, 1998). All of this is structured in a temporally and spatially specific manner (Reissman, 2004).

Colette Daiute and Cynthia Lightfoot (2004:viii) advocate the use of narrative analysis as a tool "for addressing the unmet challenge of integrating culture, person, and change ... [where] the texture of modern life is increasingly defined by weaving together separate generations, lifestages, cultures, and social and political ideology." For these researchers, narrative analysis and inquiry has four benefits not easily achieved using other methods: interpretive tools designed to examine phenomena, issues, and people's lives holistically; provides a context for examining social histories that influence identity and development; generates unique insights into the range of multiple, intersecting forces that order and illuminate relations between self and society; and permits the incursion of value and evaluation into the research process (Dailute and Lightfoot, 2004: xi - xiii). 
Some may question whether what one gets from semi-structured interviews are truly narratives. The participant is not completely free to relate their life stories. That said, I would argue that I do get a particular narrative from the semi-structured interviews. My guideline is structured in such a way that $I$ in essence get the story of their experiences as craftspeople: how they became involved in this work, what keeps them in it, where do they see it going. They are narratives about how experiences of work relate to broader experiences of society and culture. In spite of the individualistic nature of narratives, Riessman (1993) states that one is able to grapple with the culture that the narrator is a member of. As she points out, culture speaks through individual narratives, as each narrative is a representation of a certain time and place. Glucksmann (2000) shows that this is particularly useful when investigating issues surrounding work. By analysing a series of narratives taken at about the same time, one is potentially able to understand specific occurrences in a culture. One is then able to place the individual's experiences into a larger context. This relates back to the actionist connection between the craft, the individual, and the society.

When finding participants for research, May (2001) states that Kahn and Cannell's three conditions are necessary for successful interviews: accessibility, cognition, and motivation. Accessibility is the criterion that the interviewee has the information that one is looking for. In my case, I needed to find professional craftspeople to aid me. I started by contacting people through two ways - an established list of professional craftspeople in Newfoundland and word-of-mouth. The list is one posted on the Website entitled "Crafts of Character" 
(www.craftsofcharacter.com). This is a government sponsored marketing site used to promote Newfoundland crafts. I decided to use the list on this website as theoretically all those on it are partaking in a government sponsored programme. While one might assume the limitation of this is that you do not tap into those that do not receive any financial support from the government, I quickly learned that all businesses do receive some sort of government assistance in Newfoundland (see Overton, 1999). I sent an email to all those that had posted e-mails, and mailed letters to those that did not. I followed up via e-mail and telephone calls. I received eighteen affirmatives. I initially interviewed fifteen of them; the other three had conflicting schedules for when I would be travelling through their area. I did followups with these three but was unable to make contact. Two other interviews came about through neighbours and colleagues. I ended up with seventeen participants: two sets of couples and thirteen individuals. I was confident that my participants would be able to provide me with the information I was seeking. All of the interviewees were professional craftspeople who had participated in government programmes on some level. While I have no way of knowing if this is an adequate percentage of the craft producers in the province, the province does not themselves know how many producers there are, I found that I reached a point whereby I was getting similar responses to my questions.

Kahn and Cannell's second condition, cognition, requires that the participant is aware of what is expected of them in the interview situation. For this reason, as well as for ethical considerations, each interview began with a description of the research I was pursuing (they had already received a brief description in my initial 
contact letters) and of the securities that as an academic researcher I am obliged to observe. $^{12}$ I assured them that the participants could count on my confidentiality and their anonymity to make them comfortable with answering my questions. I also told them that they could refuse to answer any question. I asked them to sign a consent form and to give permission to tape the interview. All except Brad, a woodworker in St. John's, did so; Brad decided to complete the interview first before signing the consent form, as he was concerned about the fact that I did not plan to destroy my data. He signed the form as he felt my questions and the information he provided were "benign."

The final condition, motivation, requires that the interviewees feel their participation is valued. May (2001) suggests that using open-ended and probing questions demonstrates that you are interested in what the interviewee has to say. It allows the participant to express their thoughts in their own words and as such shows that what they have to say is of importance to the researcher. I also made sure that the participants knew where this research would end up and who would see it. I found that in the eyes of some of my interviewees the fact that the dissertation, as all in Canada do, ends up at the National Library in Ottawa gave the research an air of importance.

The interviews are qualitatively analysed to identify the themes that run through the narratives using analytic transcription. This involves multiple listenings of the taped interviews to identify the themes and threads that run through each

\footnotetext{
${ }^{12}$ Due to ethical concerns about possible illegal activity, in particularly tax evasion and fraud, the Carleton Ethic's Committee would not permit me to ask questions about the income and financial status of the participants and their businesses. I was also required to place a clause in the consent form that if by chance I should discover some financial information, I would keep that confidential.
} 
narrative. I then transcribe each of the participants' responses and corresponding questions, thematically for closer analysis. Then the noted themes from each interview are brought together to identify the common experiences and those that are unique to the individual. One of the main reasons for using analytical transcription is that as a learner I retain information better if presented orally. It also allows me to make better use of the referential and mediated knowledge that I gathered at the time of the interviews.

Jane Elliot (2005) points out that when analysing narratives researchers often position themselves on a continuum between naturalist approaches that focus on content, and the structure / form focus that attempts to reveal how the presentation and context of the narrative shapes what we know about the narrator. For my project, I focus on the content of the narrative. I am more concerned with what the participants have related, than how they related their narratives, as I believe this approach is best suited to get the knowledge that will speak to my puzzle. As Elliot points out, narrative analysis is "to develop an understanding of social groups, classes and cultures and the structural relationships between them" (2005: 39). This is one of my central concerns - how craftspeople's work relates to the government development policies.

After analysing the narratives, I organise and present the information into two types of narratives: first order and second order (Elliot, 2005). The first order narratives are case studies where I show how craftspeople constitute meaning and motivation for their work, as well as elements of identity. Within each narrative I show how different themes run through the narratives. From the first order narrative 
themes I construct second order narratives. The second order narratives are where I as the researcher organise the information to show how I make sense of the craftspeople's social world. I pull out elements and themes from the different individual narratives to piece together a narrative that allows me to speak to the research puzzle.

I had to make a decision about the presentation of the narratives in text form. Language can be a contentious issue when presenting the words of others to the reader. Do we as a researchers provide the narrative its raw form, with dialect and grammatical errors, or do we polish the narrative to be grammatically correct with no indication of dialect? I have opted to present the narratives in their raw form. I did this in order for the reader to gain a feeling for the place; one cannot deny that the Newfoundland dialect is distinct from any you would hear elsewhere in Canada. I also feel that it is incumbent upon me as a researcher not to alter the participants' words. The words they choose are important to how they wish to communicate their narratives.

Newfoundland's European descendents come primarily from Ireland and Western England. It is from these areas that Newfoundland's unique dialect developed. The Dictionary of Newfoundland English (Storey et al., 1999) provides a brief description of the dialect's components:

1. Nouns after numerals above one have no plural -s: 'Now a cod-trap is about sixty fathom on the round.'

2. Finite verbs in the present tense take $-(e) s$ for all persons and numbers: 'I thinks this is unlawful, and as others informs me is onproper and onpossible, and this the liviers here, all could tell ye.' 
3. Only one form is employed for both the past tense and past participle of strong verbs: 'She was gangboarded, fore-cuddy an' after-cuddy on her, and freeze come on, they got drove off.'

4. Am, is, and are are employed for an assertion about an event at the present moment, while be's, for all persons, indicates continuous or repeated activity: 'There's a sunken rock. You know when the water's high, that it be's under water.'

5. To have (already) done (something) is not a normal usage, the notion being expressed by to be after doing (something): 'How many times am I after tellin' you?'

6. The unstressed object form for he is un: 'We'd see the sun steady for three months, never lose un.'

7. The stressed forms for the personal pronouns after verbs (including forms of be) and prepositions are I, he, she, we, they:

'[Fairies] was only little small people, they used to tell we.'

'He thought to hisself he'd a-killed the two of 'em [but] 'twasn't they now.' 'Never mind they-let 'em bite.'

(The unstressed forms, except for example 6 above, are the same as in standard colloquial English.)

8. Stressed he and she are often used as substitutes for count nouns, but it for mass and abstract nouns like crookedness, fog, weather: 'But the first hour we hauled in the log, and he registered three miles. So the next hour we hauled 'im in again, and she's got another three miles.'

9. Adjectives derived from names of materials end in -en: 'tinnen cup, glassen pole.'

10. For many speakers the plural demonstrative determiners are those with objects and events that are current, and them with objects and events that are past: 'Years ago, not so much those days, you'd always have a gun line.' 
The geographical isolation has acted to protect against the influences of other English-speaking communities and thereby the unique Newfoundland dialect has been perpetuated.

With semi-structured interviews, the content and context of the interviews are both important to the research process. As I noted above, the starting point of this particular puzzle was the 2002 provincial craft report. I use the narratives and the report in a "reciprocal" relationship; that is, the narratives provide the bases to critique the report and the report contextualises the craftspeople's experiences. As pointed out, "[d]ocuments are now viewed as media through which social power is expressed ... [they] might, for example, reflect the marginalisation of particular groups of people and the social characterisation of others" (May, 2001: 183). It is with this critical understanding of documents, particularly government reports and records, that I approach the texts. To some degree this research is a class analysis of property, therefore there needs to be a way to investigate levels of power. By using documents as part of my research, I am able to delineate the formal levels of power, particularly in relation to government-sponsored socio-economic programmes. The documents will not be used to investigate the "disparate knowledge" that exists in individual remembrances and official record (see Glucksmann, 2000), but as a context within which self-employed craftspeople operate.

For the document analysis, I use a qualitative approach. I do multiple readings to see the tendencies, themes and patterns that immerge. Jennifer Mason (2002) stipulates that there are three ways to approach document analysis: literal, 
interpretive and reflexively. The literal analysis is understanding the document at face-value. It involves accepting the information presented in the document as fact. Within sociology, we know that nothing is created in isolation. That is why we need to move onto an interpretive form of analysis. To look at a document with an interpretive lens means contextualising the document in terms of production, use, what meaning they have and what they represent culturally. Lastly, document analysis, like other forms of qualitative research, needs to be done reflexively. As Scott (1990) states:

Textual analysis involves mediation between the frames of reference of the researcher and those who produced the text. The aim of this dialogue is to move within the "hermeneutic circle: in which we comprehend a text by understanding that frame of reference from which it was produced, and appreciate that frame of reference by understanding the text. The researcher's own frame of reference becomes the springboard from which the circle is entered, and so the circle reaches back to encompass the dialogue between the researcher and the text (32).

I see that these three steps in document analysis correspond well with Schlereth's approach to examining material culture work, as discussed earlier. As a qualitative researcher, I move from being an observer at a distance, to listening to or reading my data, to being incorporated into the research.

While doing this, I keep Scott's (1990) criteria of meaning interpretation. This involves questioning the author's intent, how the reader receives the information (including myself), and the content meaning of the text. After noting these, I then set 
out to interpret them in a critical-analytical approach. This stance "considers the ways in which a text attempts to stamp its authority upon the social world it describes. In doing so, the social world might be characterised by the exclusion of valuable information and the characterisation of events and people in particular ways according to certain interests" (May, 2001: 1995). Using this stance allows one to see whose agenda is foremost and whose experience is missing. In this research, we see that it is the Newfoundland government's agenda at the forefront and the craftspeople's experiences missing in the documents.

\section{Conclusion}

We see that this reflexive research came about from my MA research, with a slight detour. I have employed methods that speak to the nature of the puzzle at hand; the semi-structured interview brings about the experiences and understandings of the self-employed craftspeople, while the documentary research contextualises the power arrangement as seen by the provincial government. Supplementing these is the experiential knowledge I have gained from previous work experience and living in Newfoundland. The remainder of this dissertation now sets out to analyse and interpret the information these sources have brought to the table. 


\section{Chapter Three \\ Crafting development}

Before setting out to analyse work narratives, it is important to understand the context within which a person works. The first part of this chapter sets out to establish an historical and theoretical framework that I use to understand selfemployed Newfoundland craftspeople. This includes looking briefly at Newfoundland's attempts at development since 1949, understanding cultural industries, and exploring (re)creation of territorial identity. The second part of the chapter uses a critical-analytical approach to examine Newfoundland's Department of Industry, Trade and Rural Development's 2002 report on strategies for the province's craft industry. Key areas of concern will be identified and used to demonstrate how the government's strategy for developing the craft industry is product and market-focussed to the exclusion of the craftsperson as an integral component of the industry.

\section{Historical context of development in Newfoundland}

In 1949, Newfoundland went from being an independent dominion under the British Empire to a province of Canada. Up to this time, any "development" done in Newfoundland was initiated and carried out by churches and charity organisations. They were trying to help the "poor outport people" (see Harling Stalker, 2000; Cullum, 1994). There was very much the sense of noblesse oblige; the paternal 
instinct of Newfoundland's elite to look after and improve the plight of those that lived in rural fishing villages.

From Newfoundland's inception, the area has had difficulty putting into place an economic system that benefits the whole province. Finbow (2004) points out:

Development was limited by the system of merchant credit, which tied fishers to the merchantile elite in St. John's in an exploitive manner. An internal dualism between the commercial core of St. John's and the Avalon peninsula and the rural hinterlands and outports, combined with dependence on foreign investment to shape the province's unique economy and culture (152).

Over the years this dependence, and some would argue it as being exploitive in nature, will manifest itself in Newfoundland in many ways: provincial - federal government, multinational corporations, rural vs. urban residents.

In the post- World War II era, governments in North America and Western Europe were moving toward welfare-state systems. The Newfoundland government could ill-afford any of the pensions and insurance that go with being a modern welfare-state - its treasury was bankrupt and the British government was not interested in maintaining the colony. It is for this reason that Newfoundland looked to ride Canada's "coat-tails," benefiting from the Canadian welfare-state (House, 1999). Newfoundlanders could take advantage of income support programmes, like unemployment insurance and old age pensions, and the government would receive transfer payments from the federal government to commence "development." 
Joey Smallwood's development attempts. ${ }^{13}$

Joey Smallwood, the crusader of Confederation and first Newfoundland premier, impatiently announced to fellow Newfoundlanders in 1950, "We must develop or perish" (quoted in Leto, 1998: 1):

Smallwood felt that Newfoundland would have to rely on federally funded social programmes in the short term for economic expansion when it became a Canadian province in 1949. In the long term, the new province would have to expand its industrial capacity to extract and exploit natural resources, whether marine or landward. Such industrial expansion was the only way Newfoundland would escape dependence on federal transfer payments (McBride et al., 2002: 271)

Smallwood thought that if Newfoundland developed, and in his mind this meant industrial development, they could stop the flow of out-migration that was growing not only in Newfoundland but all across the Atlantic region. Smallwood sponsored the creation of plants to manufacture everything from hydroelectricity to chocolate bars and rubber boots, and implemented the infamous resettlement of Newfoundlanders to "growth centres". The resettlement of many outport communities centralised labour to provide the new industries with readily available, not to mention cheap, labour (McBride et al., 2002). Leto (1998) points out that the combination of Newfoundland's history as a fishing colony, and Smallwood's haste and lack of planning, caused the industrial development to fail. Newfoundlanders for

\footnotetext{
${ }^{13}$ For a concise synopsis of Joey Smallwood's economic development attempts, see Brian Slemming's article (1999) "The mad mad schemes of Joey Smallwood, a 50 ${ }^{\text {th }}$-anniversary look at Newfoundland's first premier." (http://www.nextcity.com/contents/spring99/15smallwood.html)
} 
generations had known how to work with natural resource harvesting - timber, hunting, and especially fishing. The Newfoundland government ignored natural resources for industrial creation; they wasted their limited and valuable monetary resources as nearly all the manufacturing initiatives failed (Leto, 1998; McBride et al., 2002).

There were those that were weary of the Newfoundland government's development plans. Overton (1996), in his discussions of the perspectives taken toward culture in Newfoundland, describes the regional sentiment and counterculture movement of the 1960 s and 1970s. "Broadly speaking, this movement was an anti-material, and often romantic, rejection of certain aspects of urban-industrial society with its orientation towards progress, its bureaucratic rationality and its middle-class values" (Overton, 1996: 49). For the large part, those involved in this movement were academics, particularly those with the Institute for Social and Economic Research (such as Brox (1972) and Wadel (1969), who were doing "rural development" studies), and those from the mainland (like Farley Mowat who tried to get "back to the people"). They were countering Smallwood's policies of modernisation and resettlement. "Small is beautiful" was the doctrine advocated by many of these academics, and activists like Mowat felt that modern society was turning people into "beasts."

Overton believes that this perspective is a reaction to the development of capitalism in the province. He sees the romantic and nostalgic perspectives as representing the values and way of life that capitalism is destroying. While he is Marxist in his own theoretical stance, he is critical of those in this movement. The 
members of this movement have not looked at situations through the "lens" of a Newfoundlander. He contends that one must be ready to look through the "lenses" of Newfoundlanders' experiences before making any critique or assumptions about their culture. He contends that the aforementioned romanticism and nostalgia perspectives imposed upon Newfoundlanders are elitist, and mask issues such as class and power struggles. Again, noblesse oblige permeated through Newfoundland and Labrador's attempt to do economic development. His assertion is not too far off from the mark. The rigid class system that the province inherited from Britain, its colonising "parent," becomes overlooked in the desire to save for posterity the folk-life of Newfoundlanders. At the same time, the groups he is criticising do provide us with a sense of the social norms and values of Newfoundland outports that his own theoretical stance might overlook. The "lens" must not only recognise the classist social structure but also the inherent social norms and values.

\section{Development since Joey Smallwood} Joey Smallwood retired from premiership in 1972, after being in the position for twenty-three years. He left the province with a large financial deficit.

Because of the multiple failed attempts at industrial development, Newfoundland's economy became almost exclusively dependent upon the fish industry. Starting in the 1970s the Newfoundland governments have focussed on modernising the fishery. Governments assisted in capital expenditures, such as 
longlingers and trawlers, and increased the boundries of Canadian waters. The result was less dependence on seasons, and an increase in cash profits.

Reginald Byron (2003) tells us how the modernisation of the fishery changed the outport economy from a pluralistic one that exploited various natural resources, to one that was highly dependent upon the success of the fishery:

As development policy proceeded, from the 1960s on, and as people's expectations of living standards came to be increasingly influenced by urban values and underwritten by improved incomes and income-supported programmes, rural Newfoundlanders gradually drew away from homespun, pluriactive strategies of household provisioning that relied on the seasonal exploitation of a range of natural resources and craft activities, to much more specialised and narrowly focused ways of making a living (7).

Newfoundland outports were turned into "one-company" towns and remained so into the 1990's. The traditional moral economy, where everyone had open access to resources, was replaced by a market economy controlled by capitalist interests. In many cases, multinational corporations held these interests.

The modernisation of the fishery at the expense of the pluralistic activities is one of the reasons for the harshness of the 1992 cod moratorium. The outport communities had no other significant industries to fall back on. The federal and provincial governments' responses involved throwing money at the situation, as Smallwood had done. Those affected by the fish moratorium were offered additional financial support and make-work projects. 
In the last few years, the shift in the government's development plans has searched for new natural resources to exploit. The oil and gas industry has been exploring and drilling off Newfoundland's coast, with the current big project being Hibernia. The government has also used secondary-industry as a bargaining chip. In order for INCO, a Canadian mining corporation, to secure the rights to extract minerals from Labrador, they had to agree to build and operate a smelter in the province. The attempt is to secure as many jobs as possible to again quell the flow of out-migration.

Jim Overton (1999) critiques the development policies adopted by the Newfoundland governments of late. He argues that some government officials and academics are pushing Newfoundland into the neo-liberal agenda. They are doing this by privatising crown corporations, such as the provincial park system, and accepting the social transfer cutbacks as inevitable and almost desirable. This push into the neo-liberal model is portrayed as a means to make Newfoundlanders selfsufficient and self-reliant; the cutbacks are merely a form of "tough-love" (Overton, 1999: 113). Overton points out that this is unrealistic, as no enterprise in Newfoundland is independent of government subsidies. From fishplants to the craftworkers in this study all receive some form of government support. What Overton wants to see happen is the banding of Newfoundlanders, in particular those in organised labour, to take part in "organisation, education and continuous opposition" (115) to oppose the liberalisation of Newfoundland's social systems. He even broadens his call to include "all those who are fundamentally committed to justice, equality, democracy and collective responsibility for each other must draw 
together and fight together" (115). While Overton strikes a militant position, he does have a valid point that Newfoundlanders have long relied upon government support. This, I would suggest, is similar in many insular regions. For the government to maintain a market-driven neo-liberal stance does not take into account the uniqueness and socio-cultural elements that exist.

\section{Cultural industries}

As I have shown, development policies have mostly focussed on the industrial and natural resources. I would like to look at an industry that has garnered minimal attention within the Newfoundland context - cultural industries. Cultural industries exhibit the dialectical relationship between culture and economics. Currently, there is a shift away from understanding culture as merely "high arts," to one that promotes the popular and vernacular forms of culture (Kong, 2000). Governments are developing cultural policies that sponsor the creation of cultural industries. These policies are seen by many, especially in urban centres, as a modern and innovative response to the globalisation of capital (Kong, 2000). ${ }^{14}$

Cultural economies are concerned with the production of cultural identity. "In cultural industries the primary value of goods is symbolic and short-lived; it is lodged in ephemeral signs, meanings and senses of style" (Bank et al., 2000: 455). While there is concern over what aspects of a culture will sell, these industries are atypical in that their sole concern is not profit. As Bank et al. (2000)'s research on cultural entrepreneurs shows, there is more concern with the need to be creative and to be a

\footnotetext{
${ }^{14}$ This is contrary to rural areas where the use of cultural economies and industries is perceived to be a reaction against modern values.
} 
member of a cohesive innovative network of like-minded individuals. Being a part of the cultural economy then is more about lifestyle choice than about economic success.

Ray's models for cultural economies.

In the literature on socio-economic development, there are few who focus solely on the impact of cultural economies ${ }^{15}$. Christopher Ray, a British researcher, has produced the greatest amount of conceptual and theoretical discussions on the topic. In particular, he has developed models that one can use to examine cultural economies.

There are four models that an area can use to develop a cultural economy: commodification of local / regional culture, incorporation of cultural resources into territorial identity to promote to the "outside", selling itself internally to create loyalty of locals, and normative capacity to seek alternative paths for development (Ray, 1998c). This last model is of interest as it sets cultural economies up to be "ethical" economies (Ray, 1998). One sees this model in action in two ways. First, development using cultural economies can address or even undo injustices of socioeconomic decline. As with the European Union's (EU's) LEADER programme, regions that are significantly below the EU's economic averages are given assistance to devise development plans that promote a region's culture in the belief that this will provide economic benefits. Secondly, cultural economies can market

\footnotetext{
${ }^{15} \mathrm{~A}$ new branch of the literature is starting to grow that focusses on cultural tourism. See McKercher and du Cros (2002), and Aitchison et al. (2000) for discussions on issues pertaining to heritage management, gatekeeping, and representing landscapes.
} 
ethical consumerism, such as eco-tourism. This initiative uses the local knowledge to get tourists to spend time, and of course money, in the region without seemingly doing any harm.

Local knowledge, the community's way of doing things and ways of understanding (Ray, 1998a), is interpreted in two ways. One can see local knowledge as continuously evolving. Often, communities see local knowledge at its height before the introduction of modernity to a region. It is to this point that communities wish to (re)discover in their development initiatives. By adopting traditions that were present in the local area, the members of the community can promote them as unique, and exploit the nostalgia element of sale.

The other way of seeing local knowledge is by turning it into intellectual property. "Economic agents in localities wish to continue their traditions but rather than in the context of local production and consumption, they increasingly seek to exploit their knowledge through the global market economy ... [They] transform tradition into the concept of intellectual property" (Ray, 1999b: 531). A well-known example of this is the French wine industry. They have made it so that only wine made in Burgundy can be called burgundy; wine made in Champagne can be called champagne. This, in essence, provides legal protection for the local knowledge, so that no one from outside the region can claim to offer the same product. Turning local knowledge into intellectual property strengthens regions' claim to producing the "real," or authentic commodity. One sees them then as having a unique product available on the global market. The local knowledge is not only beneficial to the possessors of the knowledge, but also to others in the community. It gives added 
authenticity to other cultural industries in the area (Ray, 1998b). This is because the "authentic" local knowledge is tied to a place. By drawing attention to the region, it encourages people to investigate what other things are available for sale. If continuing with the French example, textiles (especially in Provence) and regional cuisine have benefited from the popularity of wine.

One needs to be careful not to be too focussed on the local when talking about cultural industries. Kneafsey et al. (2000) did a study of four different cultural industries in West Wales and examined the local and extra-local connections. They found that the main weakness in Ray's work is that there is too much focus on the local. There is not enough discussion on how people from outside the region or community can influence and partake in the cultural industries. Of particular interest to this paper is their investigation of the craft industry. It found that many craftspeople in rural Wales are not originally from the region. The craftspeople explain this by emphasising they made a lifestyle choice. This choice is usually seen in opposition to an urban existence. Craftspeople are therefore willing to live on a lower income in order to have a rural life. Because the craftspeople have low incomes (often supplemented by a spouse), they are not direct employers, and therefore are not large economic engines in the region. While they may not provide jobs to the area, craftspeople are beneficial. They can attract tourists, who can then purchase other products and services while in the region. Craftspeople can contribute to the local image and add to regional capital. Kneafsey et al. (2000) state that craftspeople do this by purchasing old farmhouses and restoring them. These homes would otherwise be left to decay; so by living in the home craftspeople 
assist in beautifying (or rejuvenating) the area. The craftsperson also purchase local supplies and services themselves, thereby keeping money in the local economy. One should therefore not see craft production as a direct source of economic development, but look at the social and economic spin-off effects to a region.

\section{Cultural industries in Newfoundland}

The use of cultural industries in Newfoundland is not a new phenomenon. The province has promoted its "culture" to tourists for over a century (Overton, 1996). Within Newfoundland, the government promotes tourism as a mean of rural development. It is seen as something that can offer employment to the outports. In the years following Confederation, the Smallwood government implored Newfoundlanders to open tourist homes and to take lessons on etiquette. Folk traditions and customs were encouraged, if not invented, to have people come to Newfoundland. However, only the traditions thought to sell were kept. For example, the simple craft of producing handknit socks is promoted as reminiscent of a time when life was simple and people were independent. What is ignored is that when socks were knit on a regular basis, people had no choice because they were too poor to purchase them. The nostalgic and romantic promotions do not include this fact.

What was being created through this selection by the province's elite was a cultural species, with little or no input from the Newfoundland citizens-at-large 
(Overton, 1996). ${ }^{16}$ It was promoted as a uniting tie to Newfoundlanders to their romanticised past, as well as a means of getting employment in the present and future. This employment was seen as a means of potentially replacing jobs lost in the fishery, and to making Newfoundlanders independent. What this form of economic development does, according to Overton, is to subject people to lower incomes, short work seasons and locks Newfoundlanders into underdevelopment. Hickey (1997) demonstrates the elitism that occurs in the realm of craft production. The elitism in this case tends to be from urban people toward rural craftspeople. She discusses how in Canada "rural craft is regarded by some as engagingly naïve, unspoilt and genuine. To an urban market, the rural craftsperson can be cast as a noble savage living in one's backyard" (Hickey, 1997: 92). This is particularly so when a purchase is made at a craftsperson's studio. The consumer feels more like a patron of the arts, as opposed to a mere buyer. Because of this intrigue by the urban elite with the rural craftsperson, Hickey notes how, in Newfoundland, crafts (as an offshoot of tourism) is promoted as an employment alternative in the wake of the crisis of the fishery.

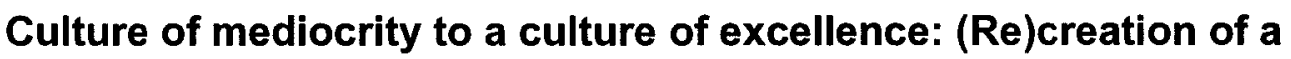
Newfoundland identity

While reflecting upon and analysing his time as chair of the 1980's and 1990's Royal Commission on Employment and Unemployment, and Economic Renewal Commission, J.D. House (1999) puts forth the idea that Newfoundland is a society

\footnotetext{
${ }^{16}$ McKay (1994), in his Marxist analysis of the development of "folk" traditions in Nova Scotia, specifically illustrates how a cultural species was created in this province by promoting its Scottish fishing heritage, while ignoring the Irish, German and Acadian farming populations.
} 
stuck in a rut of dependency. House calls this a culture of mediocrity. A culture of mediocrity came about from an economy with the following characteristics: nonsustainable / environmental neglect, narrowly resource-based, transfer-dependent, low productivity, high unemployment and large corporations (20). He states, "People [Newfoundlanders] had become too dependent on government programs. They needed to throw off the yoke of dependency and work to create new forms of wealth and employment in both established and new industries appropriate to their regions" (176). ${ }^{17}$

What we see House doing then is to call for a shift, or a refocussing of the Newfoundland identity. This is one important aspect of an endogenous development plan $^{18}$-- the (re)creation of territorial identity (Ray, 1999b). This is an attempt to "reconstruct an identity to enable the territory to become a vibrant, creative, successful entity" (Ray, 1999a). Often this is done in rural areas as a reaction to modernity. Modernity is frequently placed as the antithesis to tradition. In order to be modern, one must give up the local "traditional" ways to a part of the modern era. As Ray (1999b) uses Giddens' reflexive modernity, he believes that the harking back to previous ways of life, and glorifying them, is a way for communities to validate themselves. There are two models for identity (re)creation: the psychological and the sociological (Ray, 1999a). The psychological model involves the community finding sources of local identity and then exalting and exploiting them. It provides

\footnotetext{
${ }^{17}$ Dependency on federal government social programmes is not isolated to Newfoundland. The whole region of Atlantic Canada is dependent upon central Canada (Veltmeyer, 1990), and Canada is a dependent nation upon the politics and markets of other nations (see Drache, 1995 discussion of Harold Innis' Staple Theory of Development).

${ }^{18}$ Endogenous development, an integrated approach that includes consultation with the grassroots population, advocates a socio-economic development plan that relies upon the resources (natural, cultural, and social) found locally (see Ray 1998, 1999a\&b)
} 
only one focal point to which the local area attaches itself and "sells" when able to. In the sociological model, there is the construction of many local identities that meet the local needs and match it to extra-local opportunities. This allows the community to have various inclusive ideas about itself, and then as opportunities for development occur they are able to pick which identity best suits the opportunity. $(\mathrm{Re})$ creating a territorial identity is an important step to development as one uses it to convince the government to initiate development. By having developed an identity, and along with it a "history," it empowers the region to deem what is authentic. One can call this identity (re)creation a rising of ethnic consciousness; this does not become "an end in itself, not just a marketing ploy, but a framework to give deeper meaning to individuals and community development" (Ray, 1999b). The (re)creation of a territorial identity can allow development to promote and provide social solidarity to the region, and turn negative images of the region into positive ones.

The creation of identity is important to development in Newfoundland. What House does is call for the creation of a "culture of excellence." This is to be in the spirit of the self-sufficient fishers and their families before Confederation. This highly romanticised idea is used as a call to unify Newfoundlanders under one common purpose - to eliminate dependency. In order to do this, Newfoundland needs to embrace a "new economy" of sustainable / environmental stewardship, knowledgebased and diversified industry, self-reliant and market-driven economy, high productivity, low unemployment, small business and multinational corporations (20). In order to change the culture from mediocrity to excellence the province must follow 
a path of change within "education, research and development, service standards in the tourism industry, the quality of manufactured goods, competitiveness in a revitalised fishing industry, environmental stewardship, the province's cultural industries" (249).

There is definitely merit to this call of pre-Confederation society. With Confederation, Newfoundland experienced a purging of many of their "traditional" ways of doing things. For example, Pocius (1976) tells how women had abandoned their spinning wheels and many also abandoned their knitting needles and mat frames, after Confederation. There was a stigma that to do anything handmade was a sign of poverty. Why knit socks when you can easily purchase them at the store? That is the "modern" way of doing things. Ommer and Sinclair (1999) describe how Newfoundlanders have lost many of the skills that were necessary for survival before Confederation. Industrialisation, fishing quotas, and government social programmes have led Newfoundlanders to lose their ability, and opportunities, to partake in different forms of work throughout the year, in order to be self-sufficient. In Newfoundland "modernisation has been a source of cultural dislocation as well as economic stress to the old outport way of life" (Ommer \& Sinclair, 1999: 62). It is because of the encouraged seasonality of work, with the use of social benefits during the off-season that portray Newfoundlanders as dependent, slow and lazy (not to mention the numerous jokes at their expense).

Culture therefore is a central key to development; "because a culture manifests itself geographically, it is potentially available to animate, and even to define, endogenous development" (Ray, 1999b). As this is the case, one needs to 
look at the products of culture and see how they are used in the development of a vulnerable territory, such as Newfoundland. The purpose of cultural industries is to help provide the Newfoundlanders with a means of self-sufficiency, a means to endogenous development. They would not need to turn to outside help. The government took this view to heart, and started by publishing a report on the state of the craft industry in Newfoundland. This report sets the stage for using crafts as a part of the development plan for the province.

\section{Newfoundland and Labrador Craft Industry Development Strategy: Summary and recommendations (2002)}

As indicated earlier, the impetus for this research came from a report released by the Newfoundland and Labrador Government in 2002 about the current and potential future of the province's craft industry. The strategies in this report are created out of a study done the previous year for the former Department of Industry, Rural Development and Trade (2000). ${ }^{19}$ The 2002 report set out to develop a comprehensive understanding of the current state of the Newfoundland craft industry. AMEC Earth and Environmental Limited, an international project management group, and Hollett and Sons, an information brokerage located in Newfoundland, were commissioned by the provincial government and funded by the Canada-Newfoundland Comprehensive Economic Development Agreement to carry out the initial report and provide recommendations.

The report states that the current industry employs approximately 2000 people and has 200 companies. This is larger than the provincial agriculture,

\footnotetext{
${ }^{19}$ This branch of government is now "Department of Innovation, Trade and Rural Development."
} 
logging and forestry industries. In the previous ten years, the industry's worth grew at a rate of eight per cent per year from $\$ 10-12$ million to $\$ 38$ million. Despite this steady growth, there is a call to "catch up" to other similar jurisdictions (e.g., Ireland, Quebec, Maine) to make crafts more of an economic driver.

In order to catch-up, the strategy report of 2002 puts forth a goal to double the industry's worth to $\$ 75$ million within five years, and to increase the number of professionals by five hundred. The strategy addresses eight key areas: training; product development / production methods / small batch processing; design; markets / marketing; communications; business and technology; retailers; and support services (5). ${ }^{20}$ Within each of these subsections a goal is stated and objectives are presented as a means to achieve the goal

Having some knowledge of the craft industry in Newfoundland, both through my own experience working at a yarn store and my MA thesis, I was intrigued by what the report might advocate to improve the future of Newfoundland's craft industry. Upon first reading, I instantly became aware that the report missed any social understanding of craftwork. I set out to do a closer reading. While analyzing this report using a critical-analytical approach (May, 2001), it becomes clear to me that there are four key concerns needing to be addressed: definition of craft, locals and extra-locals, traditional skills, self-employment and (re)creation of identity.

Defining craft. The report commences by providing the reader with a definition of "crafts:"

\footnotetext{
${ }^{20}$ Unless otherwise stated, all page numbers in this section refer to Newfoundland and Labrador Craft Industry Development Strategy: Summary and recommendations (2002)
} 
The craft industry of Newfoundland and Labrador is defined as a group of individuals and companies involved in the design, production and / or marketing of products which display unique and distinctive characteristics of design, technique and presentation and where the producer maintains direct control over hand tool and machine operations used in the production process.

Inclusion of products within the craft industry may be further defined through the marketplace. For example, craft industry products are primarily sold in craft or gift shops. (1)

This definition, which came about through a 2000 Department of Development and Rural Renewal, Craft Division focus group, is not so much a definition of craft as they indicate in the preamble, but one of the industry, as made explicit in the definition. The more conventional definitions about craft include the one by Coleman (1988) discussed earlier in chapter one, or the one Becker provides in the pivotal work Art Worlds (1982). He puts forward that craft is "the knowledge and skill which produces useful objects and activities [that] implies an aesthetic, standards on which judgments of particular items of work can be based, and an organisational form in which the evaluative standard find their origin and logical justification" (274). Crafts are therefore objects or performances done within a tradition that have a potential utilitarian use.

The definition put forward by the report makes no mention of these fundamental elements of craft. The part of the definition that particularly sets out what is craft ("products which display unique and distinctive chacteristics of design, technique and presentation and where the producer maintains direct control over 
hand tool and machine operation used in the production process") does not distinguish craft from many other forms of work or production. The report's definition is devoid of the key elements of craft: established body of knowledge, skill, and utilitarian use. It is obvious that although the authors introduce this as a definition of craft, it is about the "craft industry." The tone initially set is one of economics: the marketplace is the dictating force catered to with little thought given to the sociocultural aspects of craft.

Local and Extra-local. The emphasis on the marketplace is especially noticeable when looking at the relationship put into place by the report between craftspeople and contingents found within the local and extra-local realms. Implicitly, the report treats the "local" as the province of Newfoundland and Labrador. There is little breakdown in the discussion between different regions in the province ${ }^{21}$, as well as between rural and urban craftspeople. This omission allows the nuances and variability of experiences shaped by place to be missed. As put forth earlier, one's experience of work is shaped and mediated by the complexity of place (Peck, 1996; Glucksmann, 2000). Self-employed craftspeople on Newfoundland's Northern Peninsula, for example, will have different experiences, and have different requirements to be successful, than someone working in St. John's. The isolation of the Northern Peninsula makes getting access to technology, education, and markets more difficult. ${ }^{22}$ For this report, the local's importance is as a marketplace. There is a call to "[i]dentify products for which a local demand exists and for which production

\footnotetext{
${ }^{21}$ The exception to this is Labrador, which the report does single out occasionally.

${ }^{22}$ For a comprehensive of examination of the social conditions on the Northern Peninsula since the cod moratorium see Felt and Sinclair's Living on the edge:The Great Northern Peninsula of Newfoundland (1995).
} 
is currently non-existent or insufficient" (10). The local, therefore, is not treated as a place of work for self-employed craftspeople, but only as a market that needs to be tapped into and cultivated.

The extra-local, all those not residing in Newfoundland and Labrador, are treated as potential customers, and sources of knowledge and inspiration. Like the local, extra-locals make up two marketplaces where the Newfoundland craftspeople need to gain access. As seen throughout its history, Newfoundland has looked to those who "come from away" to bolster the provincial economy through tourism. Overton (1996) demonstrates how since the late 1800s the Newfoundland governments employ tactics that promote Newfoundland as a nostalgic and pastoral location to vacation. People were encouraged to hunt caribou, view the natural rugged beauty, and experience the famous Newfoundland hospitality. ${ }^{23}$ This report continues in this vein by recommending the craft industry "[d]evelop stronger and more effective linkages and partnerships with the tourism industry" (16). While the report does not specifically state how to market to the tourist trade, there is an undertone of promoting the pastoral aspect of crafts. There is a push to have the craftspeople's studios open to the public, especially "bus and small party tours" and "retreat weekends with tour operators" (16). This will allow for the promotion to the urban patron who wishes to support the rural artisan. As Hickey (1997) puts it, "[c]raft is seen as pre-industrial by these consumers [those from urban areas] - it comes from the past or is old-fashioned and rooted in a place and traditions" (96). By purchasing from the studio, as opposed to other retail outlets, Hickey concludes

\footnotetext{
${ }^{23}$ Overton describes how the government and merchants invented traditions to promote Newfoundland. This included the "time-honoured" tradition of screeching-in: a person from outside the province must go through a rite of passage (drinking rum and kissing a cod fish) in order to be an honorary Newfoundlander.
} 
the consumer attaches greater authenticity and personal meaning to the product. By promoting the studio environment, the report is solely concerned with the attachment of the extra-local consumer to the craft, not the meaning the craftsperson might have for his or her work and product.

The extra-local is also the focus of the wholesale market. The report strongly supports the self-employed craftsperson to sell their product on the wholesale market. This is done in two fashions: in the province and outside the province. Within the province there is a suggestion that crafts be sold to conventions and retail outlets, such as Parks Canada locations, "through special purchase campaigns with industry cost-sharing" (16). The other wholesale market is the one outside the province. The report explicitly mentions the United States as a highly underdeveloped market (15). It goes so far as to suggest that for the apparel subsector the government provide financial support to expand into the U.S. market. For all craft production, the report sets targets for increases to current levels of exports outside the province: twenty per cent in four years, thirty per cent in seven years (16). This is to be accomplished by providing the government support for attendance to trade shows out of the province and by monitoring market trends. The focus on these markets would then encourage more mechanised and small batch production. Omitted is any discussion on the cost, and the feasibility, of entering such markets. It never asks the question, "Can the craftsperson afford to be in this market?" Is it truly possible to sell labour-intensive products in a wholesale market?

The extra-local is also a source of knowledge and training in craft products and traditions not native to Newfoundland. One example is blown glass. At the time 
of the report, blown glass decorative balls were fashionable crafts. Retailers said that they had to go outside the province to obtain merchandise. The report suggests that teachers be brought in to train Newfoundlanders in this skill. However, there is little recognition that cultural products, like crafts, are ephemeral, and when looking at self-employed people in cultural industries there should be more focus on the lifestyle and background they promote (Bank et al., 2000). By importing craft traditions, one can compromise the connection to place and its inherent traditions. Without the local knowledge base in the imported crafts, there will be a continuous need to retrain craftspeople to meet the current trends and fads. This, while admittedly on a much smaller scale, would mirror the government's efforts to retrain those from the fish industry and other industries downsizing.

Traditional skill. There are instances throughout this report where the suggestion is made to provide training and education for "traditional" craft production. The report states that the Department of Industry, Trade and Rural Development (DITRD) ${ }^{24}$ and the Craft Council need to "[i]dentify traditional skill which have either been lost or are in danger of being lost. Work with Memorial University's Department of Folklore and other appropriate organisations to document these skills and techniques" (9). In developing a group of craftspeople that can maintain these "lost" skills one might suppose that the authors are putting this forward to save a piece of Newfoundland culture and heritage from extinction. It would be done for social reasons - to ensure that the future generations of

\footnotetext{
${ }^{24}$ When the Progressive Conservative party took power in 2003, the name changed to the Department of Innovation, Trade and Rural Development.
} 
Newfoundlanders will know the material culture traditions of their ancestors. Again, there is a nostalgic and romantic sentiment that one might attach to such an action. However, when taking the whole report's focus and tone into account, it is questionable that such a suggestion is socially motivated. As indicated earlier, this report focuses on the marketing and economic aspects of the craft industry. A suggestion to identify and nurture traditional skills can be linked to an economic and marketing ploy. Earlier in the report, there is a call for "[p]roduct development tied to heritage and regional / provincial themes to tie in with the growth in cultural / heritage tourism" (7). A craftsperson that practices a traditional Newfoundland skill will easily be able to promote and market their products to the cultural / heritage tourism sector.

The report, in calling for traditional craft skills, falls short in two respects: definition and temporal considerations. This report has a problem throughout when it comes to comprehensively defining concepts and ideas. "Traditional craft skill" is left in such a fashion that it provides no indication as to what might be an example of such a skill. The authors leave it to others, such as Folklore academics, to take on this task. While the academics are a valuable resource, this implies a top-down approach to the development of this branch of the craft industry. This strategy leaves itself open to repeating an elitist paternalism (as well meaning as it might be) that has occurred throughout Newfoundland efforts to develop (Overton, 1996), and craft development in other rural areas (McKay, 1996; Becker, 1998). This discourages endogenous development by placing the decision-making power of 
what is traditional with agencies that do not necessarily have representations from Newfoundlanders.

The other issue of concern has to do with time. "Traditional craft skills" implies the production of labour-intensive items. One thinks of skills that were prevalent before mechanisation. This could include making fudge without an electric mixer, or building a wooden chair without the use of power tools. Even with the inclusion of mechanised tools under the direct control of the craftsperson (such as the electric mixer or power tools) traditional crafts consume a large amount of time. As the old adage goes "time is money." Since traditional skills are labour-intensive, they could not provide the same level of economic benefits that come from a mechanised work environment. For example, one is able to produce many more machine-knit sweaters in the same amount of time as it takes to handknit one sweater. In most instances, each sweater would sell for the same price. If not for economic gain then, what would be the benefit of using traditional skills? By advocating traditional craft skills, the report runs contrary to its aim to grow the craft industry substantially. There seems to be a sense of tokenism - as if mentioning traditional skills would appease people looking for a more "pure" understanding of crafts.

Self-employment. Anecdotally, the craft industry for the most part consists of primarily of self-employed commodity producers. These people are involved in every aspect of the business - design, production, distribution, material management marketing, selling, and bookkeeping. As we will see in the narratives, 
this is often attributed to the lack of resources to hire someone else to do any of these jobs. We will see that if at all possible craftspeople would focus solely on the design and production phases of their work.

There are different government programmes in place that are to provide loans and grants to small businesses (although not necessarily self-employed people). Employment Insurance offers an apprenticeship programme where they will pay half the wages if a craftsperson will teach their skills and pay the other half of the wage. This is problematic as many craftspeople are not making much of a profit and are reliant upon the financial support of family members (see Chapter Five). Atlantic Canada Opportunities Agency (ACOA) provides start-up loans for small businesses, but they are focussed on capital expenditures. There is not any funding available to help with operating costs. The provincial government does offer travel grant money to cover a portion of expenditures, in recognition that most business connections happen off the island. Again, however, the limited resources of the self-employed business are such that travelling can still be cost prohibitive.

This report lacks a discussion on the precarious nature of self-employed work. The treatment of the craftsperson as a disembodied economic entity does not recognise the pressures and constraints that doing this type of work entails - not even the economic ones. It is assumed that as craftspeople they are independent commodity producers, the quintessential capitalist occupation. The reality is somewhat different. The craftspeople are in fact dependent commodity producers on a variety of levels that this report does not acknowledge. As we will see later on 
in the narratives, self-employment is dependent upon the financial stability of the household, government programmes and policies, and consumers.

$(R e)$ creation of identity. Previously in this chapter, Ray's models for (re)creation of identity in development were presented: the psychological model and sociological model. In this report, we see that the authors are advocating a sociological identity of Newfoundland crafts. Rather than focussing on one particular item to tie the industry's identity to, the report advocates implicitly a variety of crafts around which to create an identity. By having a broad selection of crafts produced in the province, identity can be recreated according to the demands of the marketplace. The craft industry's identity is connected to, if not fettered to, the trends and fads of consumers. In order to create this sociological type of identity the report suggests the provincial government:

Develop a visual design bank consisting of two elements: design elements integral to our province's culture, heritage and environment and work by designers whose work displays a distinct style and strong personal statement. The purpose would be two-fold: to provide inspiration and a sense of identity to interest craftspeople as well as promotion and development tool to connect clients to designers. Prioritise by including examples of craft items for which there is an unfilled market demand (12).

This recommendation fulfills the requirements of a sociological identity - variety of crafts, and flexibility to prioritise according to the marketplace.

The next step is to take this multifaceted identity and "brand" it. The strategy is to create brand recognition that draws extra-locals to buy Newfoundland crafts 
through "promotional collateral pieces" (14). This promotion is to be connected to the existing Crafts of Character logo. One of the keys to promoting the identity brand is by developing "craft icons," such as Mary and Christopher Pratt for the arts, or Mary Walsh and Rick Mercer for media (14).

The report also wants to create brand loyalty among locals: "[p]romote the crafts industry as a vital and viable sector that contributes significantly to our economy and to our pride as a people to stimulate the market demand and develop brand identity" (14). This nationalistic undertone is reminiscent of Doug House's call to create development in the spirit of the independent fish harvester. However, unlike House, this call intends to neither improve the social wellbeing of Newfoundlanders, nor recognise the cultural contributions crafts can and do make to the province. The call is put forward to sell the product. In doing so, Newfoundland as place is not recognised for how its culture, society and environment shape the work experience. The place is only important in the marketing and selling of crafts. As such, we see that the recommendations commodify place. Again, the strategy is to focus on the economic contributions and market demands.

The sociological model of identity (re)creation done in this report is void of the social. It presents an identity for the Newfoundland craft industry based primarily on the needs of the marketplace. In doing so, the strategies do not address or recognise some of the indirect economic and non-economic benefits crafts bring to the province. 


\section{Conclusion}

In this chapter, I have contextualised crafts as a form of development in Newfoundland by looking historically at the province's development, the idea of cultural industries in development, and the (re)creation of identity. Having established this context, I used a critical-analytical approach to examine the Newfoundland and Labrador Craft Industry Development Strategy: Summary and recommendations (2002). I discovered that there are four key concerns with this report: defining craft, the local and extra-local, traditional skill, and (re)creation of identity. While each area has a specific concern, overall we see that since the report focusses on the marketplace it does not realise the non-economic context that exists. When looking at who wrote the report, private firms, this is not a surprise. In doing so, the report seems to be solely concerned with the product as opposed to the producer. It does not examine work experiences, work environments (physical, social and cultural), and workplaces. In doing so, the self-employed craftsperson becomes a disembodied economic entity.

As I pointed out, the experiences of craftworkers are missing from this report. For the rest of this dissertation I fill this void by bring the craftworkers' narratives to the forefront. I demonstrate how the self-employed have concerns above and beyond the economic, as suggested in the craft report. I show that the concerns I have with the report do play out at various levels in these narratives. The remaining chapters of this dissertation will examine and analyse the work narratives of Newfoundland craftspeople and attempt to answer: if craftwork "is not an economic 
driver for all our craftspeople," as the report suggests, what is it that drives people to undertake this work? 


\section{Chapter Four \\ Crafting case studies}

As discussed in chapter two, narratives provide a glimpse into a particular culture at a specific time and place (Riessman, 1998; Glucksmann 2000). In this chapter, I want to introduce some of the participants in this research: Alf, Joan, Mark, Brenda and Matthew. I have chosen each of these people because they represent different aspects upon which I want to critique the government's strategies for the craft industry. The choice of these particular five case studies was made after numerous reviews of the interviews, and recognising that while each touched on most of the conceptual concerns I present here, there was a particular theme that ran predominantly throughout each.

Alf represents, for me, the craftsperson that searches for control over his immediate work environment. When he found craftwork could work as an occupation for him, he left the fishing industry. Joan shows me how culture and social norms and values shape the work experience. Mark, the one of these five participants not from Newfoundland, highlights that not only is control over the work environment critical, but so is control over your time. We see in Brenda the attempt to straddle the line between crafts and small-scale manufacturing. Lastly, Matthew typifies the importance of place in shaping our work. While selecting each of these participants to exemplify a particular segment of the self-employment experience, I do not want to say that they do not experience any of the other issues. I show through these narratives that there is a complexity to how people relate their understanding of work. 


\section{Alf: control over immediate work environment}

Alf is the first craftsperson I interview for this project. I learned of Alf and his wife Laurie from their profile on Crafts of Character Web site. As they did not have an email address listed, I sent a letter to them and followed up with a telephone call. They agreed to meet with me two weeks later.

I had seen and actually purchased a piece of Alf's work the first time I lived in Newfoundland. His woodworked vase, his signature piece, stands out for his high craftsmanship, smooth finish and beautiful shape. His work is very distinctive, and you can find his pieces in many of the province's craft shops and historical sites.

Alf lives and works about an hour drive outside of St. John's on the Avalon Peninsula. His property is located not far off the TransCanada Highway. The property contains his house that he shares with Laurie and their two children and the workshop / retail store. Surrounding the property are woods, where he gets some of his raw materials.

Our meeting took place in the office part of the workshop. Laurie took part and their son was busy at the lathes, turning products. After going through the ethical considerations related to this project, and setting up the recording equipment, we started to talk.

As described in my Interview Guideline, I started the interviews by asking how the craftspeople, and Alf in particular, got involved in the business. Alf proceeded to tell me that he worked in the fishery before taking up woodworking fulltime. Instantly, I assumed that he had been forced out of the fishery, like many others, 
because of the cod moratorium. ${ }^{25}$ I was surprised to discover that this was not the case. Alf had decided to leave fishing a few years after the moratorium occurred. In 1995, Alf left the draggers to start up his woodworking fulltime. When looking back, Alf's narrative is filled with emotions of relief and liberation:

I never thought, when I was on the dragger, I never ever thought I was gettin' off. If someone was to say 'you goin' to be up on the road doin' this, doin' wood working' I don't know about that. When I look back on the dragger, you're always sayin' to yourself 'hell, am I ever going to get off this.'

It was evident in his tone of voice that this was not a decision he regrets. ${ }^{26}$

I next wanted to know how he came to learn this particular craft. Was it traditional skills that he had learned or did he come to it later in life? It turned out that it was a combination of the two circumstances. Growing up Alf had watched his father craft wooden boats. At the time, Alf did not learn to do wood working, but the seed of interest was planted. When describing his father, there is awe in his voice:

No, I never learned it before. I was always interested in woodworking, I guess. Dad was a boat builder in town ... he never had no tools, just a plane and a bucksaw axe, that was it right. He never had no tools, right? He did it all by hand.

\footnotetext{
${ }^{25}$ In 1992, the Canadian government placed a moratorium on fishing cod, the staple of the Newfoundland fish industry, due to concerns of overfishing and low stocks.

${ }^{26}$ Evidence of Alf's days on the draggers is still visible in the workshop. With pride, he showed me a room he designed to paint and varnish his work. The equipment was made with dragger lines.
} 
As he relates this to me, he looks around the workshop and points to all the power tools he uses on a daily basis. Alf comments that these are things his father would never have imagined in his day.

It was another family member that introduced Alf to woodworking - his brother. As a way to fill spare time, Alf and his brother would make products that they would sell at craft shops and craft fairs. "My brother, I guess, had a small business using wood lathes; supplying the craft shops around Newfoundland. Basic attitude of growing out and expanding. I seen the potential of what we was doin', goin' to craftfairs and that. And that's it."

As most people doing business in Newfoundland, Alf has received financial support from government agencies. At the time I was there he and Lori were in the process of applying for funding to expand the business. When asked about the involvement with government, Alf replied, "Don't get me started!" For him the bureaucracy and paperwork was excessive redtape that was not easily accessible. He commented that, "I'm not as educated as some, but I do have highschool." The government does not provide straightforward and simplified processes to access support. While this is not a new complaint, it is one that is often lobbied at governments in various venues, it illustrates a hurdle that self-employed commodity producers, with limited resources, need to overcome.

In his narrative Alf highlights that, for him, craftwork done as a business is a combination of mundane production and exciting design:

We do a lot of, we got a certain size vase we make, say a 6 inch vase, actually there over there on the shelf, that we supply to the craft shops 
around. There's not a lot of fun in that. It's just the same shape, right. Same thing all day long. But when you get into, when you sees a different piece of wood, then, and you says what's in there, what's hidden away in that wood there. Or a different shape, or you experiment with things like that where the fun comes in. Or you got time to design something, let's try something different. Then I can't wait to get back in, in the morning or sometimes after supper, right [chuckle].

When craft is a business, you have to be aware of the marketplace. Alf has learned that in Newfoundland the craft industry is very much a seasonal business. People, especially tourists, buy crafts in the summer and fall. Since this is the case, Alf has diversified his business into three markets: retail, wholesale, and local. The retail market is geared primarily to extra-locals that visit the province. He has his shop and attends craft shows where he sells his crafts directly to the consumer. The wholesale market caters to the craft shops and provincial historic sites. It is to this market that Alf must provide a product consistent in size and shape, like the 6" vase he talked about above. The provincial government steers him into this market. $\mathrm{He}$ does not enjoy this as much as the retail market. He says that "wholesale takes away time to design new things." Finally, in order to tap into the local market, Alf has set up a bandsaw and kiln on his woodlot. He is now able to take special lumber orders from people in this area. This fills in the gap in low retail and wholesale sales that winter brings with it.

Having a bandsaw and kiln also lets Alf prepare the raw materials he needs for his crafts. Much of the craft product Alf makes comes from birch that grows on his woodlot. The materials become cheaper when he prepare it himself. He 
qualifies this by saying, "It isn't a big deal now if you makes a mistake. You can use it for kindlin', right." Having this equipment also allows Alf to have more creative freedom in his designs. He is not tied to the standard sizes that are available at lumber stores. This creativity was illustrated when he took me for a tour around his workshop and retail space. He picked up a bowl that was on display in the middle of the shop. It was a birch bowl with a large knot in it. The knot added character to the piece. He told me that this particular bowl would fetch a high price because of that knot. He laughs at this because in most instances a knot in the wood would make it useless. He is also chuckling at the fact that someone, that is someone who "comes from away"27, would pay the price.

He has learned through trial and error what sells. For example, he tells me, "Anything with Newfoundland sells here. I'm just discovering that this year." To fill this demand, he has created Christmas ornaments (which during the interview Laurie is tying string to), clocks and wall mounts. Newfoundland is important to the product that they sell. The raw materials are predominantly local, the design and product is local, and some of the pieces are pictorial representations of the local.

Newfoundland as a place is important to Alf. He is living and working in the same area of the province that he grew up. He cannot imagine what it would be like doing this work anywhere else: "I don't know what it would be like doing it [woodworking] somewhere on the mainland." It is as if the idea of living elsewhere is inconceivable to Alf. He survived the cod moratorium and has a business that has "create[d] a job for us" and is "doing something you love." Newfoundland is

\footnotetext{
${ }^{27}$ A colloquial term for a non-Newfoundlander.
} 
intertwined into Alf's life and he said that it was very important for him to stay in the province.

\section{Joan: embedded in social norms and values}

Joan lives and works on the Avalon Peninsula, about a one-and-a-half hour drive outside St. John's. She lives in the same area where both she and her husband were raised. They live in what was once her mother-in-law's house, and can see the place where she was born while standing on her front step. There are so many people in the area with the same last name that I initially went to the wrong house. Joan operates her business out of her home with her husband. They converted the "granny flat" on the lower level to accommodate the jellies, fudge and chocolates they make. The space consists of a large kitchen, storage room and office. For the interview, Joan showed me to her office. Her husband declined to participate in the interview, and went to work on an addition he was building for Joan's weaving looms (a recreational craft she does).

The business started with making jellies from local produce: dandelions, dogberries (mountain ash berries), blueberries, partridgeberries, bake apples, and rhubarb. ${ }^{28}$ She describes her initial forays into jelly making:

I've been making jellies since I was a kid. The first jelly I ever made my brother and I took partridgeberry, we started to make partridgeberry jam when Mom was gone away. And we screwed it up. We ended up with partridgeberry jelly. I thought it was pretty freaky. I was about fourteen. After

\footnotetext{
${ }^{28}$ Joan jokes that her products are organic, as the berries come from the woods and the dandelions are ones that she lets grow on her front yard.
} 
I got married, we preserved everything. We had a garden. We bottled jams, and jellies, and pickles, just about everything.

This skill became important to her household's economy before she decided to turn it into a business.

Making the move to self-employment was not one she had envisioned herself doing. Joan was at a folk festival demonstrating weaving to children. She explained that in exchange for doing this, the organisers provided space for her to sell any weaved pieces she had available. One year, she did not have any weaving available for sale, so she put some of her jellies out for sale. She could not believe how quickly they sold. In 1992, she started her business with jellies. She then expanded the offerings to include fudge and chocolate from businesses that she bought out in subsequent years.

Being self-employed has not been an easy road to follow. There have been conflicts between Joan's personal philosophy and the provincial government's small business advice. In Joan's case, the government representative encouraged Joan to borrow money to help pay for new product labels. Joan took the advice and has since resented this decision:

We've always lived, there's a philosophy that's rarely put into words. A bayman owns not owes. And I'm a bayman. And I own, I don't owe. If I owe money, it drives me nuts; the fact that I had to borrow money to buy the labels and it left me no money in the bank. 
The cultural value of self-sufficiency embedded in Joan's way of life runs contrary to the government's actions. The government does not seem to understand Joan's small business needs. Joan again relates this in her narrative as she talks about another craftsperson in the area:

He's still at the government tit, excuse the vulgarity. If it's not going to float on its own it shouldn't be done. Government wants to help small business, give us marketing help. I can make the product but I know I'm a lousy marketer. I've been to wholesale show and I can't close the sales ... These people have degrees in marketing; they've got degrees in this, that and the other thing. They have never ever depended on making something and selling it to make a living. They've always consulted.

Throughout her narrative, Joan voices her frustration with the government. She has as little to do with them as possible. Joan feels that the government, and those working for government, do not understand the precarious nature of self-employed work. The money you make as a self-employed commodity producer depends almost entirely on the amount of product you make and your ability to sell it. In Joan's case there is no one else for her to fall back on as the business is just supporting her and her husband. She talked about the El apprenticeship programme and would love to take advantage of it but does not have the financial resources to even pay another person half-wage. The only financial support she has received has been with the aforementioned labels and some travel expenses.

Joan no longer partakes in volunteer activities or membership in association. She finds that her time is limited, and that every possible moment must go to the 
business. She has also had a falling out with the different associations. She found that a "double-standard" exists against those from Newfoundland in the provincial craft association. A British Columbian company making a similar product to hers was not required to go through the same scrutiny about the origin of ingredients and label compliance as she was. Because of this, and because only a small percentage of her yearly sales comes from this show, she decided to sever ties with the association.

Being self-employed in craftwork has come at a financial cost. Joan has not drawn any money from the business. Her husband collects a minimum wage salary that they live on. This is not easy to do with one child in college and one still in high school. She comments that she and her husband have not been on a holiday since the late 1980's. Most of their energy and money is directed at maintaining the business. If there is all this frustration and cost to the business, why has she continued? When I asked her what has kept her at it she replied:

I don't know if I'm still in business because I'm persistent, l'd like to think so, or if I'm stupid, which is what I'm beginning to believe. I think there is a very fine line between persistence and stupidity.

She later explains the determination to maintaining the business in terms that are more personal: "For me it's like another one of my children that I can't let it go." 


\section{Mark: control over time}

I met Mark through his wife while working at the university. When she found out the subject of my dissertation, she told me about how her husband Mark makes and sells handcrafted instruments. I arranged to meet him at their home.

Before going to the interview, I looked at Mark's Web site. It shows different instruments he has made over the years. As well, it lists the various woods that he uses in his instruments and the tonal quality of each. One can also find out the price of the instruments -- $\$ 1000$ to 1500 (US $\$$ ). For the most part, the instruments are crafted out of wood that Mark imports to the province, as the indigenous woods are not suitable for crafting instruments.

At the time of the interview, Mark was living with his wife and two young children in a rented house in St. John's. He had converted a couple of the basement rooms into workshop space. The computer was located in the family room. His wife was in the kitchen getting ready to go to work and their youngest was taking a nap.

Mark is what Newfoundlanders classify as a CFA - come from away. He was born in the US, and has spent most of his life in Southwestern Ontario. A stint overseas made him realise his love for woodworking:

When we were in [Europe] I really missed having a workshop and working with wood. There just isn't a culture of that there, at least in the city there isn't. There's no access to resources, no books, no magazines available at all. Even the major US magazines aren't available. I was subscribing and then getting them shipped. I just think being away for that long, and realising there was something I enjoyed more than other interests that when we got back here I said, 'Hey, now is the time to try it.' 
When deciding on a product to make, Mark combined this love of woodworking with his university education in music. Out of this came his unique instrument. ${ }^{29}$

Newfoundland provided many of the necessary elements to encourage Mark to start his own business. To start, his wife had just started a job that provided a good standard of living; as he said, she was "making a good buck." The next was the lack of job prospects in his field. Mark had worked many years in entertainment management and marketing.

Geographically, Newfoundland's isolation provided the necessary remoteness to allow Mark the time to do his work:

I really like the distance. I don't think there is another place in the world that this would have worked as quickly or as well. I was thinking last night that a lot of the guys that do this would be on the West coast of the U.S. or Canada, and I just can't imagine the distractions. If you lived in LA, everybody's going to be dropping by, popping in. Time is just so precious, especially with the family that this is great because I really don't have a lot of distractions other that the things that are really important.

Furthermore, Mark describes how the cultural atmosphere is conducive to doing craftwork. He describes it this way:

I mean the whole mystique of Newfoundland, I don't know if that's the right word. But to me, walking around downtown, you see the Devon Craft House, to me there's something about the place that makes me think artisan lifestyle

\footnotetext{
${ }^{29}$ Mark's instruments have won awards at instrument competitions, and are played by various Canadian rock groups, such as the Tragically Hip.
} 
... Why would anyone want to live anywhere else? There's no crime, it's absolutely gorgeous, the people are great. There's a happening nightlife, not that we get to experience that (chuckle). You're a flight away from Europe or Ontario.

Newfoundland is important to Mark's work experience even though he is not a "Newfoundlander."

To get his business off the ground, Mark took advantage of a start-up loan from Atlantic Canada Opportunities Agency (ACOA). This allowed him to by the capital equipment he needed to make his instruments. The loan was limited to only capital expenditures and, according to Mark, has good terms. Because of the mandate for it to be on capital expenditures, Mark said that he had to be careful. When he went to purchase the equipment he comment it was a bit like "being a kid in the candy store." He had to be sure that what he was buying really was necessary for the business. The other thing he noted was that he had to spend the whole amount he was approved for. While all that he bought was necessary for the business, he could see people going into debt further than was perhaps necessary. Mark is one of the few craftspeople in this study that relies heavily upon information technology. He has developed and maintained a highly sophisticated Web site to promote his business. In fact, the Web site is the only medium, except perhaps word of mouth, that Mark uses to promote, exhibit and distribute his instruments. He also uses computers to design his products; "I'm not doing a whole ton of 3-D mock-ups on the computer, but for almost every aspect of it at some point 
I have used the computer to design: the tooling, the jigs, or the fixtures, or the actual instrument." He has found that he can use the technology to his advantages.

Beyond the design that he does on the computer, Mark likes other aspects of his work:

I enjoy the tactile feel when it's done. I enjoy the finished product. I really enjoy the process too. I enjoy work with hard sought after woods. A big part of me is working with the clientele. I really like working with customers. We had developed this hoop product where you could order it and not even talk to me. There was really very few questions I needed answered. I didn't find it as satisfying as some of the bigger ticket items. That's where you spend a lot of time with the person, going back and forth designing.

While he finds these aspects of the work gratifying, Mark realises that there are "pros and cons" to what he is doing. When I asked him if this was "work," he replied as follows:

I guess it is because it is what I do for a living. But it's more than that, and that's good and bad. There is no turning it off, especially since I work from home. There is no getting a way from it, which can sometimes be a problem. It's also a lifestyle that I love. I think that, in a way, in the back of my mind I think it's kind of noble, romantic or something like that to say that I'm an artisan.

\section{Brenda: negotiating between craft and manufacturing}

Like most of my participants, I contacted Brenda through the Crafts of Character listing. She produces items for the apparel market within the craft industry. She 
sees what she does as bringing back "romanticism of the cloth and put it into urban fashion." This sentiment harkens to her formal education at an art college and career in historical costumes.

I met Brenda in her St. John's workshop. It is located in the downtown core of the city. She occupies one floor of a multi-storey building. This space consists of a production area, an office for design and business, a "lunch room," and a packing area. She is one of the few participants to employ people to do the production work. At this time, she had three sewers and an assistant working for her. She therefore straddles the boundary between craft production and small-batch manufacturing.

Getting into this type of work has been a calling, or vocation, for Brenda. She recognised this at an early age. Growing up in a small outport in western Newfoundland meant that she had limited access to modern fashions. In order to get the clothes she wanted to wear, Brenda learned to sew:

My mother put me in sewing when I was thirteen. And so I think it was just gradual. I always say it chose me, I didn't choose it. It was a path that just kept coming back to me. I didn't choose anything else in my life. That just came very easy to me.

This "path" was one that she continues to follow today with her business.

The design and creative aspects of the business are the most enjoyable and perhaps the least "work-like" for her. This is part of the lure of the craft. This however is not completely understood by her family: 
I mean they don't understand it. They've never understood what I've done. They've always looked at me as the weird creative one. But you know, my family, my husband, my friends have all been supportive.

Brenda admits that without this support, especially from her husband, being a selfemployed craftsperson would be difficult.

Going into a craft business comes at a cost. For Brenda, the greatest cost is her creativity:

You lose part of the creativity in the business part of it. You have no other choice. We have tried to keep it through, you know, your marketing materials and stuff like that. But you do lose it.

In order to sell a product you must contend with market demands and trends. Brenda laments, "If I were to design for me it would be much harder to sell things."

Brenda's focus is therefore on having a prosperous business. She feels there are primarily two ways to accomplish this: technology and government involvement. Brenda uses technology extensively in her business. The "computer is a tool of the future." She has a website to display her product and uses a CADD programme to design her clothes. The use of technology is paramount for the craft industry's survival:

I think it's [technology] the only way to take a craft and grow it successfully into a business to make a living. The bottom line for all of us is we have to make a living and the cost of living is high. Anyway, technology can help your craft if that's what it is for you to make a living, and for your stuff to make a 
living and for it to grow. So yes, there has to be support for technology. In turn, the craftsperson has to embrace it well. They have to embrace it. And sometimes I think that's a really hard jump because it's another learning curve.

Brenda has welcomed the advantages technology offers to the business. She continually searches for new ways to make her production more efficient so that she has more time to be creative.

Government involvement is essential to Newfoundland businesses according to Brenda:

In Newfoundland, you absolutely need it (government financial support). The cost of doing business off this island for a small business. This is where $99.9 \%$ of my business is, off the island. You know getting off this island to do business ten times a year is a big cost for a small company. We do get funding for that.

Brenda is not a passive recipient of government funding. She is involved in craft and apparel boards at all levels of government and lobbying levels: local, provincial and national. She is a strong supporter of growing the craft industry. Through her experience, she says that this is a challenging undertaking. She said, "We've [in the craft industry] had a lot of mouths but no legs." Brenda finds that there is no one taking the initiative to move forward. There is not leadership within the craft industry to challenge and work with the government. Part of the problem, again, is time. There is only so much time one can take away from their business to work on these various bodies. 


\section{Matthew: importance of place}

Before I met Matthew, I had seen his pieces for sale at many locations across the province. His jewellery has a distinct character that sets it apart from the mass produced items for sale. When looking at his various pieces (predominantly earrings and necklaces), I could easily see that Newfoundland heavily influences his designs.

Matthew lives and works in a small outport in western Newfoundland. It was here that I met with him. He has renovated a building on the main street of the community to accommodate a retail store and workshop. The retail store sells both his products and also handcrafts done by others in the local area. The back half of the building is his workshop. This is quite a change from when he first started making jewellery:

As a student, I started out with a polishing machine that I made out of a washer motor. I rewired the motor and made a polisher out of it basically. And I started out in a mud basement in my mom's old house that was fifty years old. I got through that. Thank God.

We talked in his workshop where, for the latter part of the interview, an apprentice he has taken on through one of the Employment Insurance programmes is quietly working.

Jewellery-making started out as a way for Matthew to stay in Newfoundland. He had spent ten years on the "Mainland," working in a factory outside of Toronto. He had returned to Newfoundland because he was, in essence, homesick. Like many Newfoundlanders, Matthew was desperate to find a way to stay in the 
province. He discovered a pilot course offered at the local College of the North Atlantic campus. This course taught two crafts, stone-carving and jewellery-making. Matthew tells me how the decision to take the course came about:

It was a course that came up at a time when I was trying to make a decision whether or not I would have to move to the mainland or not. Move back to the mainland that is because I moved back here nine years ago. It was either go back to school or sit around all winter and wait for spring to go away. I didn't like sitting around so I went and took the course. That was something I enjoyed doing. Sometimes you just go to take that chance.

Through this course he had found an occupation -- and perhaps more accurately a vocation - that made it feasible for him to stay in Newfoundland.

When Matthew started school, he did not know that he was embarking on a vocational path. When I asked him at one point if this was work, he found it difficult to put into words what jewellery-making means to him:

[Is this work?] No, not really. It's, God it's hard to describe. It's part of my life for sure - a very important part of my life ... It's not about the money. You have to make some money to pay the bills. Time, very time restraint. A lot of sacrifice. I don't get as much time with my family as l'd like to have. That's the big problem. That really bothers me. Eventually l'd like to get to the point where I'm still making a living but not putting as much time into what I'm doing. I'm sure my family would too of course. They've been very supportive. They know, they see how much passion I get from this, how much I love this. 
This part of Matthew's narrative highlights that the self-employed work does cost him in the way of time with his family. In spite of his dislike for the time sacrifice, Matthew still uses strong language to describe how much doing this means to him. It is not about the financial rewards, which are not necessarily great; it is about a more personal connection that he makes with his work.

Having found this vocation, Matthew has discovered a deeper appreciation for Newfoundland. Matthew moved back to the same community he grew up in. Like many, he did not realise how important Newfoundland was to him until he moved away. I asked Matthew about how Newfoundland played out in his work after returning to the province. He explained:

After moving back home, I had been back home a year then [when he started jewellery-making]. I had all the images in my head. After living away for ten years, you keep mulling things over in your head: the ocean, the seashore, the fish, all the things you could do when you were living here but didn't. But when you move away you wish you could do those things. That was part of it.

Matthew quickly recognised that his outmigration experience, while not entirely unique to Newfoundlanders, is prevalent. He decided to use this as a guiding element of his business:

Being away from home for ten years, if I had gotten a Newfoundland map ornament for Christmas I would have been overjoyed. Anything of Newfoundland, especially when you're living away. There are so many of us that have lived away or are still living away. So that was the market I had in mind when I created Newfoundland images. 
Matthew takes the uniqueness of Newfoundland and incorporates it into his business.

While Matthew's narrative demonstrates the importance of place on his craftwork, he firmly believes that crafts are important to Newfoundland. We were discussing government support of cultural industries. Matthew unequivocally states his position on government involvement:

It [eliminating government financial support of crafts] would be like cutting off your culture. The artists and craftspeople reflect the culture, history, the traditions. Without that, you probably just like everybody else. Newfoundland wouldn't have the appeal it has if it wasn't for the people, you know. The different way of life, it makes you special.

As such, Matthew has taken advantage of various government programmes, and is perhaps unique within the craft industry. As mentioned earlier, at the time of the interview he had an apprentice working for him using the El programme, and had used travel grants and ACOA funding to grow his business.

Place, then in Matthew's eyes, is a dialectical relationship. Newfoundland influences the designs he produces, and he as a craftsperson helps to shape the cultural uniqueness of the province.

\section{Conclusion}

I have shown through this chapter the complexity within self-employed craftspeople's work narratives. These first-order narratives show us how work, and 
in particular self-employed work, is complex with its various meanings and motivations. This being said, there are some particular elements I highlighted as central to each of these five participants' accounts: control of immediate work environment, embeddedness in social norms and values, control over time, negotiating between craft and manufacturing, and importance of place. In the upcoming two chapters, I want to take these elements, among others, to analyse self-employment and place as they relate to Newfoundland's attempt to develop the craft industry. I am going to take the narratives of these five plus the other participants, to present a second-order narrative that demonstrates the relationships that exist within self-employment, and how this can then inform rural development. 


\section{Chapter Five \\ Crafting self-employment}

As we saw in the third chapter, the strategy report for the Newfoundland craft industry ignores the context within which the craftsperson works. It is most concerned with the product and the markets for the products. In doing so, the report treats the craftsperson as a disembodied economic entity. There is little thought given to the non-economic reasons that shape the actions of craftspeople. In particular, there is little discussion for the overall reasons why people decide to become self-employed craftspeople in Newfoundland.

Self-employment is a longstanding tradition in Newfoundland. Historically, it has been the lone fisherman, or a family working to harvest enough fish to sell to the merchants (who were also self-employed and employers) to accumulate enough credit to purchase the staples the household and fishing boats needed for the upcoming year. Of late, with the cod moratorium and large draggers, selfemployment in non-fishery related ventures in Newfoundland generally has been held up as a way to overcome economic underdevelopment. Between November 2004 and November 2005 the number of self-employment in Newfoundland went from 25900 to 29200 - an increase of over twelve per cent (http://www40.statcan.ca/l01/cst01/labr66b.htm). Doug House (2003), the commissioner for the 1985 Royal Commission on Employment and Unemployment (RCEU), maintains that the RCEU's emphases on "rural renewal and small-scale enterprise" (231) remains relevant today. The small-scale enterprises would build 
on the strengths and talents that exist locally within the province, with support from regional economic boards and post-secondary institutions. It would be a way to move Newfoundland and Labrador away from being a "transfer economy" (one supported primary from federal government social payments such as unemployment insurance) to a "market economy" that is self-sufficient. In essence, House puts forward that small-scale enterprise is a cornerstone to having Newfoundland become an economically vibrant society. Ommer and Sinclair (1998) concur that supporting self-employment initiatives is one way to draw on the historical strengths of Newfoundlanders to develop strong economic futures for the communities.

In this chapter, I analyse the explanations my participants gave in their narratives as to why they got involved in self-employed work, and what has kept them doing it. To do this I borrow Miriam Glucksmann's "total social organisation of labour" (which she shortens to TSOL). In her monograph Cottons and casuals: The gendered organisation of labour in time and space (2000), Glucksmann develops the TSOL as a framework to investigate people's narratives about work. ${ }^{30}$ Initially, TSOL is a macro-level theoretical standpoint that puts forth that "the totality of the social organisation of labour is to be conceived not as a pre-given entity or one with outside edges but rather as the overall relational network between the various differentiated sectors that happen to exist at a particular historical conjuncture in a particular society" (20). This means then that economic and non-economic spheres have blurred edges that cannot be separated from one another. The distinction between each is dependent upon temporality, place, and prevalent norms and

\footnotetext{
${ }^{30}$ She started to develop this theoretical standpoint in an earlier work, Workers Assemble: Women workers and the 'new industries' in inter-war Britain (1990).
} 
values present in the society. This is a fluid understanding that realises that perceptions and boundaries change as relations change within society. When Glucksmann uses this on a micro-level, she does so to demonstrate the relationships that exist between paid work and household labour for "particular people, occupational groups, and local labour markets" (20). I want to take this theoretical understanding to explore how work and one's ideas of work, go beyond the "pre-given entity" of economic benefit and value to include non-economic rationales and relationships.

Throughout the literature on self-employment, there is a focus on what draws people into this form of work. What we see is a strong dichotomy of views that divide the motivations for entry into self-employed work between pushed and pulled. People who are deemed to be pulled into self-employment cite "entrepreneurial values" (independence, control over decisions, and the challenge) as the prime motivators to venture out on their own (Delage, 2002). In fact, many quantitative studies show that the "pull" into self-employment out weighs the "push" factors. The loss of work is cited as one of the main theoretical reasons believed to push people into self-employment. However, Arai (1997), while looking at the relationship between unemployment and self-employment found that once seasonality was controlled, the link between self-employment and unemployment was very weak. Hughes (2003) contends that these aggregate level analyses of selfemployment end-up understating the push factors. In her study on self-employed women, Hughes demonstrates that while respondents initially indicate "entrepreneurial values" as the prime reason for entering self-employment the 
subsequent interviews revealed that there were more push factors, such as downsizing and low morale in the work environment, underlying the women's decisions. Hughes argues, therefore, that the dichotomy established in the field of aggregate analysis is too rigid to allow for the complexity that exists in decisionmaking. As she says about her study, "These findings suggest a need to broaden current conceptualisations of 'push' factors and to explore further how 'push' and 'pull' factors are intertwined for some individuals" (450). Beaucage et al. (2004) concur with Hughes' assertion. They found that it is not so much a dichotomy of push and pull, but a continuum upon which we would find the motivations for selfemployment. My study here will contribute to this exercise.

This chapter will fill in another gap in the literature on self-employment - the meaning of the work. Within the field of self-employment literature, much attention has been directed at how people come to this work. There is little discussion however on what meaning the work has for the people. Why are people staying with self-employment? What kinds of emotional attachments do people make and invest in this type of work, particularly when the financial rewards are less than being an employee (Delage, 2002)? When searching the literature on self-employment I found little discussion about what keeps people involved. With this study, and this chapter in particular, I will show that self-employment provides meaning to people in this study and, perhaps not surprisingly, in a gendered way.

Finally, I show how all these decisions are not made in isolation but are also embedded in the support, both economic and otherwise, provided by the spouses and families of the self-employed workers. The current literature shows that women 
cite the need to balance work and home as a reason for entering self-employment situations (Delage, 2002; Arai, 2000). This however, is as far as the selfemployment literature goes when it comes to household strategies. There is no discussion at this time about how the household deals with the uncertainty of income derived from self-employment. We see through craftspeople's narratives that in order for self-employment to work there needs to be household strategies in place to accommodate the demands of this form of work. Since, in most cases, I only interview one member of the household, the household is not a unit of analysis, neither are its strategies a method of analysis (see Wallace, 2002). I use the concept of household as a way to illustrate how the self-employed craftsperson is embedded in a relational network beyond what is found in the economic sphere. I am able to do this as the TSOL encourages us to go beyond the economic sphere when examining work, and to see where the non-economic, in this case the household, intersects.

Before presenting the analysis of the narratives, I need to make it clear that the dichotomy of "economic / non-economic" is used heuristically because the Newfoundland craft strategy report sets up this dichotomy. As one reads the craftspeople's narratives about self-employment it is evident that the dichotomy is overstated, and that self-employed work is more complex than the craft report allows. We know from the theoretical and conceptual discussions earlier that in reality there is no clear-cut understanding of what is economic and what is not. As such, in order to speak more directly to the craft strategy report, I equate economic to financial in my analysis. This is not unlike Glucksmann (2000) who uses 
economic to relate to the public sphere and non-economic to correlate with the private arena. It is through this dichotomous use of the terms that we can see how it is insufficient to present understand work in such a manner.

\section{Getting into self-employment}

Making the decision to strikeout on ones own is not one that comes lightly; there is often great consideration before one takes this action. The self-employed craftsworkers are no different. We see that their reasons can be categorised into economic or non-economic priorities.

Economic priorities. In any capitalist society, monetary concerns are strongly tied to discussion about work. We see that economic motivations are not merely about making money. The motives can be external, such as the loss of a job, or internal, such as an entrepreneurial spirit. There is a debate as to whether these motivations can be classified as "pushing" (external) or "pulling" (internal) factors (Hughes, 2004). When looking at the narratives it is not always clear if the participants felt pushed or pulled into self-employment. Often it is a combination of the two. Three participants in particular - Jim, Jill, and Bill - demonstrate how economic priorities played a factor in their decisions about getting into self-employment. Each of these participants provides examples of the craftspeople who are classically "pushed," "pulled," and a combination of the two.

In an underdeveloped place, there is always the search to find employment for the citizens. Newfoundland is no different. This is especially true since the 1992 
cod moratorium. Because the cod fishery and its spin-off jobs were key to the economic survival of many communities (House, 1999), the moratorium plunged the rural outports into deeper unemployment. Jim is the man from Western Newfoundland that makes food products out of seaweed. His work was affected by the 1992 cod moratorium. In his narrative, Jim describes how he moved from providing a service to the fishery to being a self-employed craftworker:

We got into it [self-employment] in 1990 when the fishing closed for the first time. And we were servicing the fishing industry doing welding and maintenance on fishing boats, and so on. So we were doing a lot of fishing related work. So when the fishery closed down there was absolutely nothing to do. I was totally out of work so I had to find something else to do. So we looked at the resources we had and the structure we had and seaweed was one of the things we thought we could make some money out of.

Like many people in the Newfoundland outports, Jim was pushed out of one form of employment and into another. The economic conditions that existed in his area of Newfoundland were such that Jim had to search out new avenues to generate income. He looked at what was available to him in way of work and turned to the sea as many of previous generations of Newfoundlanders had done. Only this time, we see that Jim had to be inventive to create work that provided money with the natural resources available. With the closure of the cod fishery, Jim is an example of how Newfoundlanders had to devise new ways to generate income in an underdeveloped area. 
Jill, who does stonework in central Newfoundland, states that her reason for getting into self-employment is economic. For her however, it is not so much about being pushed into it by uncontrollable economic conditions, but pulled by an economic drive within her. She says,

If somebody's going to produce a product you have to take the business aspect of if. You can't just be artistic and you know there is a line when you do this stuff. There is a real world. And I think this is an attitude that needs to be developed with craft producers. They need to be realistic. You know you can't just be all over the place, try this try that. You have to sort of set, you know ... I have that drive in me that I'm not going to be satisfied until I see a viable business from it. So you're torn like you say from the artistic end. You say that's for the birds and leave that alone. It's time to get serious.

The economic priority Jill gives for undertaking self-employed craftwork comes from a personal entrepreneurial drive. As she tells us in her narrative, Jill's motivation for doing this work is the desire to have a successful business. A successful business is one that generates profits and is financially viable. Jill is pulled into selfemployment.

The other way of looking at economic priorities is the recognition of market suitability. Bill, a print-screener in St. John's, got into self-employment in Newfoundland by recognising a niche that he could fill:

I've been print screening for seventeen years. Mostly on t-shirts and some printing on paper. I moved to Newfoundland five years ago and realised all 
the t-shits in the stores were crap. So there was an opening there to put good artwork on t-shirts locally ... I thought I could make a go of it

Bill felt the pull to take up self-employment because there was a way in which he could make a living using a skill he possessed. He identified a need in the Newfoundland marketplace for a product that he conceived as being feasible to make and sell. Bill does not fit the common conception of pushed or pulled into selfemployed work. Having moved to the province from British Columbia, Bill was looking for employment. This in itself would be an external motivation that could push Bill into self-employment. Further than this however Bill exhibits an entrepreneurial drive, as he recognises an opening the marketplace for a product he could produce. This internal motivation to realise his vision of a marketable craft would "pull" him into self-employment.

We see that even within one end of the economic / non-economic dichotomy there is variance. Economic motivations are not merely about making money. They include internal and external motivations in a realm where it is often assumed that economic equates with external motivation. One needs to be aware of the various complexities that accompany any discussion about work. Looking at how Jim, Jill, and Bill relate to the economic motivations for self-employment has allowed us to see this. By starting with an understanding of work as being fluid, such as the TSOL proposes, we see that we can get at these nuances.

Non-economic priorities. The non-economic priorities to do self-employed work are as important as the economic ones. Using the TSOL allows us to examine how 
these types of priorities come through in the craftspeople's narratives. We see Anthony's, Mark's and Matthew's narratives prioritise control over the entire work process, work outcomes, and the desire to do one's craft.

The desire to have complete control over the work process is a compelling reason to undertake self-employment. Anthony, a potter in Western Newfoundland, provides us with his narrative about how he came to this realisation:

In geography, I found I really enjoyed doing the physical course work, the outdoor work, that was great. Writing the reports wasn't so much fun. So I wanted to get into something that was more hands-on. That's when I went into design and that was fun. But that ended up creating designs for someone else to execute. Again, it was all office work. And I felt there was too strong a separation between designing and making. I thought of going into clay on a full time basis. And having creative control in that manner was really good. And as well just the immediacy again. You could write reports and who knows whatever happens to those reports. Whereas with clay, I mean, you have an idea, you execute it and you actually sell it to the end user yourself. So the opportunity to be your own boss, and create something you have a vision of creating and actually moving to the end stage is something I think is very rewarding. I feel personally I make more of a contribution to society by making pots than designing restaurants for people to eat in. And so that's my position.

The desire to have control of your work from start to finish is a desire that many craftspeople state as the reason to enter the profession (see Metcalf, 1997). Anthony tells us that in other forms of work he had little control over the whole process and very little control over the distribution and use of the final product. 
Doing craftwork in a self-employed environment, allows the person to experience control over his or her immediate work conditions. This becomes a strong pulling motivation to draw people into self-employment.

Mark also echoes Anthony's realisation that self-employment fulfills an inner desire to have control over one's work. In his narrative, the instrument-maker in St. John's tells us,

When we got to Newfoundland and I looked around at the lack of job prospects I thought at the time that I was at the age that if I ever wanted to work for myself this was the time to try it ... I do it because when we got here I said, 'l've had jobs and the same thing always happens. I end up doing really well at the job, taking on more and more responsibility, and not necessarily getting paid for that additional responsibility.' If I could just channel that into my own thing then what else is there? ... And I felt like l've had a couple of career changes, so it was like, okay, I think I can do this. Along the way you look and see why small businesses succeed or fail. Are you this kind of person or whatever - tick it off. I can totally do this.

We see that with the experiences of other jobs and the maturity that comes with age, Mark demonstrates self-confidence that the decision to undertake self-employment is a correct one. At this point in his life, in his forties, that he is able to take control of his work environment to direct his energies and skills in such a way that it benefits himself and not an employer. He is able to make use of any surplus labour that he creates for his own business and be rewarded for it (monetarily or otherwise). He also shows that he has personally reached an age where he needs to be self- 
reflective about the work that he is doing. It is the opportunity to decide what will make you satisfied with what you do.

We also saw in Mark's case study, how control over time is another component to the decision to make self-employment your work. Mark told me how self-employed work allowed him to make choices that not only fit his style of working, but also provided him the opportunity to spend more time with his children. In his previous jobs, Mark admits to me that he would give his job all that he could, and in the end take on more tasks (see above quote). This reduced the amount of time with his family. By working out of his home, Mark is able to spend time with his toddler and ten-year old. As he said, "Mackenzie is a neat kid. I get to spend more time with him."

People are also drawn into self-employment because they have a skill that they wish to use; they find that there is really nowhere else that they can use it. Matthew, who we met in chapter four, learned to do his craft at the College of the North Atlantic's Port-aux-Basque campus. He discovered that jewellery making excited him and it developed into a passion. Matthew describes how he came to self-employment,

It was a pilot programme put off by the College ... and it offered jewellerymaking and stone carving. I took the stone carving really. And once I found out what jewellery-making was all about I fell in love with jewellery-making stone carving didn't matter any more ... I guess I was the only one [out of the class], I don't know if you call it crazy enough or daring enough to start his own business ...As a student, I started out with a polishing machine that I made out of a washer motor. I rewired the motor and made a polisher out of 
it basically. And I started out in a mud basement in my mom's old house that was fifty years old. I got through that. Thank God.

Matthew's determination to do his craft required him to be innovative and to endure less than ideal conditions. By taking up self-employment, Matthew made his own employment opportunities that would otherwise be non-existent.

Economic and non-economic priorities. To assume on my part that the selfemployed craftspeople have either economic or non-economic priorities when deciding to undertake this form of work would be naïve. It is often through careful consideration of both ends of the spectrum that one makes the decision to be selfemployed. Alf, who I introduced as one of the case studies, provides us with a good example of this.

Alf is a woodworker from eastern Newfoundland. He produces decorative wood items in his workshop with the help of his wife, Laurie, and his seventeen-year old son. Before Alf became self-employed he worked on draggers. When working on draggers, people are away from their homes for extended periods. As we see from his narrative, this type of employment did not suit Alf,

I gave up a full time job after the fishery came back for a bit. I gave up a full time job to stay at this [self-employed craftwork] ... Back on the boat we was gone the second January until the twenty-third December and you were only two days home, then days out, two days home. So, and there wasn't no big call among there. And by the following year I was doing as much [earning as much money] as when I was draggin'. So I said why go out there when you 
don't like it. When you can be home with the family every night and get to enjoy it. I love it so.

In this piece of Alf's narrative, we see that there are economic and non-economic reasons as to why he left paid employment on the draggers for self-employment. $\mathrm{He}$ did not give up his job on the boats until he was sure of an income. He wanted to be sure that there was enough money available to be made before giving up his job, even though it was a job that he was not fond of. The non-economic reason was that self-employment permitted him to leave a job he did not like. He could now pursue work that he found more enjoyable. Finally, this narrative shows that his desire to be at home with his family every night become one of the key deciding factors. Self-employment allows Alf to have a family life that is consistent and more to what he deems as important.

In this case study of Alf's reasons for getting into self-employment we see that there is negotiation between the non-economic and economic reasons for undertaking self-employment. It is not necessarily the case that one type of reason supersedes another. Often, two different reasons culminate at the right time to enable the person to decide self-employment is the right avenue to pursue. There is a blurring between the economic and non-economic spheres, as the TSOL allows us to see. This understanding of the complexity of motivations for self-employment is something that is missing from the craft strategy report. 


\section{Staying with self-employment}

While it was easily recognisable that economic priorities did play a part in the decision to undertake self-employment, it is much less so when asking why do people stay with this work. There are some craftspeople, such as Bill, who say they are staying in it for the monetary return on the business. Bill says, "It's a craft business. I have to be a business. You have to be successful monetarily or else you can't do it." There has to be some sort of financial reward for some people to stay self-employed. However, most of the participants state that the reasons they have stayed with their work have more to do with non-economic priorities. When we take a close look at the participants a gender pattern emerges. For the male participants, self-employment has come to mean control over the work environment. They are their own "bosses." The women, and in particular those with children who work from home, talk about the business as an extension of their families.

Males. Jim, the person who got into self-employed craftwork because of the cod moratorium, provides is a good spokesperson for how the men perceive their selfemployment. He says that even though he is not making much money at his business he stays at self-employment for the control and freedom it affords him. $\mathrm{He}$ says,

Probably the reason I'm still in it is that I do love it. I do enjoy it. I enjoy the freedom of being on your own, even though there isn't much freedom (chuckle). I enjoy coming up with ideas and developing them and that and stuff like that ... And you stay at it 'cause you think it's going to work. There's 
nothing worse than getting up and having to go to work at something you hate and having to go at it for the next thirty years.

While as a self-employed person, you do not have as much "freedom" as you would assume, because if you do not do the work no one else will. However, there is still the illusion of freedom. The perception that every person is to be his or her own boss is embedded in the Newfoundland values of self-sufficiency. It is like the selfsufficient pre-Confederation fisherman doing everything necessary to have enough fish, wood and game to last throughout the year (House, 1999; Ommer \& Sinclair, 1998). This image of the strong independent man permeates throughout capitalism dogma. The ability to own the means of production, have control over the labour process, and distribute the product is held in high esteem. Even Karl Marx holds up the independent craftsman as the ideal unalienated worker. He has the opportunity to use his hands and mind to put something of him in each product created.

Females. The women, especially those with children, feel a sense of parental responsibility to the business. Jill, the stoneworker that got into self-employed work because of her entrepreneurial drive, describes the place her business holds in her life:

Well, I guess I started years ago [self-employment] and haven't really let it go. Couldn't let it go or something. I don't know. It's just become my way of life ... you have a responsibility to this business and that's a baby too. 
Joan, who makes preserves and other delicacies in eastern Newfoundland and who we met earlier as a case study, uses this same type of language to depict her commitment to self-employment:

I don't know if I'm still in business because l'm persistent, l'd like to think so, or if I'm stupid, which is what I'm beginning to believe. I think there is a very fine line between persistence and stupidity ... I think it's just stubbornness. I think it is. That and the fact that we have invested so much time and money into it. Bill was working and he thought there was no end of the money we poured into it ... For me, it's like another one of my children that I can't let it go.

We see that for these women, self-employment is not merely a job; as children are extensions of ourselves so are their businesses. The meaning of the work they do goes beyond any economic benefit. In fact, in other parts of their narratives they describe how self-employment has involved economic loss as opposed to gain. One sees that the meaning becomes embedded in the same norms and values about good parenting. The parent needs to be sure that she is looking after the needs of her child. Where with children one can describe the needs as physical, social, emotional, and mental, with the business the needs are monetary and temporal. Even when one is contemplating leaving self-employment, there is still this sense of caring for the business. At the time of her interview, Catherine was exploring options for the future of her notecard business. She tells us about the stage she is at: 
At this point now, I've gone back to work fulltime. I'm actually evaluating whether or not I can keep the business going. If I could find someone that would like to start it as their own business I would sell it to them ... But having said that the couple of times I threw up my hands and said this is insane l've had people stop their cars at the local hotels that had a card rack in the lobby, phone me and say, 'I'm out of cards.' Then you say, 'Okay, well maybe l'll keep going for now.' And it's hard to give up something that you spent that much time at. It's yours so to speak for three years, but also I don't want to see it like into nothing, so if someone wants to take it over that's okay.

Catherine never said that she was going to walk away from her business. She is looking for someone to "take it over." It is as if she wants to be sure that someone is going to care for the business as much as she does. She does not want to abandon what she had created; Catherine wants to feel comfortable that her business will be looked after. Again, one sees a woman providing sentiments that closely mirror what one expects from a parent.

We see in these three women's narratives a possible gender trend. These women all have children of various ages, operate their businesses from home, and they all have a parental sense of duty toward each of their businesses. None of the men in this study expressed this sentiment, and neither did Brenda (see her case study), a woman without children. While analysing the narratives I looked for other ways that participants might have expressed this parental sentiment. For instance, I listened to the male participants to see if there was a desire to maintain the business so that it might be passed on to the next generation, or if they had received the business from a parent themselves. When asked about their children in relation to the self-employment, most of the participants said that their children were not 
involved. Alf and Bill are two participants that have children working at their businesses, but they did not indicate that the children would remain at the business. In Alf's case, during the tour of his workshop, he said that his son was going to be heading to college and his young daughter was rarely in the shop. He never stated or implied that he expected them to takeover his business. Bill's daughter works in the retail shop of his business, but she has not learned the craft production part of the business.

This all being said, it is in no way my intention to essentialise the women's experiences to that of mothers. However, it needs to be recognised that the selfemployed women in this study often project the same commitment to their businesses as one would expect to their children. It is a "labour of love," not just an economic venture. The norms and values of motherhood have permeated into their business ventures. This may be accounted to the fact that in Newfoundland, indeed in many other Western cultures, women have long been in charge of all dealings within the home and the men outside the home on the sea and in the woods (Porter, 1995). Men have had their "work" separated from the house, where women's work has been centred in the home. With this strong division of labour comes the women's primary responsibility of caring for all those that reside within the home. With all Jill's, Joan's, and Catherine's businesses being home-based, the business becomes folded into those that require caring. 


\section{Spousal and family support}

Key to many of the craftspeople is the support of their spouses and family ${ }^{31}$. The TSOL model allows us to look at how the economic spheres and non-economic spheres intersect. We see that the household, being the non-economic sphere, is crucial to the viability of self-employment. Within the household, there is a dichotomy that I can use heuristically to show how support from family is important. We see that in the household the self-employed worker gains non-economic support in the form of moral and temporal support. Perhaps the most important support that the household provides to the self-employed is financial. The participants tell us that without a steady income coming in, or the labour power of their spouses, selfemployment may not have been an option.

Non-economic support. Moral support is a general form of encouragement that the self-employed person needs to make it through the difficult times. Brenda, an apparel maker in St. John's, describes how crucial the support is from her husband and those around:

Oh yeah, absolutely. I mean they [her extended family] don't understand it. They've never understood what l've done. They've always looked at me as the weird creative one. But you know, my family, my husband, my friends have all been supportive ... Because of the support from my husband, and just the support he gives me, I couldn't do it. The times when I feel really down and want to quit he'll just say, 'you do good products, this is what you

\footnotetext{
${ }^{31}$ The phrase spouse is used for those that are married and common-law.
} 
do.' You know, like he always makes me feel better about what I do and I think that's really important because it's hard.

Being self-employed requires one to spend many hours on your own, so as Brenda's narrative illustrates, being embedded in a network of supportive people provides an outlet of necessary encouragement to continue with self-employment.

The time that self-employment requires takes time away from the families. Matthew talks about how his family has provided him with temporal support to do his work:

I don't get as much time with my family as l'd like to have. That's a big problem. That really bothers me. Eventually, l'd like to get to the point where I'm still making a living but not putting as much time into what I'm doing. I'm sure my family would too of course. They've been very supportive. They know, they see how much passion I get from this, how much I love this.

We see that the worst part of self-employment for Matthew is the fact that it requires a lot of time. He appreciates how his family has been so understanding in the way that they allow him to work at his "passion."

Eileen and Jake, a married couple that have an apparel-wear business, talk about how their children, three teenagers, provide them the time they need to operate the business. When asked what their children thought of them being selfemployed craftspeople they said:

They [their children] think it's cool. Jake 
They're pretty patient with the long hours. Eileen

We don't have supper most nights till 9 or 9:30 most nights. Jake

They wish it would come together faster. Eileen

If their children were younger, Jake and Eileen may not have been able to work together because the children would require more time from them. As it is, they are able to devote a substantial amount of their days devoted to their business.

Economic support. Having the financial support of someone else in the household can be crucial for the self-employed person to continue doing his or her chosen work. We see that the economic support a spouse provided for the craftspeople is important at all phases in the businesses' existence: deciding to start-up, early years and beyond.

Mark, the St. John's instrument maker, says how the financial support of his wife was a critical component in his decision to undertake self-employment. He says, "I think the first thing was that we got here and I knew Brenda was going to be making a good buck, that again if ever there was a time to try something on my own it was now." The fact that the household would be receiving a constant and reasonably substantial income made Mark feel more comfortable undertaking selfemployment.

The early years of a business are turbulent and difficult. Often times there are more expenditures than revenues coming in. Bill, the print-screener, tells us how during the initial stages of his business his wife's income allowed him to work at his business without a lot of financial stress: 
That [financial] support was pivotal. For the first two years I didn't make any money. But I didn't have the pressure because we had other income. So now that it's , basically there's more income to be had from here then to have in that incubation period here without a lot of financial stress that other people would probably face starting their own business.

Bill's wife, a nurse, is able to provide the household with a guaranteed income and benefits that allowed Bill to continue with his work.

Even after the initial stages of self-employment, there is no assurance of a steady income coming from your work. Jim, who we have heard from throughout this chapter, tells us how his wife's employment has been important to his ability to be self-employed:

Of course the best part would be if you can do all these things, pay all the bills and at the end of the week go on a paycheque yourself. That's the best part and that has to be because you can't stay at it if it don't. Although I've been very fortunate, I haven't been doing that I've been very fortunate because my wife has a good job and she can pay the bills, you know, she can keep us living. So without that I wouldn't be able to stay at this. We would have been closed up now a long long time ago. Only through her support, her financial support, that we've been able to stay at it.

When Jim's business is not providing what he ideally wants, a paycheque for himself, his wife's economic support allows him to continue with the work that he enjoys without the stress that financial instability would bring. Having a steady and 
dependable income within the household has prevented Jim from having to close up his business and look for other work.

Nick, another instrument-maker on the Avalon, concurs with the other participants about how important a spouse's income is to the likelihood of continuing with self-employment. He describes his situation, "I'm extended to my limit. If my wife wasn't working, we'd be in trouble. [What does you wife think of you doing this?] She wants me to do it but she also doesn't want to end up in the poor house." Nick shows us that even when the self-employed craftsperson is experiencing financial difficulties, the spouse is necessary to make sure that the household's needs are being met. At the same time, Nick is recognising that there may be a limit to how long his wife's income alone will allow him to continue making instruments.

For many of the participants, there is a reality that what they make monetarily as a self-employed craftsperson makes little contribution to the household. Jill, the stoneworker, states that her husband is in essence the sole financial supporter of the family: "He supports the family, this doesn't. Which is something, you know, I can be greatful for compared to others. And again, that may be a turn off to some people." Jill also demonstrates how important it is to have someone else in the household with a steady income to provide for the family when there is a selfemployed person. Without this support, as Jill points out, people may not be willing to make the decision to become self-employed.

There are two couples in this survey that work together at the business: Eileen and Jake, and Alf and Laurie. Anthony and Joan also work with their partners. Within each case, there is a distinct division of labour. Eileen and Laurie 
are both responsible for the "business" end of the business. They work on the marketing, doing bookwork, filling out government forms, and retail sales. The men, Jake and Alf, focus on the "craft" end of the business. They do the design and production of the crafts (apparel and woodworking respectively). Anthony and his partner are both potters; however, the division of tasks is stringent. His partner throws the pots and he does the detailing work on them. Joan and Donald, her husband, perhaps have the least strict division of labour. They are both involved in the production and distribution of the jellies, fudge and chocolates, but it is Joan alone that develops the recipes and takes care of the bookwork. The spouses, then, while not doing outside employment, provide vital economic contributions to the selfemployed craftworker. The relatively strict division of labour is important to the prosperity of the business and in turn the household. ${ }^{32}$

Self-employed craftspeople who do not have spouses to provide financial support may find that the need to maintain other jobs to support themselves. The two participants, Louise and Brad, who do not have spouses, have jobs outside their craft businesses. Both of them had jobs that are professional in nature (museum administrator and electrical engineer) and provide the income and benefits that most of the other participants received from their spouses. Neither of these two were willing to make the "leap of faith," as Brad said, to leave their jobs to do nothing but

\footnotetext{
${ }^{32}$ It should be noted that the incidence of unpaid work by family members is rare. We saw earlier how Bill and Alf's children did work for the businesses, but it was unclear whether they were paid as employees.

Participants with children tended to indicate that the children wished to have little to do with the business. The only other participant to indicate unpaid work occurred was Roger, whose wife occasionally helped to work the booth featuring his product at shows. Her participation was infrequent because of being busy with her paid job. I would say that this is the case for the other spouses that do not work full-time with the participant.
} 
their crafts. Without the backing of someone else in their household, they did not think that being fully self-employed would allow them to survive financially.

\section{Conclusion}

In this chapter, I have examined the participants' narratives about how they got involved in self-employment and what is keeping them in this form of work. We have seen that despite the craft strategies report's (discussed in chapter three) focus on market and economic concerns, the craftspeople have discussed their work in terms of economic and non-economic priorities. What we see is that the economic priorities may be somewhat more important when getting involved with selfemployment; however, they are not as prevalent when looking at what keeps them at this work. When looking at what keeps the craftspeople in self-employed labour, we see that a gender pattern emerges. Where males discuss the meaning of their work in "traditional" terms of control and freedom, the women, especially those with children, see the self-employed business as an extension of their families, and, in their narratives, they identify the parental responsibility they feel.

The craftspeople also recognise the need to have household strategies that permit them to do this work. It is necessary for them to have spouses that have stable incomes outside the business, or to work together. Furthermore, they need to have non-economic support that provides the moral and temporal support to maintain them at this work. Without these supports in place in the household, fulltime self-employment is not a realistic option to undertake or to continue. Selfemployment, therefore, is not a solo enterprise. It requires household strategies 
about how the spouse will contribute economically. Without the economic contributions, either in the form of outside work or participation in the business, selfemployment would not be possible. At this point in time, the self-employment literature, as well as government documents such as the craft report, ignores this vital element of continual self-employment.

By using Miriam Glucksmann's Total Social Organisation of Labour, I have been able to move beyond merely looking at self-employment as a part of the economic sphere. This theoretical understanding has allowed me to incorporate non-economic priorities that are too often overlooked. While I have divided my discussion between the economic and non-economic priorities, I use the distinctions in a heuristic fashion. I have shown again that one of the weaknesses of the Newfoundland craft strategy report has been its blinders to anything that is not economic, or more specifically market-focussed. We see that the road to selfemployment and the continuation of this work, involves many other factors beyond the economic sphere. We need to remove the blinders to see how different spheres are blurred and where they intersect. If governments wish to use self-employment as a key component of development policies, as Newfoundland does, they need to take into account the non-economic priorities and household strategies that pertain to perpetuing self-employment.

With the realisation that economic priorities are not only things self-employed craftspeople use to understand their work, the following chapters will delve deeper into the non-economic aspects of their work. I will first examine how the craftspeople develop identities as craftspersons. How does being a craftsperson 
shape one's narrative about them? Next, I will look at how Newfoundland as a place affects the craftspeople's work narratives. Essentially, we will see that commodification of place as it relates to the crafts produced and the relationship to the locals and non-locals shapes the narratives about work. 


\section{Chapter Six}

\section{Crafting place}

In this chapter, I set out to analyse how the concept of place has come to shape the participants' narratives. Place can be understood on many different levels: the immediate location (such as a house), a neighbourhood, a town, a province, a region, or country. In this study, place is the province of Newfoundland and Labrador. Political, cultural and geographic boarders define this place. As such, before I analyse the narratives as they relate to place, I first want to contextualise Newfoundland geographically and culturally. From here, I will move into my analysis of the narratives. Into this analysis I take Peck's (1996) argument that "uniqueness stems from the geographically variable nature of labour qualities, spatial patterns of labour mobilisation and utilisation ... and the ways in which structures and practices are institutionalised in different places" (89). To do this I focus on how Newfoundland draws people to stay, come and return to the province, how Newfoundland becomes commodified, and finally the paradox of the relationship between the craftspeople and Newfoundland's support of the industry. As in previous chapters, this analysis is tied to my critique of the provincial craft strategy report of 2002. 
Newfoundland - Geographically contextualised

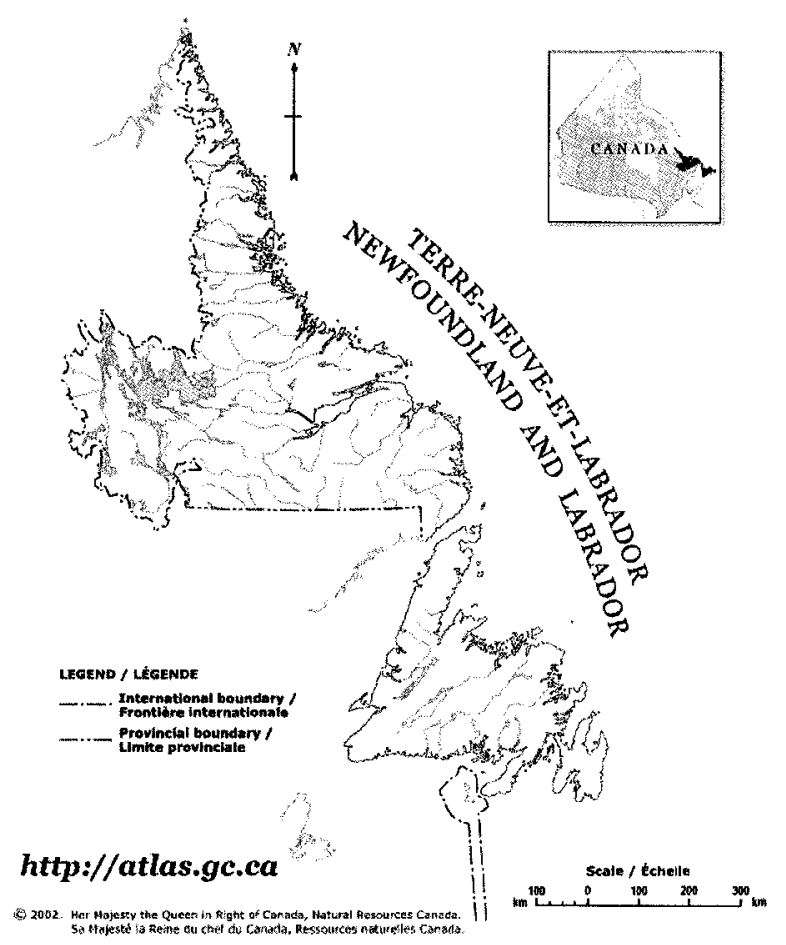

Map 1: Map of Newfoundland and Labrador

Source:

http://atlas.gc.ca/site/english/maps/reference/outlineprov_terr/nfld_outline/refe rencemap_image_view

The province of Newfoundland and Labrador is located in Eastern Canada. It consists of two landmasses. Labrador is part of the mainland of Canada, at the north-eastern end of the Canadian Shield. It is north and east of Quebec. The Labrador Sea and the Straight of Belle Isle run along the coast. It is rich in many ore deposits and the rivers are harnessed for hydroelectricity production. As much of Canada's north, it is isolated by its distance and extreme weather conditions.

The second part of the province is the island of Newfoundland. It is located off the Grand Banks in the North Atlantic Ocean. The landscape is highly varied 
across the province. On the east coast, you find rugged rocky coastline. Central Newfoundland is forested with swift rivers running through it. The Northern Peninsula is much like Labrador, with tundra-like physical features. Finally, the west coast is mountainous as part of the Appalachian mountain range. It is also the lushest area, with warm air coming off the Gulf of St. Lawrence.

Newfoundland is a one of the largest islands in the world. To drive from Portaux-Basques in the south-west to St. John's on the east coast takes approximately ten hours. That takes you from one end of the TransCanada Highway to the other.

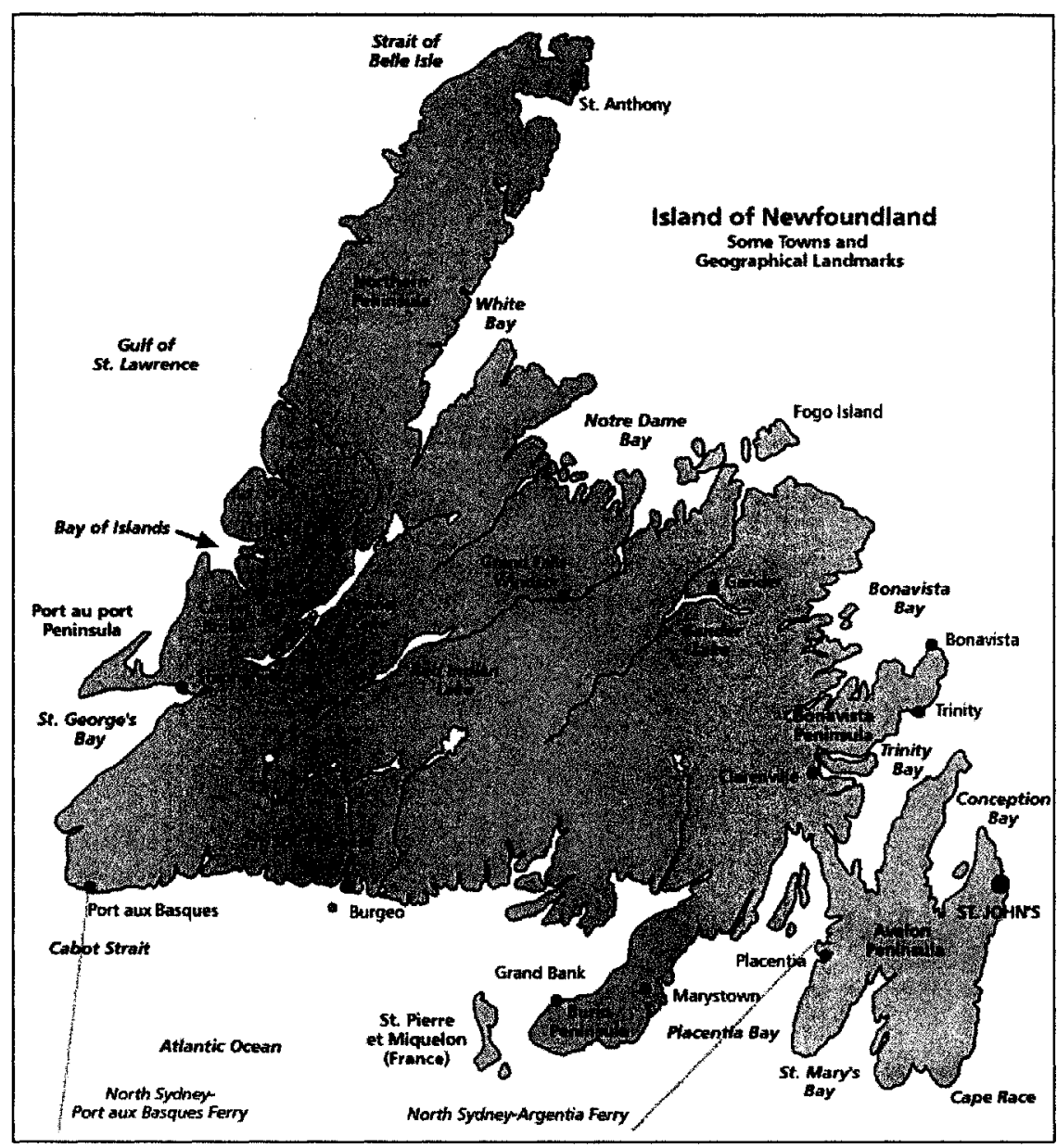

Map 2: Map of Newfoundland

Source: http://www.heritage.nf.ca/nfld fullmap.html 
When you talk about places in Newfoundland, two pieces of information are important. The first point is that towns and villages are referred to as "outports." Villages and small towns are outports even if they are not on the coast. This terminology is indicative of the province's fishing heritage. Second, you must be familiar with the names and locations of bays and peninsulas. People often talk about where they are from in terms of not only their outport but also the bay and peninsula where the outport is located. This part of the geography has heavily influenced the colloquialism and dialect in Newfoundland. People have divided themselves in terms of "Baymen" and "Townies," and when they say where they are from, you will often hear that they are from "around the bay."

Newfoundland is isolated from the rest Canada by its geographical location. There is no permanent link to the mainland, as with Prince Edward Island and Cape Breton. You must fly in or take a ferry from North Sydney, Nova Scotia. The ferry trip to Port-aux-Basques takes approximately six hours. The ferry going to Argentia (an hour drive from St. John's that runs only in the summer), is a fourteen to eighteen hour run. To travel to Newfoundland you must also consider the driving time to get to the ferry terminal in North Sydney, Nova Scotia, and the time to drive to your destination once you get off the ferry. As such, it takes forethought and planning before you travel to and leave the province.

Because of its geographical features, Newfoundland has long depended upon natural resources as its primary economic driver. The initial settlement happened because of the abundance of codfish in the Grand Banks and along Labrador.

\footnotetext{
${ }^{33}$ See Joan's case study to see this identification.
} 
Later, pulp and paper as well as mining and hydroelectricity have all played significant roles in the Newfoundland economy. Today, we see the development of another natural resource - offshore oil and gas. As such, we can see that Newfoundland is typical of Innis' Staple Economy, with the raw materials harvested in the province and sent elsewhere to be processed and sold. This is why we see the Newfoundland government attaching secondary industry conditions to the sale of mining rights.

\section{Newfoundland - culturally contextualised}

I now want to turn my attention to the cultural elements on Newfoundland. While I do provide detail on the "stereotypical" elements of culture - language, food, housing - I do not wish to fall into the trap that Pocius (2000) identifies as frequent in academia: cultural glorification and objectification. As he says, "Newfoundland culture does not exist in an abstract category that has somehow been captured and is being packaged to 'give back to the folk" (276). What I do want to do here is describe some of the sights and sounds that one encounters in Newfoundland and connect these to the geographical isolation, and to the social norms and values that shape the modern culture here.

As discussed in chapter two, Newfoundland has a distinct dialect that is easily recognisable. It is generally a mix of Irish and West England pronunciations. This dialect has been a key distinguishing characteristic to Newfoundlanders. There were times when the provincial government even held classes to be sure that Newfoundlanders retained the dialect to add to the authenticity of a tourist's 
experience (Overton, 1996). The context for the dialect is similar to the Appalachian drawl in the United States; as inNewfoundland geography prohibited travel and the isolation caused the retention of cultural aspects such as language from British ancestry (Becker, 1998).

Newfoundland also has a distinct culinary tradition that is different from other parts of Canada, and even from the Maritime provinces. In Newfoundland, the diet has long consisted of salt beef, salt cod, wild game, root vegetables, and canned milk. The isolation and rocky terrain has meant that fresh produce is difficult to get, and that what you have must last throughout a long cold winter. These foodstuffs are still the bases for many Newfoundland meals. ${ }^{34}$

The traditional Newfoundland home around the outports has been in the "Salt box" style. These are narrow homes painted in bright colours. The colours are said to brighten the dreary days, and can be seen from the water with greater ease.

They are also narrow as to allow more families to have access to the coast, where they would have their boathouses. More often than not newer homes are bungalows or are modernised beyond recognition of the earlier layout. Pocius (2000), in his community study of Calvert, puts it this way, "A house must provide basic necessities and not become a vehicle for social class, like some of the modern houses in St. John's today, or like some of the equally expensive St. John's renovated 'heritage' houses" (276).

Newfoundlanders, especially those from around the outports, have placed value in the ability to do hands-on work and to provide for themselves as much as

\footnotetext{
${ }^{34}$ My uncle's wife is a Newfoundlander, and when you go to visit, her dinner consists of Jigg's Dinner (a boiled dinner of salt beef, carrots, potatoes, parsnips and cabbage), peas pudding, and roast turkey. For dessert, Figgy Duff (boiled sweet pudding with raisins) would be a frequent offering.
} 
possible. For example, as Felt, Murphy and Sinclair (1999) discovered in the Northern Peninsula, more than fifty per cent of the men in their study built their home, and more than a third of the women built their home. Subsistence activities (such as hunting, collecting wood, gathering berries, and making clothes) are quite common among those living in the outports. Felt et al. conclude that:

The widespread informal sector in the Great Northern Peninsula and, presumably, in other similar areas, is best understood as a constructive reaction to the environment, isolation, small population, and poor local economy ... Yet the informal sector is more extensive than it need be, if getting by were the only motivation for participation. We have seen that household income, for example, does not determine involvement, which appears to be culturally as well as structurally conditioned. That is, many activities are undertaken because they are socially valued (101).

In this same volume, Omohondro (1995) argues that hands-on work, or home production as he terms it, is part of being a Newfoundlander. As he says, "Newfoundlanders do not want to be like Ontarians, but to be close to the sea and forest, where they can own their own home, hunt and fish, and share with family and neighbours" (126). This cultural value is critical to my understanding of Newfoundland craftspeople's narratives. 


\section{The desire to stay, move or return to Newfoundland}

Newfoundland draws the participants in my study to stay, return, or move to the province. Jim, one of the food producers, says that Newfoundland offers a lifestyle that he would not be able to find anywhere else:

The rural or outport life in Newfoundland is not a bad life. You're very close to the land. You can still pick berries and the water's still clean - you can drink from the pond. You can hunt and chase the birds. You can go to work and leave the doors open back home. It's a good easy way of life. I can walk to work in fifteen minutes or drive in four. There's a lot of land at the back of my house. The next place you're going to reach is Gander and it's six hundred miles away, you know. There's still wild life and it's still wild.

Because of his desire to stay in Newfoundland, Jim searched for work that allowed him to stay when the fishery collapsed. He looked around at the natural resources available to him and found a new sea product to develop into feasible specialty food product.

When I asked Jill, the stoneworker living in central Newfoundland, if she would live elsewhere, her answer is an unequivocal no:

I wouldn't live anywhere else. [Are you from the area?] Yeah. My mom is from here and my dad is from Northern Ireland. He's from Belfast, and he moved here when they constructed the hydro station. And they met, and married and had eight kids. I'm the second oldest of eight. 
Jill still lives in the same place where she grew up. She did spend some time in St. John's; she has no desire to move. It is important to her to be near her extended family.

For those who did move away, the yearning to return to the province was great. As we saw in Matthew's case study, the pull to return and stay in Newfoundland is keenly felt. Once he settled back in Newfoundland, he found an appreciation for the uniqueness of the place that he had once taken for granted:

Since moving back to Newfoundland nine years ago, I've become a real history buff. Anything culturally, historically anything about Newfoundland that I find now I really take an interest in. When I was living here, of course, you don't, like anybody, when you're livin' somewhere you take a lot of things for granted around you. Since moving back, l've been really interested in Newfoundland. I pass it along to people visiting here ... they're really amazed. It shows the resiliency of Newfoundland not to buckle under pressure.

Now that he has moved back, Matthew's connection to Newfoundland has increased. He has set out to know more about his birthplace, the same place where he lives and works today.

Matthew is not the only one to return. Jake, an apparel-maker in eastern Newfoundland, and his wife Eileen, moved back to Newfoundland. Jake grew up in Newfoundland and then spent over twenty-years living in Nova Scotia where he owned and operated a tannery. Despite being away from Newfoundland for a long 
period, he considers this place home. When faced with the chance to return to Newfoundland, he could not let it pass:

I had an opportunity to move home. I was approached by a company in Newfoundland to buy my equipment. They wanted to set up a tannery in Newfoundland. It was a pretty good offer. And they offered me the plant manager's job. So I worked for that company and we set up the new tannery here in Newfoundland. I worked for them for three years and I missed being on my own. Then started up this one.

[Eileen] It was always on the back of his head that he saw the job as a way to get back here to start up business again.

The draw home was so great that Jake and Eileen moved their family who had grown up in Nova Scotia to a new province.

Nick, an instrument-maker in St. John's, has a similar narrative. He moved back to Newfoundland initially because of a job, and then eventually struck out on his own. He says that all Newfoundlanders are trying to find a way to get back "home." As he pointed out, "What other province has a club of people who move away?" The identity of "Newfoundlander" is so strong that a first priority is to try to return to the province, and if that is not possible, then they set up meeting places for others in like circumstances.

The lifestyle available in Newfoundland is not only desirable to those from the province, but also to those who "come from away." Mark, the instrument-maker we met in chapter four, moved to Newfoundland because his wife got a good job. Upon arriving here, he quickly realised that it was the place for him to try his hand at self- 
employment. As we saw earlier in his narrative, he also found Newfoundland conducive to the environment he wanted for his family:

I mean the whole mystique of Newfoundland, I don't know if that's the right work, but to me walking around downtown, you see the Devon Craft House, to me there's something about the place that makes me think artisan lifestyle ... Why would anyone want to live anywhere else? There's no crime, it's absolutely gorgeous, the people are great. There's a happening nightlife, not that we get to experience that (chuckle). You're a flight away from Europe or Ontario. It's not like you're as isolated, I don't know, now that we've travelled it doesn't seem as isolated anymore.

This isolation, however is important to Mark's business. To reiterate what we saw in Mark's narrative earlier, he tells us how it works to his advantage:

I really like the distance. I don't think there is another place in the world that this would have worked as quickly or as well. I was thinking last night that a lot of the guys that do this would be on the West coast of the U.S. or Canada, and I just can't imagine the distractions. If you lived in LA, everybody's going to be dropping by, popping in. Time is just so precious, especially with the family that this is great because I really don't have a lot of distractions other that the things that are really important.

Newfoundland, as a place, then affects the temporal aspects of work. It allows for the removal of distractions, so that a craftworkers focus on their products. 
Brad, a multi-media craftsperson in St. John's, recognises this as a positive and, depending on your personality, also a negative aspect of self-employment in Newfoundland:

I think the pressures are not there. I think that the competition is so far removed. There's pros and cons to all this. I find that I'm a competitive person. And if I was by another ... manufacturer, by God, l'd try to pounce. I've already put one competitor out of business out of discouragement because they couldn't keep up with my ambition to get new woods, new designs, new laminates, new colours, new products all the time. After two or three craft fairs, this person hasn't come back. On eBay, same thing. Two people were prominent. Since I came on one of them is gone. Another guy, he does this for a living. Right now, he puts off less [product] than I do.

We see that in absence of local competition, Brad has expanded to take on competitors over the internet, where he sells much of his product. The need to fulfill the capitalistic idea of competition is not easily met in a relatively small place like Newfoundland. This, as Brad points out, is a pro and con of working in Newfoundland.

\section{Inspiration, culture, value}

Isolation can also be a positive condition when it comes to looking for inspiration. Matthew points this out:

I've heard a lot of other artists and craftspeople say there is no lack of inspiration. Everywhere you look, there is inspiration: nature, people, 
everything, everything about Newfoundland. There's something about this province that is just totally appealing to artists ... It's so unspoiled. It's not mainland Canada by any means. There's something about living on an island. Maybe it's the isolation factor. The fresh salt air. The beautiful surroundings. There is no end of what you can come up with when you work in this environment.

The physical and geographical environment provides another force that shapes the work they do. It provides the inspiration for the form and design of many of the craft products.

Anthony concurs that Newfoundland's natural beauty shapes and inspires craftwork. Anthony is a potter in Western Newfoundland. He joined his commonlaw partner in her business about ten years earlier. She is a Newfoundlander from the same outport where they currently live and work. Their studio is located on the main road into town facing the bay. He tells me about the frequent sightings of whales in this bay, the waterfalls, and the mountains. In describing his and his partner's craftwork he says, "The roots run deep and the inspiration is right there at the doorstep." As such, images of whales frequently grace their pottery pieces, as well as colours and shapes motivated by the area around them.

The influence of Newfoundland in the design and form of the craftwork is particularly evident in those who are born and raised in Newfoundland. I see that Newfoundlanders will incorporate either local natural resources or traditional skills into their work. Beverly, a knitter in eastern Newfoundland, does "traditional" patterns (such as "salt and pepper caps" and "trigger mitts") using homespun wool. 
The skill is indigenous to the province but the materials have to be shipped in. ${ }^{35}$ Jill's craft, on the other hand, is not traditional to Newfoundland, but the stone she uses for carving comes from a mine in eastern Newfoundland. And as we saw in the chapter of case studies, Alf primarily uses local woods to make his crafts, and Matthew's designs are heavily influenced by the symbols of the province (such as the wildlife and Inuit symbols). Frances's narrative shows us how a traditional Newfoundland craft brought her to self-employment:

I suppose I guess I got started cause I made one [indigenous style of jacket] for my husband and people seen it. It was sort of adapted from a jacket the Grenfell Association were making at the time. They got into problems and difficulties and they weren't making them anymore. And then I redesigned the jacket myself and redesigned and my husband graphed out all the knitting designs and so on. And basically, that's how it started.

Anthony tells us that culturally crafts are complimentary to Newfoundland culture. Newfoundland's isolation required Newfoundlanders to rely heavily on their skills in building, gathering food, and making clothing. One can say that historically Newfoundlanders have been self-sufficient people (see Ommer \& Sinclair, 1999). When describing his partner, Anthony says, "She's like a lot of Newfoundlanders very hands on people." Craftwork is compatible to what it means to be a Newfoundlander, at least the perception of what a Newfoundlander is.

Bill, a print screener in St. John's, came to the province from Western Canada with his Newfoundlander wife. Upon arriving, he wanted to find work that helped him

\footnotetext{
${ }^{35}$ See Pocius (1978) to see traditional Newfoundland knits, as well as a discussion about how women abandoned spinning their own wool.
} 
become accepted into the community. He discovered that the city is rich with artistic talent and heritage. As such, Bill decided to make clothing that incorporated images that artistically symbolised Newfoundland. In doing so, he consciously tries to ensure that what he does is well received by locals:

I want to do things that are accepted by people that live here, especially not being from here. The CFA ${ }^{36}$ wanting to be accepted by the people that are here ... I enjoy St. John's, especially the arts community.

The desire to do work that is accepted by the culture community pushes Bill to put out the best quality product he can.

Part of doing craftwork in Newfoundland is to recognise the long tradition of excellent craftsmanship. ${ }^{37}$ Frances, the oldest participant, is in the apparel business in Eastern Newfoundland. She was born in Newfoundland and lives close to where she grew up. Like many people, early in her marriage she lived on the Mainland. They returned at the first opportunity her husband had for steady work. She talks about what the label "Made in Newfoundland" carries with it:

... And it's very important when you put that label on you realise that label says Newfoundland and your work is kept up to a very high degree of excellency, you know. Because once you start to let your, your, you know, your work is slip shot you might as well toss it all. Not only for you but for the whole group that goes out from Newfoundland. Our knitters are great.

\footnotetext{
${ }^{36}$ A "CFA" stands for "Come From Away." It is a Newfoundland colloquialism for someone not born and raised in Newfoundland.

${ }^{37}$ See Scott (1990) for a discussion about Newfoundland knitting being among the best in Canada.
} 
Whether they're machine knitters or hand knitters. We're a province well recognised. Very successful.

Craftwork is like an ambassador for the high standard of work that one expects from Newfoundlanders. If someone produces inferior quality products, it represents poorly on all Newfoundland craftspeople and, as implied by Frances in her narrative, all Newfoundlanders.

\section{Commodification of place}

So far, we have seen that Newfoundland as a place is integral to the craftspeople's narratives. It is the importance of place, upon which the government's craft strategy report wishes to capitalise. The authors of the report wish to have craftspeople provide unique and "quintessential" Newfoundland items for the marketplace. This is not a new strategy for development in Newfoundland. Overton (1996) points out how Joey Smallwood had implement programmes that taught people how to be "Newfoundlanders." For example, courses taught Newfoundland women how to cook Newfoundland food so that they could open guest homes or diners that would cater to tourists.

With this being the push from government, as well as from the market itself, craftspeople are almost forced to produce "Newfoundland" items. Three of the craftspeople in particular identified this as important to their businesses - Alf, Matthew and Brenda. Alf, the woodworker, tells me that, "anything with Newfoundland sells here. I'm just discoverin' that this year." He therefore started to make items that depicted quintessential Newfoundland images. He makes 
Christmas ornaments in the shapes of a Newfoundland maps, puffins ${ }^{38}$, and boats. Since the interview, his Newfoundland line has expanded to include wall mounts and clocks. ${ }^{39}$ The repetitious production of these items takes away from Alf's desire to design and experiment:

There's not a lot of fun in that. It's just the same shape, right? Same thing all day long. But when you get into, when you sees a different piece of wood there and you says, 'What's in there? What's hidden away in that wood there. Or a different shape, or you experiment with things, like that's where the fun comes in.' Or you got time to design something different. Usually after supper you say, 'Okay, let's design something; let's try something different.' Then I can't wait to get back in in the morning or sometimes after supper, right. [chuckle]

The power to decide what to produce is somewhat diminished with the pull to meet market demands and government wishes.

Matthew, on the other hand, immediately recognised the importance of Newfoundland to his product. As such, many of his products are indicative to Newfoundland at some level. He discusses how he actively made products that would attract those looking for Newfoundland images:

Being away from home for ten years if I had gotten a Newfoundland map ornament for Christmas I would have been overjoyed. Anything of

\footnotetext{
${ }^{38}$ Alf jokes that he does not understand what the big attraction to the puffin birds is. During the tour around his workshop and store, he laughs that there are still some "old-timers" that would gladly eat puffin meat.

${ }^{39}$ I visited his new website, which had the new products on it.
} 
Newfoundland, especially when you're living away. So that was the market I had in mind when I created Newfoundland images.

Matthew realised early on how his experiences of place could benefit his business. When living away from the province Matthew developed a romanticised and nostalgic notion of Newfoundland. Upon returning, Matthew used this experience to gear his craft toward this sentimental and even pastoral understanding of the province.

Brenda strongly encourages this line of marketing. She discussed her thoughts about purchasing items when she herself travels. Brenda prefers to purchase locally handmade crafts and art from the places she visits. She put it this way, "It's as much as the telling of ownership that the person buys ... the more that we can promote those stories of marketing and placement [the greater the success]." The "telling of ownership" represents how and where the consumer purchased the craft. The item becomes symbolic of the place where it was purchased - the consumer is buying a bit of Newfoundland culture to take home. Brenda thinks that by strongly marketing the crafts as "Newfoundland" or at least "maritime" items will improve the sales.

The commodification of place is neither new nor unique to Newfoundland. Overton (1996) demonstrates how this has long been a government strategy in the province to attract tourists. He tells how as early as the late nineteenth century there were campaigns underway to present the province's rugged beauty as a desirable destination. Subsequent governments would have various development projects in place to train the Newfoundlanders to be marketable "Newfoundlanders." This tactic 
is not only place specific, but we see this happens amongst all craftworkers. Hickey (1996) points out that in a consuming society crafts represent the pastoral rural life many urban dwellers idealise. By purchasing crafts, especially when they do so at the craftsperson's studio or workshop, they feel that what they buy is more authentic, and they are like patrons supporting the arts.

The provincial craft report wholeheartedly supports this marketing tactic. We saw that they wish to sell Newfoundland to as many buyers. To do so, place has to be commodified; a price tag is attached to culture. This marketing of culture takes away the power over what is produced, how it is produced, and even where the craft is sold and made from the individual craftsperson. The marketplace and the government dictate this instead. While as an academic I see this as problematic, the craftspeople themselves do not see it in this light. For them, they are willing to embrace this commodification of place as necessary to the survival of their business. In this instance, the craftspeople are willing to relinquish some decision-making power in order to make a sale. ${ }^{40}$ I see this as preserving and promoting a culture that would be virtually one-dimensional - only the marketable Newfoundland traditions and skills will be worthy of supporting.

\section{Lack of local support}

It would seem that craftspeople would have the support from the local communities and the province as a whole. We see that this type of work fits well with Newfoundland values and norms, including the idea of self-sufficiency and hands-on

\footnotetext{
${ }^{40}$ One notable exception to this is Mark, the instrument-maker. As his business happens primarily over the Internet to American customers and he does not present his products as tied to Newfoundland. Commodification of place does not affect him the same way it does others.
} 
work. We also see that the government, at least on some level, supports the province's craftspeople. They do provide some financial assistance, and they did do the research into the future of the industry. However, the craftspeople told me a different story. They presented me with a tension between what would be strong support from Newfoundlanders for this industry to the personal encounters craftspeople had with their neighbours.

When asked if the customers appreciated the process and product of their labour, many of the craftspeople expressed how their work was almost belittled by Newfoundlanders. Frances, the apparel-maker in central Newfoundland, was quite adamant about this. She tells me this in her narrative:

But when you, after a number of years people say, 'Ph, she's doing fine. She's making a mint. I could do this too.' Maybe you get that in Ontario too, but you get it here. Maybe it's a lack of opportunity here ... You see, having seen these squaw, they call it squaw jacket, having seen these squaw jackets for years in Newfoundland with the knitted insert that's the identification of a squaw jacket. And people say, 'Oh yeah, I've seen squaw. My mother makes them.' No, your mother didn't make the one we made. Of course, they're similar and that was the thing you know. When you took it to the mainland it was something new.

Being self-employed and making a product that had roots in Newfoundland's cultural history did not garner support from locals. She puts it down to the fact that Newfoundland has long been a "have-not" province, so that her success (or appearance of success) incurs envy among those who have a hard time making ends meet. As well the fact that the jacket she makes is rooted in Newfoundland 
culture makes people dismiss them. However, it is a different experience from those on the mainland and tourists for who the jackets are unknown and unique.

Catherine, who is in western Newfoundland making notecards, agrees with Frances's experience with locals. She tells me about her experience at craftshows,

I think there is a tendency for people to look at something and say, 'oh, I can do that What's the big deal? I can do that. Why's it so expensive? I can do that.' ... that minimises your product.

We again see this belittlement of a locally made product by local people.

Jim tells me about how he too experiences a lack of local support for his business:

But we don't do that well locally. That's not unusual for Newfoundland and Newfoundland business. We seem to not support locally. We're good at that actually (chuckle).

His product, a specialty food product harvested from the ocean, is not a traditional Newfoundland food so it is not surprising perhaps that it has not been accepted by locals. Again, however one would assume that there would be support of a local self-employed person who is able still to gain work from the sea.

Alf sees the lack of local support not so much from Newfoundlanders themselves, but coming from the government. In Newfoundland, one of the largest retailers is government-run historic sites. Each site in the province has a gift shop that is to promote not only the specific historic site, but also the whole province. 
When you walk into any one of these sites, you will often find a variety of "Newfoundland" products. The problem, as Alf sees it, is that the locally made objects do not necessarily get priority in shelf-space at these sites. In his narrative, he tells about going to see his product at one of these sites:

Biggest [tourist] site in Newfoundland [Signal Hill] carries so little of our stuff ... if we makes a go of this it will be an act of God, an act of God.

There is a note of frustration in Alf's statement. He makes a craft that uses local raw materials and harkens back to traditional skills, but he cannot get the support he believes he deserves.

Nick, an instrument-maker in St. John's, has his own explanation for why this occurs in the province. He says that the reasons for the lack of local support are found in past socio-economic development policies:

Newfoundlanders are a funny group. There's a whole perception among Newfoundlanders that if it's made in Newfoundland it must be two left rubber boots ... back to my point. I guess the people of Newfoundland are so jaded now that to the point that a guy building [instruments] in Newfoundland is like to them the only thing pop into their head is giving away electricity, two left rubber boots. You know, obviously the government must have funded this guy to do something here that is a joke. That's the way I feel. I tell people I build [instruments] here and they're like it can't be - must be a joke. My [instruments] would have to be popular everywhere else before Newfoundlanders would see them as acceptable. We can't judge our products to be good enough if they're made right here. We can't do that. 
The references Nick makes go back to many of the Smallwood projects after

Confederation. They include a boot factory that reportedly did not have the ability to make a left and right boot, and the now infamously bad deal Newfoundland made with Quebec for electricity at Churchill Falls, Labrador. Both of these examples, according to Nick, have made Newfoundlanders cynical of anything produced locally. As he said, a Newfoundland product needs to be successful elsewhere before it would receive local support. It is hard for a craftsperson to counter such an emotionally charged argument when promoting their product to those in Newfoundland.

The government's craft report advocates a strengthening of local markets for crafts. They talk about making sure the crafts are of quality workmanship, and marketed such that Newfoundlanders will take ownership and pride in locally produced crafts. Nowhere in this report do they deal with this inherent lack of local support. They need to see that the lack of support is deep-rooted in the cultural and political history of the province.

\section{Conclusion}

In this chapter, I have shown how place shapes the work narratives of self-employed craftworkers. This is evident through discussions on the desire to be in Newfoundland, the commodification of place, and the paradox between how craftwork matches Newfoundland's cultural norms and values but does not receive local support. These are all areas that the provincial craft strategy report does not address. I believe I have demonstrated that place does shape one's narrative about 
the work they do. It is not merely space that we occupy, but its geography and culture that are critical to the work we do and how we come to understand our work. 


\section{Chapter 7}

\section{Crafting a conclusion}

Throughout this dissertation, I have presented my analysis of self-employed craftworkers in Newfoundland. Their narratives about their work has led me to some key conclusions about self-employed work, the situation of place in relation to commodity production, the importance of narratives and narrative analysis to questions surrounding work, and finally, the need to have socially-grounded rural development.

Self-employed work more than the economic self. Self-employed work, and particularly self-employed commodity production, is not the romantic and idealised craftsperson in the workshop. The self-employed craftsperson is not isolated in his or her workshop creating items that he or she wishes. They are not doing this work solely for self-actualisation. Moreover, it is not the person who wishes to make a lot of money. The Newfoundland craftsperson is someone looking to find work that will allow them to pay the bills. It would be naïve to assume that this is not an important consideration. Nevertheless, using Glucksmann's concept of the "total social organisation of labour" has allowed me to demonstrate that the connection between the often dichotomised economic and non-economic spheres is not so clean cut. We see the importance of learning the various priorities people have for choosing and staying with self-employed commodity production. The priorities for undertaking this work include economic rationales such as making profit and entrepreneurial 
spirit; however, the non-economic rationales are more important. Self-employed commodity production, as craftwork is, is chosen because it allows the craftsperson to have control over the immediate work environment, including control over time, and is a form of work that mirrors many of the social values and norms in Newfoundland. It becomes not only a rational decision about economic viability, but about lifestyle choices. The reason that they stay with this work takes on a gendered element. Women working out of their homes envelop the business as included in the family, per se. They talk about their business as being a child needing to be cared for. As I mentioned in chapter five, I do not wish to essentialise the women's experiences to that of mothers; however, I do think it is important to highlight this trend.

We also saw, using the TSOL, the importance of the household in the work narratives. The self-employed craftworkers of course need the moral support of their families and spouses; however, the financial support is critical to their work. Each household needed to have strategies in place to ensure the economic survival of the family. We saw three strategies in place. The first is where there is a member of the household who has employment outside the self-employed business. Referring back to Table 1 in chapter two, the spouses and partners in these situations often had professional jobs that not only provided good salaries, but also benefits. This meant that the craftworker knew that the household did not need to count on the economic well-being of the business to survive. This allowed them to proceed during the initial start up phase, as well as when there was not much profit being generated. The next arrangement is two spouses working together at the business. 
We saw that this was the case in four businesses. The labour of both partners is essential for the viability for the business and in turn the household. The last arrangement is the case when there is only one person in the household and they are working at two jobs. Brad and Louise are both in this situation. They both felt they could not proceed with the craft business unless they had employment elsewhere. As Brad told me, he was not willing to take the "leap of faith" it would require being solely a self-employed craftsperson. The jobs they held were the ones that Louise said, "paid the bills," as well as providing benefits. We see therefore from this discussion on household strategies that it is deemed by the participants not to be feasible to do self-employed commodity production on one's own. You need to have either a steady income from an outside source, or you need the labour of a partner.

By looking at household strategies, we see that self-employed craftwork is about a lifestyle. The participants use self-employment to meet priorities other than just economic ones. This includes such things as creativity, control, childcare, or just being home with family. The household strategies then become critical, as a means to support this lifestyle.

We see therefore that as a class craftspeople are not the romanticised independent commodity producers people envision. While they may seem to own and control their immediate work environment, we see there are layers of dependency that proletarianises them into being dependent commodity producers (Clement, 1984). All the participants are dependent upon the government for some financial support, either in the form of travel grants or more substantial capital 
expenditure loans. Beyond this, self-employment means that you are dependent upon members of your household to contribute financially. As noted above, without the economic support of a spouse in most cases the craftspeople could not continue with self-employment. Lastly, the craftsperson is dependent upon consumers. One may assume that a craftsperson goes into his or her workshop to create whatever he or she pleases. We have seen that the reality is that craft producers have to make goods that will sell, and are therefore dependent upon the purchasing power of consumers.

Place shapes the search for work, the products, and the relationship to locals. The place that work happens is important to self-employed work. In this dissertation, I show how Newfoundland is an influential actor in the participants' work narratives. This influence operates on a variety of levels. To begin, self-employed commodity production allows the participants to live in Newfoundland. Newfoundland is known for high unemployment and outmigration rates, especially in the rural outports. The craftworkers indicate that undertaking self-employed commodity production allows them to return, stay or move to Newfoundland where there is little other employment opportunity. The desire to be in the province is such that they actively create work for themselves, using talents and skills that are hard to use in "ordinary" employment situations. Newfoundland, through its culture and natural environment, is conducive to craftwork. Newfoundlanders' ability to do hands-on work is noted throughout various literatures. There is a history of having to rely on ones ability to make the items needed to survive. Craftwork in the province draws on this heritage. 
Furthermore, the natural environment inspires many of the crafts produced in the province. Whether it is the designs that reflect some aspect of the coastline, or the use of local wood, Newfoundland's influence is readily seen in the crafts offered for sale.

Because of the importance of Newfoundland to crafts, and its unique culture and environment, place is commodified in this industry. Place goes beyond influencing the crafts; it becomes the selling feature. As we saw with Alf, "anything with Newfoundland sells." Place not only has the non-economic draw of lifestyle and artistic inspiration, it takes on an economic value. In order to make the craftbusiness successful, the craftspeople need to offer products that overtly represent Newfoundland. We see that this is particularly the case for those whose sales happen primarily within the province. By having to cater to the market for Newfoundland souvenirs, the craftspeople have less time to devote to the design and production of new products. They need to reproduce the same item repeatedly. We see therefore that the commodification of place takes away some of the immediate control over the work process and product that are priorities for undertaking self-employment in the first place.

When I started this research, I had thought that craftwork would fit in well with the Newfoundland society and culture. There is a longstanding history for excellence in work such boatbuilding, jam-making and knitting that I had anticipated crafts would be supported by fellow Newfoundlanders. This history however has actually had the opposite effect. Many of the craftspeople told me that they receive little support, both economic and non-economic, from the local communities. They 
hear comments that they feel belittle the work they do. Newfoundlanders will say things like, "Oh my mom can do that," or "why are they charging so much for something I can do." Furthermore, because craftworkers receive government support, there is the feeling that the products cannot be of good quality; this harkens back to the various industry failures in Joey Smallwood's governments. It is an unexpected tension that here we have a form of work that seemingly fits well in with Newfoundland's social norms and values but is not supported by the local residents.

Narratives are more than individuals' stories. I set out to gather individual's work narratives about their experiences as self-employed craftworkers. I did so with the recognition that while each narrative is an individual's account of his or her work, the narratives come to represent a culture at a particular time and place (Riessman, 1993, 2004). I have found that as a methodology narrative analysis does gives insight into the intersection between self and society (Daiute \& Lightfoot, 2004). It is an effective tool to connect the macro government policies with the micro concerns of the participants. In this research, the narratives tell us about the economic and non-economic spheres where self-employed commodity production happens in Newfoundland. Without narratives, revelations about the blurring of the connection between these two dichotomised realms would not be easily obtained. This is one of the strengths of qualitative methodology; we are able to get details and probe respondents to develop an understanding of work experiences.

In doing so, I have contributed to the further development of Glucksmann's TSOL. I have shown, like Glucksmann, that there is a blurring between what has 
been dichotomised as the economic and non-economic spheres. This approach is not only appropriate for paid employment but is beneficial for investigating selfemployed commodity production. I have further demonstrated, more pointedly than Glucksmann, that the household cannot accurately be thought of as the "noneconomic" sphere. As the craftspeople's narratives have demonstrated, the household, in its financial support of the self-employed, go beyond discussions about unpaid work. The economic strategies of the household are integral to the self-employed commodity producers' decisions in the "economic" sphere.

By adopting an actionist approach, I have been able to incorporate the three types of knowledge I outlined in Chapter 2 (referential, mediated, and experiencial) in such a way that the analysis of the narratives that facilitates the contextualisation of their experiences. I feel that by my having previous experience in the craft industry, visiting the workshops, and being prolific in a craft myself has strengthened the contextualisation of the narratives. On top of this, I strongly advocate living in the area that you are studying. My time living in Newfoundland allowed me to gain first-hand knowledge of the social, cultural, political, and economic issues that are prevalent in the province. Without this experience, I do not think I could have presented an analysis of the craftspeople's narratives that was sensitive to the everyday issues they face living in the North Atlantic. This epistemological stance provides a reflexive way to do empirical research, particularly with commodity production.

I also feel that this dissertation has some of my own narrative in it. At all times, I have endeavoured to be reflexive about my relationship with the participants, 
with their narratives, and my own understanding of the narratives. I am constantly aware of my position as researcher, and how this shapes my analysis. As well, I was always conscious of my status as a CFA (come from away), and aspired to present a picture of Newfoundland that is just. I believe that I have looked at Newfoundland through a Newfoundlanders' lens, as Overton (1996) encourages. In being reflexive, this dissertation accomplishes one of my goals - to contribute to the discussion about rural development that connects knowledge, action, and social circumstances.

A call for socially-grounded economic development. The idea of socially-grounded economic development is not new or unique. We have seen that this is resounded throughout the rural development literature under various banners, including grassroots development and endogenous development. Through narrative analysis and document critique, I have come to add my voice to this. I bring to the forefront that self-employed commodity producers are not disembodied entities but are rooted in a culture and social environment that influences and shapes their work.

The juxtaposition of the craftspeople's narratives and the government's strategy to develop the craft industry shows the lack of voice given to everyday work experience. The self-employed commodity producer is portrayed as a disembodied economic entity. This dissertation demonstrates that there are more than economic priorities when it comes to the narratives about self-employed commodity production. We see that the participants saw their work in terms of the negotiation 
between the economic and non-economic, as I discussed above. The craft strategy report at no time recognises this.

What else is not recognised is the role of households in self-employed work. Not only is moral encouragement important, but also so is the economic support of the household. In order to be self-employed, the craftspeople's households had to develop strategies that provided economic stability. By not acknowledging the household contributions, this development policy perpetuates the notion of the selfemployed disembodied entities.

Furthermore, when looking at the nature of craftwork, that is being labour intensive and time-consuming, is it reasonable to have a high growth strategy for this cultural industry? I would argue that by focussing solely on producing growth in the craft industry more creative solutions and connections are overlooked. Crafts are by their very definition handmade on some level, and therefore one cannot produce a large quantity of products. If one does, it becomes small-batch manufacturing and loses some of the unique qualities that make an item a craft. Craftwork should be looked upon as a piece of the puzzle to growing the province's cultural and tourist industries. Isolating this industry from other like it does a disservice to potential overall growth.

How can this disconnect between the craft strategy report and the work experiences of the self-employed commodity producer be ameliorated? First, I would discourage the broad definition of crafts that the report uses. By including all involved parties (such as retailers, government agencies, not-for-profit organisations and marketer), the producer is lost. As I footnoted earlier, the Newfoundland 
government does not even know the number of producers operating. The only figure they know is the number of companies (two-hundred) and that includes retailers, historic sites and museum gift shops, and large not-for-profit organisations (such as Grenfell Association and NONIA). Second, I would remove the responsibility of the craft industry from Department of Innovation, Trade and Rural Development and give it to Department of Culture and Tourism. This is in keeping with other jurisdictions, such as Nova Scotia and New Brunswick. By placing the craft industry in the hands of Culture and Tourism, the craft industry would be under the same umbrella as other cultural industries. After all, as material culture, crafts for sale are commodities representing the culture. Furthermore, as I showed, there is little local support for crafts from Newfoundlanders. Being under the same umbrella as tourism, will allow the craftspeople better access to their prime market, the tourists. They can be better incorporated into the tourist message that leaves the province. Not only can Newfoundland be known for its "natural beauty," its crafts can be promoted as part of the tourist experience. Lastly, when new development initiatives are underway, I strongly encourage the participation of craftspeople. I am aware that to do complete bottom-up development is time consuming and does not always reach the desired goals, I would concur with Doug House (2003) that there needs to be a combination of grassroots and top-down leadership. Brenda, in her narrative, told me that, "there are a lot of mouths but not enough legs" in the craft industry. By combining government leadership and craftspeople participation, I believe that you could produce a development plan that speaks to the experiences 
and needs of the self-employed. If not, you could find that you are repeating the same mistakes that have been occurring in Newfoundland since Confederation.

\section{Further research}

While I believe I have presented a dissertation that speaks to the pressing issues around self-employed commodity production, place, qualitative research, and the necessity of socially-grounded socio-economic development, there are questions that arise that call for further investigation. First is the relationship between gender and self-employed commodity production. In this dissertation, contrary to many previous studies, I did not find great gender differences among the narratives. I am surprised at this, given the vast literature on women's work, and how work is experienced differently. I went over the narratives multiple times to be sure I did not miss anything. At the very least, I thought there would be more noticeable distinction along the lines of the types of crafts done. While there was some gender distinction, like the knitter is a woman and the woodworkers are male, it is not as steadfast as I would have anticipated. Despite this, however, there is one aspect of gender difference I did bring to light was the trend among my participants that women with children who work out of the home tend to see their businesses as extensions of the family. I would be interested to know if this is prevalent across all forms of self-employment. I would also like to see more analysis on the types of commodity production each gender undertakes. I suspect that perhaps in a larger study we might see a strong gender line between the "soft" crafts (textiles, food 
production) and the "hard" crafts (woodworking, metalsmiths). Where do crafts that fall in between, such as pottery, fit into discussions around gender?

Secondly, how do we describe the market where self-employed commodity producers sell their wares? Can we say there is strict government control, or is it laissez-faire? From this research, I would probably say that it is greyer than this black and white dichotomy. It would require one to probe deeper into the various levels of regulations that are imposed upon the producer and then attempt to grasp how they themselves see what influence these restrictions have on them. As well, a look at the "informal economy" to see if self-employed people are finding other places to sell, trade and barter their products.

Following up on this question about markets, a third area of research would be to look at the relationship between the market, community, and the self-employed commodity producer. As we saw in this dissertation, there is a paradoxical relationship between the Newfoundland craftsperson and locals. I would like to see a research project that expands on this to inquire into the above-mentioned relationships with various types of self- employed commodity producers. This would include talking to farmers, fish harvesters, and others that produce a commodity for sale. I think that this is particularly important in the rural areas where employment opportunities can be precarious, and local support is potentially vital to the survival of these types of operations.

Lastly, I would like to suggest research that interrogates the relationship between self-employed workers and the household. As we saw with Newfoundland craftspeople, the economic support of the household is crucial to the likelihood of a 
person undertaking and continuing with self-employed commodity production. It would be beneficial to determine if this is the case for all types of self-employment, or is it more particular to the case of commodity producers. The household and selfemployed work is an area I feel is under-represented in the current literature and should be there to increase our understanding of this form of work.

Of all these potential research questions left unanswered, what I believe will be a valuable next research project for me to pursue is to see how self-employed commodity producers, along with other members of their households, develop strategies for the division of labour and how this can in turn inform rural development policies. As is the tradition in sociological literature there is a dichotomous relationship between agency and structure. What is missing is an intermediary level of analysis between the individual and society-at-large. For me, this intermediate level is the household. Wallace (2002) states that in households agency and structure intersect. It is where people negotiate the demands of their culture and society with their own values and priorities. Members of a household need to strategise the division of labour, not only within the household but also in terms of who (if anyone) enter the paid labour market.

The way I envision this research unfolding is to collect the narratives from adults in households where self-employed commodity production is the primary mode of work for at least one adult. Narrative analysis illuminates the relationship between the self and society (Daiute and Lightfoot, 2004), and I would also add the intermediary level of the household. In this project I will conceptualise commodity producers to include self-employed farmers, fish harvesters, and loggers, as well as 
craftworkers. From the narratives, I will first do a class analysis on the participants that is based on production patterns (subsistence, capitalist (proletariat) commodity production, independent commodity production, dependent commodity production, and co-operative commodity production) and the relations of production (Clement, 1986). The class analysis situates the household within the local community, as well as at the provincial and national levels. It aids in explaining why certain household strategies may be chosen over others.

My next step would be to use the narratives as a means to critique and theorise rural development. In particular, I want to critique proposals for rural development for being economically driven and market focussed, as I found in Newfoundland's craft industry, to the exclusion of any discussion about the social factors that shape people's actions. This critique will contribute to the political economy literature on rural development (see Winston and Leach, 2002, Shortall, 2004; Ray, 2001). Furthermore, and perhaps more importantly, I see this research as informing governments on how to incorporate the household into their rural development policies.

This dissertation has accomplished many of the objectives I set out. I have taken the narratives of Newfoundland craftspeople to critique the provincial governments 2002 craft industry strategy report. I have shown that the self-employed commodity producer is neither the romanticised independent worker, nor the disembodied economic producer. The Newfoundland craftsperson is one that is situated within a 
place, and the social norms and values that go along with it. Using reflexive qualitative methodology, we are able to see that the decisions to be self-employed are mediated by economic and non-economic priorities. In doing so, I call for socially-grounded economic development that allows for the experiences of the selfemployed commodity producers to be incorporated and valued. It is my hope that this dissertation will not only be used to further the development of the academic debate surrounding questions of work, methodology, and rural economic development, but also used by government and grassroots organisation to created policies that are relevant to the people at whom the policy is directed. 


\section{Bibliography}

Aitchison, C. et al. (2000) Leisure and tourism landscapes: social and cultural geographies. London: Routledge.

Alfoldy, S. (2005). Crafting identity: The development of professional fine craft in Canada. Montreal \& Kingston: McGill-Queen's University Press.

AMEC Earth and Environmental Limited and Hollett and Sons. (2002) Newfoundland and Labrador craft industry development strategy: Summary and recommendations. St. John's: Canada/Newfoundland Agreement on Economic Renewal

Arai, A.B. (1997) "The road not taken: the transition from unemployment to selfemployment in Canada, 1961-1994." Canadian journal of sociology, 22, 3: 345.

Arai, A.B. (2000) "Self-employment as a response to the double day for women and men in Canada." The Canadian review of sociology and anthropology, 37, 2: 125-142.

Armstrong, P. \& H. Armstrong (1990). Theorising women's work. Toronto: Garamond Press.

Attwell, P. (1990) "What is skill?" Work and occupations, 17, 4: 422-448.

Bamberg, M. \& A. McCabe. (1998) "Editorial" Narrative Inquiry, 8, 1, iii-v.

Banks, M. et al. (2000) "Risk and trust in the cultural industries." Geoforum, 31, 453-464. 
Barrett, M. (1999) Imagination in theory: Culture, writing, words and things. New York: New York University Press.

Beaucage, A. et al. (2004) "Le passage au travail autonome: choix impose ou choix qui s'impose." Relations industrielles, 59, 2: 345-378.

Beck, U. (2000) Brave new world of work. Trans. P. Camiller. Cambridge: Polity Press.

Becker, H. (1982) Art worlds. Berkley: University of California Press.

Becker, J. (1998) Selling tradition: Appalachia and the construction of an American folk 1930 - 1940. Chapel Hill: University of North Carolina Press.

Blake, R. (2004). Canadians at last: Canada integrates Newfoundland as a province. Toronto: University of Toronto Press.

Brox, O. (1972) Newfoundland fishermen in the age of industry: A sociology of economic dualism. St. John's: ISER.

Bruckmeir, K. (2000) "LEADER in Germany and discourse of autonomous regional development." Sociologia Ruralis, 40, 2, 219-227.

Bryant, C.R. (1999) "Community change in context." Communities, development, and sustainability across Canada. J.T. Pierce and A. Dale (eds.) Vancouver: UBC Press.

Brym, R. \& J. Sacouman. (1979) Unerdevelopment and social movements in Atlantic Canada. Toronto: New Hogtown. 
Burawoy, M. (2000) "Grounding globalisation." Global ethnography: Forces, connections, and imaginations in a postmodern world. M. Burawoy et al. (eds.) Berkeley: University of California Press.

Byron, R (ed.) (2003) Retrenchment and Regeneration in Rural Newfoundland. Toronto: University of Toronto Press.

Campbell, C. (1998) "Why action is needed in Sociology: A personal view." Sosiologia, vol.35, no.2, 81-91.

Campbell, C. (1999) "Action as will-power." The Sociological Review. Oxford: Blackwell Publishers, 48-61.

Cecora, J. (1999) Cultivating grass-roots for regional development in a globalising economy: Innovation and entrepreneurship in organised markets. Aldershot: Ashgate Publishing Ltd.

Clement, W. (1986) The struggle to organise: Resistance in Canada's fishery. Toronto: McClelland and Stewart Limited.

Clement, W. (ed) (1997) Understanding Canada: Building a new Canadian political economy. Montreal: McGill-Queen's University Press.

Coleman, R. (1988). The Art of Work: An epitaph to skill. London: Pluto Press.

Crowell, D. (2003) The SEWA movement and rural development. New Delhi: Sage Publications. 
Cullum, L. (1995) “'A woman's place': The work of tow women's voluntary organisations in Newfoundland, 1934-1941." Their lives and times: Women in Newfoundland and Labrador, a collage. McGrath, C. et al. (eds.). St. John's: Killick Press.

Cullum, L. (2003) Narratives at work: Women, men, unionization, and the fashioning of identities. St. John's: ISER.

Daiute, C. \& C. Lightfoot. (2004) Narrative analysis: Studying the development of individuals in society. Thousand Oaks, CA: Sage.

Dasgupta, S. (1996) The community in Canada: Rural and urban. Lanham: University Press of America.

Day, G. (1998) "Working with the Grain? Towards sustainable rural and community development." Journal of Rural Studies, 14, 1, 89-105.

Delage, B. (2002) Results from the survey of self-employment in Canada. Hull: Applied research branch, Human Resources Development Canada.

Douglas, D.J.A. (1994) Community economic development in Canada, vol. 1. Whitby: McGraw-Hill Ryerson Limited.

Drache, D. (ed.) (1995) Staples, markets, and cultural change : selected essays [of] Harold A. Innis. Montreal: McGill-Queens University Press.

Duff, J. and Tonts, M. (2001) "Regional Development Policy in Ireland: Lessons for Australia?." The Australian Journal of Irish Studies, 1: 9-18

Elliot, J. (2005) Using narrative in social research: qualitative and quantitative approaches. London: Sage. 
Erikson, K. (1990) "On work and alienation." The Nature of Work: Sociological Perspectives. K. Erikson \& S. P. Vallas (eds). New Haven: American Sociological Association Presidential Series and Yale University Press.

Evans, M. (2003) Gender and social theory. Buckingham: Open University Press.

Evans, P.M. (2002) "Downloading the welfare state, Canadian style." Diminishing Welfare: A Cross-National Study of Social Provision. G. Goldberg \& M.Rosenthal (eds.). New York: Auburn House

Felt, L.F., K. Murphy, P.R. Sinclair. (1995) "'Everyone does it': Unpaid work and household reproduction." Living on the Edge: The Great Northern Peninsula of Newfoundland. St. John's: ISER.

Finbow, R. (2004) "Atlantic Canada in the twenty-first century: Prospects for regional integration." Regionalism in a global society: Persistence and change in Atlantic Canada and New England. S.G. Tomblin, \& C.S. Colgan (eds.) Peterborough: Broadview Press.

Freidson, E. (1990) "Labors of Love in Theory and Practice: A Prospectus." The Nature of Work: Sociological Perspectives. K. Erikson \& S. P. Vallas (eds). New Haven: American Sociological Association Presidential Series and Yale University Press.

Glucksmann, M. (1990). Women assemble: women workers and the new industries in inter-war Britain. London: Routledge.

Glucksmann, M. (2000). Cottons and Casuals: The gendered organisation of labour in time and space. Durham: British Sociological Association.

Gorz, A. (1999) Reclaiming Work: Beyond the wage-based society. Trans. C. Turner. Cambridge: Polity Press. 
Harling Stalker, L. L. (2000) Wool and needles in my casket: Knitting as habit among rural Newfoundland women. Unpublished MA thesis, Memorial University of Newfoundland.

Hickey, G. (1997) "Craft in a consuming society." The Culture of Craft: Status and future. P. Dormer (ed.) Manchester: Manchester University Press.

Hinrichs, C. C. (1998) "Sideline and Lifeline: The cultural economy of maple syrup production." Rural Sociology, 63, 4, 507-532.

House, J.D. (1999) Against the tide: Battling for economic renewal in Newfoundland and Labrador. Toronto: University of Toronto Press.

House, J.D. (2003) "Does community really matter in Newfoundland and Labrador? The need for supportive capacity in the new regional economic development." Retrenchment and regeneration in rural Newfoundland. R. Byron (ed). Toronto: University of Toronto Press.

Hughes, K.D. (2003) "Pushed or pulled? Women's entry into self-employment and small business ownership." Gender, work and organisation, 10, 4: 433-454.

Hughes, K.D. (2005) Female enterprise in the new economy. Toronto: University of Toronto Press.

Karlsonn, J.C. (1995) "Work on the rack: critique and suggestions." Research in the sociology of work, 5: 1-14.

Kneafsey, M. et al. (2001) "Exploring the dimensions of culture economies in rural West Wales." Sociologia Ruralis, 41, 3, 296-310. 
Kong, L. (2000) "Culture, economy, policy: Trends and developments." Geoforum, 31, 385-390.

Laslett, B. (1999) "Personal narratives as Sociology." Contemporary Sociology, 28, 391-401.

Leto, D. (1998) Chocolate bars and rubber boots: The Smallwood industrialisation plan. Paradise: Blue Hill Publishing.

Lloyd, G. (2000) "Quasi government in Scotland - a challenge for devolution and renewal of democracy." Scotland: The challenge of devolution. A. Wright (ed.) Aldershot: Ashgate

Marx, K. (1978) "Capital, vol. 1." The Marx-Engles Reader, $2^{\text {nd }}$ Edition. R. C. Tucker (ed). New York: W. W. Norton \& Company.

Mason, J. (2002) Qualitative research, $2^{\text {nd }}$ edition. Thousand Oaks, CA: Sage.

Mason, M. (1997) Development and disorder: A history of the Third World since 1945. Toronto: Between the Lines.

May, T. (1998) "Reflections and reflexivity." Knowing the Social World. T. May \& M. Williams (eds.) Buckingham: Open University Press.

May, T. (2001) Social research: Issues methods and process, Third Edition. Buckingham: Open University Press.

McDonagh, J. (2001) Renegotiating rural development in Ireland. Aldershot: Ashgate. 
McKay, I. (1994). The quest of the folk: Antimodernism and cultural selection in twentieth-century Nova Scotia. Montreal and Kingston: McGill-Queen's University Press.

Metcalf, B. (1997) "Craft and art, culture and biology." The Culture of Craft. P. Dormer (ed). Manchester: Manchester University Press.

Metcalf, B. (2002) "Contemporary craft: A brief overview." Exploring contemporary craft: History, theory \& critical writing. J. Johnson (ed). Toronto: Coach House Books / Harbourfront Centre.

Mitchell, C.J.A. (1998) "Entrepreneurialism, commodificiation and creative destruction: A model of post-modern community development." Journal of Rural Studies, 14, 3, 273-286.

Murdoch, J. \& T. Marsden (1994) Reconstituting rurality. London: UCL Press Ltd.

Nozick, M. (1999) "Sustainable development begins at home: Community solutions to global problems." Communities, development, and sustainability across Canada. J.T. Pierce and A. Dale (eds.) Vancouver: UBC Press.

Ommer, R. and P. Sinclair (1999) "Systemic crisis in rural Newfoundland: Can the outports survive?" Communities, development, and sustainability across Canada. J.T. Pierce and A. Dale (eds.) Vancouver: UBC Press.

Omohundro, J.T. (1995) "Living off the land." Living on the edge: the great northern peninsula of Newfoundland. L. F. Felt \& P.R. Sinclair (eds.) St. John's: ISER.

Overton, J. (1996) Making a world of difference: essays on tourism, culture and development in Newfoundland. St. John's: ISER. 
Overton, L. (1999) "Economic recovery or scorched earth? The state of Newfoundland in the late 1990s." Citizens or consumers: Social policy in a market society. D. Broad \& W. Antony (eds). Halifax: Fernwood Publishing.

Pahl, R.E. (1984) Divisions of labour. Oxford: Blackwell.

Peck, J. (1996) Work-place: The social regulation of labour markets. New York: The Guilford Press.

Porter, M. (1993) Place and Persistence in the Lives of Newfoundland Women. Aldershot: Avebury.

Pocius, G. (1979) "Textile Traditions of Eastern Newfoundland." National Museum of Man Mercury Series No. 29. Ottawa: National Museums of Canada.

Pocius, G. (2000) A Place to Belong. St. John's: ISER.

Ray, C. (1998a) "Culture, intellectual property and territorial rural development." Sociologia Ruralis, 38, 1, 4-19.

Ray, C. (1998b) "Territory, Structures and Interpretaion - Two case studies of the European Union's LEADER I Programme." Journal of Rural Studies, 14, 1, 79-87.

Ray, C. (1999a) "Endogenous development in the era of reflexive modernity." Journal of Rural Studies, 15, 3, 257-267.

Ray, C. (1999b) "Towards a meta-framework of endogenous development: Repertoires, paths, democracy and rights." Sociologia Ruralis, 39, 4, 521 533. 
Riessman, C.K. (1993) Narrative analysis. Newbury Park: Sage Publications.

Riessman, C.K. (2004) "Narrative analysis." The Sage encyclopaedia of social science research methods. M. Lewis-Beck et al. (eds.). Thousand Oak, CA: Sage

Roseland, M. (1999) "Natural capital and social capital: Implications for sustainable community development." Communities, development, and sustainability across Canada. J.T. Pierce and A. Dale (eds.) Vancouver: UBC Press.

Sacouman, J. (2005) "Capitalist restructuring on Canada's East Coast." From the net to the Net: Atlantic Canada and the global economy. J. Sacouman \& $\mathrm{H}$. Veltmeyer (eds.) Toronto: Garamond Press.

Sacouman, J. \& H. Veltmeyer (eds.). (2005) From the net to the Net: Atlantic Canada and the global economy. Toronto: Garamond Press.

Salmi, P. (2005) "Rural pluriactivity as a coping strategy in small-scale fisheries." Sociologia ruralis, 45, 1 / 2, 21-36.

Savoie, D. (2004) "Regional economic development in Atlantic Canada." Regionalism in a global society: Persistence and change in Atlantic Canada and New England. S.G. Tomblin, \& C.S. Colgan (eds.) Peterborough: Broadview Press.

Schlereth, T. (1982) Material culture studies in America. Nashville, Tenn.: American Association for State and Local History

Scott, J. (1990) A matter of record: Documentary sources in social research. Cambridge: Polity. 
Sider, G. (2003) Between History and Tomorrow: Making and breaking everday life in rural Newfoundland. Peterborough: Broadview Press.

Sinclair, P., with H. Squires \& L. Downton (1999). "A future without fish? Constructing social life on Newfoundland's Bonavista Peninsula after the cod moratorium." Fishing places, fishing people: Traditions and issues in Canadian small-scale fisheries. D. Newell \& R. Ommer. Toronto: University of Toronto Press.

Sinclair, P. (2003). "Moving back and moving in: Migration and the structuring of Bonavista." Retrenchment and regeneration in rural Newfoundland. R. Byron (ed). Toronto: University of Toronto Press.

Storey, G.M. et al. (eds) (1999) The dictionary of Newfoundland English. Toronto: University of Toronto Press.

Theophano, J. (2002) Eat my words: Reading women's lives through the cookbooks they wrote. New York: Palgrave Macmillan.

Tomblin, S.G. \& C.S. Colgan (eds.) (2004) Regionalism in a global society: Persistence and change in Atlantic Canada and New England. Peterborough: Broadview Press.

Tomblin, S.G. (2004) "Introduction and overview: Comparative New England Atlantic policy lessons." Regionalism in a global society: Persistence and change in Atlantic Canada and New England. S.G. Tomblin, \& C.S. Colgan (eds.) Peterborough: Broadview Press.

Tabart, T. et al. (2001) "Taking the future in their hands: Local development practice around the world." Rural Society, 11, 1, 5-12. 
Tigges, L.M. et al. (1998) "Social relationships in locality and livelihood: The embeddedness of rural economic restructuring." Journal of Rural Studies, 14, 2, 203-219.

Wadel, C. (1969) Marginal adaptations and modernisation in Newfoundland: A study of strategies and implication in the resettlement and redevelopment of outport fishing communities. St. John's: ISER.

Wallace, C. (2002) "Household strategies: Their conceptual relevance and analytical scope in social research." Sociology, 36, 2, 275-292.

Warde, A. (1990) "Household work strategies and forms of labour: Conceptual and empirical issues." Work, Employment and Society, 4, 4, 495-515.

Winson, A \& B. Leach. (2002) Contingent work, disrupted lives: Labour and community in the new rural economy. Toronto: University of Toronto Press.

Woolland, R. and W. Rees (1999) "Social evolution and urban systems: Directions for sustainability." Communities, development, and sustainability across Canada. J.T. Pierce and A. Dale (eds.) Vancouver: UBC Press.

Veltmeyer, H. (1990) "The restructuring of capital and the regional problem." Restructuring and resistance from Atlantic Canada. Fairley,B. et al. (eds.) Toronto: Garamond Press.

Veltmeyer, H. (2005) "Rethinking underdevelopment in Atlantic Canada." From the net to the Net: Atlantic Canada and the global economy. J. Sacouman \& H. Veltmeyer (eds.) Toronto: Garamond Press. 
Workman, T. (2005) "The decaying social compact in Atlantic Canada." From the net to the Net: Atlantic Canada and the global economy. J. Sacouman \& $\mathrm{H}$. Veltmeyer (eds.) Toronto: Garamond Press. 


\section{Internet sites}

The Atlas of Canada.

http://atlas.gc.ca/site/english/maps/reference/outlineprov_terr/nfld_outline/refe rencemap_image_view

Crafts of Character. www.craftsofcharacter.com

Newfoundland and Labrador Heritage. http://www.heritage.nf.ca/nfld fullmap.html

Statistics Canada. www40.statcan.ca/101/cst01/labr666.htm 


\section{Appendices}




\section{Appendix A}

\section{Consent Form}

I understand that I voluntarily participate in L. Lynda Harling Stalker's research on craftspeople's work. I understand that at anytime I may refuse to answer any questions. My identity and the information I provide will remain confidential. My name will not be revealed or associated with the responses I give. I am guaranteed anonymity. I understand that by participating there is little risk to me as my name and identifying characteristics will be changed for any publications.

I understand that the research objective is to understand how Newfoundland craftspeople understand the work they do, and how this relates to social and economic development policymaking. I understand that this work is connected neither to the Government of Newfoundland and Labrador nor the Government of Canada. As my identity will be changed in the dissertation and in all publications resulting from the dissertation, there is little risk that any government agency will know the responses I give. Any financial information that might be gleaned during the interview will remain confidential. The interview will be taped and later transcribed for analysis. My identity will not be placed on the transcripts. The transcripts and tapes will remain in the sole possession of L. Lynda Harling Stalker. The information provided will be used only for the purposes of academic research. Upon completion of the dissertation, the data will be stored in a locked filing cabinet for future research purposes.

(Participant)

(L. Lynda Harling Stalker)

(Date) 


\section{Appendix B - Letter to participant}

\section{Dear Craftsperson:}

My name is Lynda Harling Stalker. I am a graduate student at Carleton University in Ottawa. This summer I will be conducting research for my $\mathrm{PhD}$, Sociology, degree. The purpose of this project is to look at how craftspeople understand the work they do, and how this then relates to the government's economic development policies. I am currently looking for participants to share their work experiences in the craft field.

If you are willing to participate, I will come to a place that is convenient to you this summer. I will ask questions that try to understand the work that you do, what meaning the work has for you and what motivates you to do this work. Each interview will take about 1.5 hours. Your participation is strictly voluntary and your confidentiality will be protected.

I am a knitter myself and am combining my favourite pastime with my educational pursuits. While this project will look at economic development policies, this project is not affiliated with the Newfoundland and Labrador Government or the Government of Canada. The information you provide will be used for academic purposes. When my dissertation is written, it will be available to be read by yourself or any interested party, keeping in mind that the participants in the study will not be named in the work. I hope that it will contribute toward better understanding of the further development of the craft industry in Newfoundland and Labrador.

I appreciate your willingness to help me in my educational efforts. If you have any questions, please do not hesitate to email me at anlyas@yahoo.ca or call me at 613-544-2174. I look forward to your reply.

Yours truly,

L. Lynda Harling Stalker

PhD Candidate

Carleton University 


\section{Appendix C - Interview Guideline}

\section{Section A}

- What craft do you do? What do you remember about the first time you tried your craft? Who taught you your craft? Why did you learn your craft? What did you work on the first time you did your craft? How did it turn out? When did you know that this was something you would continue to do? Why have you continued? What do you enjoy about your craft? Have you always enjoyed it? Is there anything you do not enjoy?

\section{$\underline{\text { Section B }}$}

- When and where do you do your crafts? What things do you make? What things do you like to make? Why do you like to make these things? Do you make things that you don't enjoy doing? Why don't you like them?

\section{$\underline{\text { Section C }}$}

- Who do you craft for? Do people appreciate the items you make? Do you make different things for sale than you do for yourself? If so, do you feel differently about each? How do you make people aware of your crafts? How do you price your crafts? Why do you do crafts for sale? Do you enjoy the crafts you do for sale? If you weren't paid, would you still do your crafts? Do you ever feel pressured to do your crafts?

\section{$\underline{\text { Section D }}$}

- Do you get a sense of accomplishment when you do your crafts? Is this important? Do you like to be creative with your crafts? Explain. Do you do your own designs? How do you decide on the materials you use? Is it important that the craft you make be "Newfoundland" in essence? Do you share / discuss your craftwork with other craftspeople? Is this important? Is what you do a solitary activity? Explain. Is where you live important to the craftwork you do? Explain.

\section{$\underline{\text { Section } E}$}

- Who is in your household? What do they think about your crafts? Do they support your crafts? How do you structure your day? Are you involved in any community organisations? How does this effect what you do?

\section{$\underline{\text { Section } \mathrm{F}}$}

- Are you aware of the Craft Strategy report released last year? Where you consulted for it? What was your opinion of it? Do you know about the government's different programmes for funding craft businesses? Do you take advantage of them? Do they meet your needs? Are they accessible?

\section{Section G}

- Is this work? Explain. Have you always work at crafts? Explain. What schooling do you have? What other forms of work have you done? Why is what you make / do craft? Would this be work if you weren't paid?

\section{$\underline{\text { Section } \mathrm{H}}$}

- What year were you born? Your marital status? Your spouses year of birth? Your spouse's occupation? Your parents' occupation? Do you have any children? How many? Where were you born? Why do you live where you do? Your gender? 